\title{
New phiomorph rodents from the latest Eocene of Egypt, and the impact of Bayesian "clock"-based phylogenetic methods on estimates of basal hystricognath relationships and biochronology
}

Hesham M Sallam, Erik R Seiffert

The Fayum Depression of Egypt has yielded fossils of hystricognathous rodents from multiple Eocene and Oligocene horizons that range in age from $\sim 37$ to $\sim 30 \mathrm{Ma}$ and document several phases in the early evolution of crown Hystricognathi and one of its major subclades, Phiomorpha. Here we describe two new genera and species of basal phiomorphs, Birkamys korai and Mubhammys vadumensis, based on rostra and maxillary and mandibular remains from the terminal Eocene ( 34 Ma) Fayum Locality 41 (L-41). Birkamys is the smallest known Paleogene hystricognath, has very simple molars, and, like derived Oligocene-to-Recent phiomorphs (but unlike contemporaneous and older taxa) apparently retained $\mathrm{dP}^{4} / 4$ late into life, with no evidence for $\mathrm{P}^{4} / 4$ eruption or formation. Mubhammys is very similar in dental morphology to Birkamys, and also shows no evidence for $\mathrm{P}^{4} / 4$ formation or eruption, but is considerably larger. Though parsimony analysis with all characters equally weighted places Birkamys and Mubhammys as sister taxa of extant Thryonomys to the exclusion of much younger relatives of that genus, all other methods (standard Bayesian inference, Bayesian "tip-dating", and parsimony analysis with scaled transitions between "fixed" and polymorphic states) place these species in more basal positions within Hystricognathi, as sister taxa of Oligocene-to-Recent phiomorphs. We also employ tip-dating as a means for estimating the ages of early hystricognath-bearing localities, many of which are not well-constrained by geological, geochronological, or biostratigraphic evidence. By simultaneously taking into account phylogeny, evolutionary rates, and uniform priors that appropriately encompass the range of possible ages for fossil localities, dating of tips in this Bayesian framework allows paleontologists to move beyond vague and assumption-laden "stage of evolution" arguments in biochronology to provide relatively rigorous age assessments of poorly-constrained faunas. This approach should become increasingly robust as estimates are combined from multiple independent analyses of distantly related clades, and is broadly applicable across the tree of life; as such it is deserving of paleontologists' close attention. Notably, in the example provided here, hystricognathous rodents from Libya and Namibia that are controversially considered 
to be of middle Eocene age are instead estimated to be of late Eocene and late Oligocene age, respectively. Finally, we reconstruct the evolution of first lower molar size among Paleogene African hystricognaths using a Bayesian approach; the results of this analysis reconstruct a rapid latest Eocene dwarfing event along the lineage leading to Birkamys. 
1 New phiomorph rodents from the latest Eocene of Egypt, and the impact of Bayesian

2 "clock"-based phylogenetic methods on estimates of basal hystricognath relationships and

3 biochronology

4 Hesham M. Sallam ${ }^{1,2^{*}}$ and Erik R. Seiffert ${ }^{3}$

$5 \quad{ }^{1}$ Mansoura University Vertebrate Paleontology Center, Department of Geology, Faculty of

6 Science, Mansoura University, Mansoura, Egypt

7 2Department of Evolutionary Anthropology, Duke University, Durham, North Carolina

$8{ }^{3}$ Department of Anatomical Sciences, Stony Brook University, Stony Brook, New York

9

$10 *$ Correspondence to:

11 Hesham M. Sallam, Department of Geology, Faculty of Science, Mansoura University,

12 Mansoura 35516, Egypt. E-mail: sallam@mans.edu.eg

13 or

14 Erik R. Seiffert, Department of Anatomical Sciences, Stony Brook University, Stony Brook,

15 New York, 11794-8081, U.S.A. E-mail: erik.seiffert@stonybrook.edu 


\section{INTRODUCTION}

18 The rodent clade Hystricognathi first appeared in the Eocene, and is now represented by three

19 major groups with extant members - Hystricidae (Old World porcupines), Caviomorpha (New

20 World hystricognaths), and Phiomorpha (African cane, dassie, and mole rats) (Singleton et al.

21 2006). The largest DNA datasets currently available place Hystricidae as the sister group of a

22 Caviomorpha-Phiomorpha clade (e.g., Huchon et al., 2007; Meredith et al., 2011; Patterson \&

23 Upham, 2014). Despite their modern distribution, being restricted almost entirely to southern

24 continents, phylogenetic evidence provided by later Paleogene Asian "baluchimyines" suggests

25 that the stem lineage of Hystricognathi probably arose in Asia (Marivaux et al., 2002, 2004;

26 Sallam et al., 2009), though no members of the group are definitively known from that continent

27 before the Eocene-Oligocene boundary ( $\sim 34$ Ma: Marivaux et al., 2000; de Bruijn et al. 2003). In

28 contrast, recent paleontological work in Tunisia and Peru has revealed that hystricognaths were

29 present in Africa by $\sim 39.5$ Ma (Marivaux et al., 2014), and that caviomorphs were present in

30 South America by $\sim 41 \mathrm{Ma}$ (Antoine et al., 2012) ${ }^{1}$. The latter discovery is critically important for

31 establishing that the common ancestor of Caviomorpha and Phiomorpha must be even older than

$3241 \mathrm{Ma}$, and that stem members of Phiomorpha were already diversifying at least four million

33 years prior to the deposition of the earliest well-sampled hystricognathous rodent fauna from

\footnotetext{
${ }^{1}$ We exclude from our discussion two molars from the Silica North and Silica South localities in the Sperrgebiet area of Namibia that were assigned by Pickford et al. (2008) to the otherwise late Eocene genus Protophiomys. Pickford et al. (2014) argue that Silica North and Silica South are Bartonian ( 38-41.3 Ma; Gradstein et al., 2012) in age, but the evidence that we present later in this contribution suggests a much younger age (late Oligocene). Marivaux et al. (2014, p. 14) suggested an even younger (Miocene) age for these deposits: “... because of the abundance of associated rodent species that are clearly of Miocene affinities, the presence of Protophiomys in Sperrgebiet, and the middle Eocene age of the Silica rodent-bearing localities are questionable. These Silica localities are most likely Miocene in age, and as such the alleged "Protophiomys"like teeth are certainly referable to another genus". In the absence of much more complete material, we view the great age proposed for the Sperrgebiet Protophiomys specimens with similar skepticism.
} 
34 Africa, the $\sim 37$ Ma Birket Qarun Locality 2 in the Fayum Depression of Egypt (Sallam et al., 35 2009).

36 A recent study of molecular divergence estimates that took into account much of this new fossil 37 evidence (Patterson \& Upham, 2014) placed the caviomorph-phiomorph split at $\sim 42 \mathrm{Ma}$, the 38 divergence of that clade from Hystricidae at $44.9 \mathrm{Ma}$, and the origin of crown Phiomorpha at $39 \sim 36.3$ Ma. These estimates would suggest that the origin and initial diversification of crown 40 Hystricognathi is not yet documented in the fossil record of any landmass, but that the origin of 41 crown Phiomorpha should have occurred very close in time to the deposition of Locality BQ-2. 42 Despite this, species that are known from $\sim 39$ to $\sim 37$ Ma African sites [Djebel el Kébar in 43 Tunisia (Marivaux et al., 2014), Bir el Ater in Algeria (Jaeger et al., 1985), and BQ-2 in Egypt 44 (Sallam et al., 2009)] — i.e., from a time period that would, given Patterson \& Upham's 45 divergence estimates, postdate the caviomorph-phiomorph split by 3-5 Ma, and the origin of 46 crown Hystricognathi by 6-8 $\mathrm{Ma}$ - have not been placed as stem phiomorphs in previous 47 phylogenetic analyses (Sallam et al., 2009, 2011, 2012; Coster et al., 2010; Antoine et al., 2012), 48 but instead are consistently placed as stem hystricognaths, or as stem members of the 49 Caviomorpha-Phiomorpha clade. If these results are correct, then stem phiomorphs simply have 50 not yet been sampled in the middle Eocene and early late Eocene sites of northern Africa.

51 One possible explanation for this pattern is that early phiomorphs have not yet been sampled due 52 to a geographic bias, because all of the key sites documenting early hystricognath evolution in 53 Africa are from the northernmost part of the continent. A reasonable alternative hypothesis, 54 given the surprising discovery of $\sim 41$ Ma caviomorphs and the poor early African record of this 55 group, is that phylogenetic signal has been obscured by homoplasy between basal caviomorphs 56 and more advanced stem phiomorphs, and some or all of the earliest African hystricognaths are 
57 actually basal stem phiomorphs that retain primitive morphology similar to that of the 58 caviomorph-phiomorph ancestor. The possibility of early homoplasy between caviomorphs, 59 phiomorphs, and the Asian "baluchimyine" radiation must be seriously entertained, because at 60 present phylogenetic analyses of basal hystricognaths depend almost entirely on dental 61 characters, many of which are known to have undergone remarkably rapid evolution in some 62 early hystricognath lineages (notably Gaudeamuridae; Sallam et al., 2011). Compounding this 63 problem is the fact that any phylogenetic arrangement of basal hystricognaths implies middle 64 Eocene colonizations of large continents, which might have spurred rapid early diversification 65 (and potentially rapid morphological change) associated with filling of open niche space 66 (particularly in the case of South America, which lacked rodent competitors entirely).

67 Here we describe two new phiomorph genera and species from the latest Eocene Quarry L-41, in 68 the Fayum area of northern Egypt (Fig. 1), that are the oldest to show supression of $\mathrm{P}^{4} / 4$, one of 69 the key dental synapomorphies of crown Phiomorpha. We include these and other basal African, 70 Asian, and South American hystricognaths in a series of parsimony and Bayesian phylogenetic 71 analyses, including Bayesian "tip-dating" analyses (Beck and Lee, 2014; Close et al., 2015; 72 Dembo et al., 2015; Ronquist et al., 2012) that are able to take into account information about the 73 ages of fossil taxa, rates of morphological evolution, and models of speciation and extinction, 74 and as such are potentially ideally suited to test relationships given the challenging 75 circumstances presented by basal hystricognaths.

76 Aside from the tip-dating method's obvious utility for phylogenetic reconstruction, we note that 77 for species whose temporal ranges are poorly constrained by geological data, tip-dating takes 78 into account both phylogenetic position and rate of morphological evolution to provide age 79 estimates for those species, and this information provides a relatively rigorous testable 
80 hypothesis for the ordering of hystricognath-bearing faunas of Eocene and Oligocene age in

81 Africa and Asia (i.e., DT1 and DT2 (Dur at-Talah, Libya), Lokone in Kenya, Silica North in

82 Namibia, Paali Nala C2 and contemporaneous sites in the lower part of the Chitarwata

83 Formation, Pakistan) that was not previously possible.

85 MATERIAL AND METHODS

86 Taxonomy

87 The electronic version of this article in Portable Document Format (PDF) will represent a

88 published work according to the International Commission on Zoological Nomenclature (ICZN),

89 and hence the new names contained in the electronic version are effectively published under that

90 Code from the electronic edition alone. This published work and the nomenclatural acts it

91 contains have been registered in ZooBank, the online registration system for the ICZN. The

92 ZooBank LSIDs (Life Science Identifiers) can be resolved and the associated information viewed

93 through any standard web browser by appending the LSID to the prefix http://zoobank.org/. The

94 LSID for this publication is: urn:1sid:zoobank.org:pub:9DB0476B-E752-4EA1-8745-

95 8C92E429C65B. The online version of this work is archived and available from the following

96 digital repositories: PeerJ, PubMed Central and CLOCKSS.

\section{Terminology, measurements, and CT-scanning}

99 Dental terminology follows Marivaux et al. (2004) (Fig. 2). Teeth are referred to as I, P, and M

100 (for incisors, premolars, and molars, respectively), with upper and lower teeth designated by

101 superscript and subscript numbers (respectively) for locus (e.g., the second lower molar is 
102 referred to as $\mathrm{M}_{2}$ ). Dental measurements were taken with a micrometer mounted in the lens of a

103 Meiji binocular microscope. Specimens were scanned using a Nikon XT H 225 ST micro-CT

104 scanner housed at at Duke University's Shared Materials Instrumentation Facility and three-

105 dimensional reconstructions were rendered in Avizo v. 8. Digital surface models (in Stanford

106 "ply" format) of all specimens described here are available for viewing and direct download at

107 www.morphosource.org.

108 Some of the Fayum rodent species described by Wood (1968) were revised by Holroyd (1994) as

109 a part of her Ph.D. dissertation; taxonomic names that she considered to be invalid or incorrect

110 are placed in quotation marks pending formal revision. Fossils are housed at the Egyptian

111 Geological Museum (CGM) and Duke Lemur Center Division of Fossil Primates (DPC); a

112 collection of casts is also housed in the Mansoura University Vertebrate Paleontology Center

113 (MUVP) cast collection.

\section{Identification of deciduous versus permanent premolars in early hystricognaths}

116 Derived Oligocene-to-Recent phiomorphs have long been interpreted as having suppressed the

117 eruption of permanent premolars, so that only $\mathrm{dP}^{4}$ and $\mathrm{dP}_{4}$ are present throughout life (e.g.,

118 Wood, 1968). The recent discoveries of middle Eocene "Protophiomys" tunisiensis (Marivaux et

119 al., 2014), early late Eocene Protophiomys aegyptensis and Waslamys attiai (Sallam et al., 2009),

120 late Eocene "Protophiomys" durattalahensis and "Protophiomys" aff. durattalahensis (Jaeger et

121 al. 2010), and latest Eocene Acritophiomys bowni (Sallam et al., 2012) and Gaudeamus aslius

122 (Sallam et al., 2011), all of which retain the primitive pattern of replacing $\mathrm{dP}^{4} / 4$, have helped to 
123 clarify differences in the morphology of deciduous and permanent premolars in early

124 hystricognaths and basal phiomorphs.

125 The $\mathrm{P}^{4} \mathrm{~S}$ of all of these species are roughly ovoid and are either as long as they are broad, or are

126 mesiodistally shorter than they are buccolingually broad; the primary lingual cusp is a centrally

127 placed protocone, which is formed by a broad U-shaped crest that is isolated from buccal

128 structures in the highly specialized genus Gaudeamus, but is connected to the protoloph and

129 metaloph in all other early African species (the latter condition presumably representing the

130 primitive state within crown Hystricognathi) (see Fig. S1 for comparative images). The $\mathrm{P}^{4} \mathrm{~S}$ also

131 lack enlarged hypocones (i.e., hypocones are much smaller than the protocones, or absent

132 altogether). In contrast, the $\mathrm{dP}^{4} \mathrm{~s}$ of Fayum hystricognaths bear occlusal surfaces that are very

133 similar to those of the $\mathrm{M}^{1} \mathrm{~s}$, having mesially situated (rather than centrally placed) protocones,

134 relatively large hypocones and distinct anterior arms of the hypocone, and capacious internal

135 sinuses (or hypoflexuses), leading to a distinctly invaginated lingual margin rather than a strictly

136 convex lingual margin. When compared with $\mathrm{M}^{1}$, the $\mathrm{dP}^{4}$ also tends to be relatively small, and

137 have relatively weak lophs and cusps and a narrow lingual portion.

138 The $\mathrm{P}_{4} \mathrm{~S}$ of early African hystricognaths are also roughly equal in length and width, have

139 posterolophids that extend lingually all the way to the entoconid (rather than terminating at the

140 point of the hypoconulid, or having only a very weak crest emanating lingually from the

141 hypoconulid), and typically have a complete crest (metalophulid I) that connects the protoconid

142 and metaconid across the mesial border of the tooth. In contrast, the $\mathrm{dP}_{4} \mathrm{~S}$ of early African

143 hystricognaths are mesiodistally elongate, have metaconids and protoconids that are closely

144 approximated, have well-developed hypolophids that connect the entoconid to the hypoconid (or

145 the anterior arm of the hypoconid), and have relatively large metaflexids (i.e., basins distal to the 
146 hypolophid). Some species also have crests on $\mathrm{dP}_{4}$ that course mesially from the protoconid.

147 When taken in combination, these features have consistently allowed deciduous precursors and

148 permanent replacement teeth to be identified in early African hystricognaths (Jaeger et al., 2010;

149 Marivaux et al., 2012, 2014, 2014; Sallam et al. 2009, 2011, 2012), and we use the same criteria

150 to identify the antemolar teeth of species described here as deciduous, rather than permanent.

\section{Phylogenetic Analysis}

153 Matrix. The matrix employed here is that of Sallam et al. (2012), which was built first on the

154 original matrix of Marivaux et al. (2004), and was then modified by Sallam et al. (2009, 2011,

155 2012). The matrix contains 118 characters, mostly from the dentition, of which 77 were treated

156 as ordered in all analyses; 97 of the characters are parsimony informative. Polymorphisms were

157 assigned their own states that were situated between otherwise adjacent "fixed" states in ordered

158 characters. Three additional early African species were added: "Protophiomys" tunisiensis from

159 the late middle Eocene (Bartonian) of Djebel el Kébar, Tunisia (Marivaux et al., 2014);

160 Turkanamys hexalophus, from the Oligocene Lokone Hill sites in the Turkana Basin, northern

161 Kenya (Marivaux et al., 2012); and Prepomonomys bogenfelsi, from the Silica North site in the

162 Sperrgebiet area of Namibia (Pickford et al., 2008), which is of contentious age, either Bartonian

163 (Pickford et al., 2014) or significantly younger (Coster et al., 2012a; Marivaux et al., 2014). In

164 all analyses, the early middle Eocene "chapattimyid" Birbalomys was designated as the 165 outgroup.

166 Parsimony analyses (see Dataset S1) were run in PAUP 4.0b10 (Swofford, 2002) using the

167 heuristic search algorithm, random addition sequence, and tree bisection-and-reconnection 
168 branch swapping across 10,000 replicates. Two weighting schemes were employed - one in

169 which transitions between "fixed" and intermediate polymorphic states in ordered morphoclines

170 were equal to a single step, and another in which those transitions were scaled to a half-step, so

171 that transitions between "fixed" states were equal to a single step (as in Sallam et al., 2012).

172 Bootstrap support was also calculated in PAUP, based on 1,000 pseudoreplicates.

173 Bayesian phylogenetic analyses (see Dataset S2) were run in MrBayes 3.2.5 (Ronquist et al., 174 2012). The $M_{k}$ model for morphological data (Lewis, 2001) was used, coding was set to

175 "variable", and gamma-distributed rate variation across characters was assumed. Markov Chain

176 Monte Carlo (MCMC) chains were run for 25 million generations, with two independent runs,

177 each with one cold chain and three heated chains (temp=0.02), sampling every 1000 generations.

178 The first $25 \%$ of the resulting 25,000 samples were discarded as the "burn-in" period, and the

179 remaining trees were summarized using an "allcompat" (majority-rule plus compatible groups)

180 consensus tree. Convergence was assessed by checking both effective sample sizes and the

181 average standard deviation of split frequencies in the final generation.

182 Bayesian "tip-dating" analyses (see Dataset S3) were also run in MrBayes 3.2.5 (Ronquist et al., 183 2012). We employed the IGR (independent gamma rates) relaxed clock model and the fossilized

184 birth-death prior on branch lengths, with "samplestrat" set to "fossiltip" (indicating that tips left

185 no descendants). We ran several analyses with various perturbations of the priors "speciationpr"

186 (the prior on the net speciation rate), "igrvarpr" (the prior on the variance of the gamma 187 distribution from which branch lengths are drawn), and "clockratepr" (the prior on the base 188 substitution rate, measured in number of changes per site per Ma) (Huelsenbeck et al., 2015), all 189 of which yielded remarkably similar "allcompat" topologies, divergence dates, tip dates, and 190 support values - however many of these analyses did not show adequate evidence for 
191 convergence across all parameters, as judged by effective sample sizes and potential scale

192 reduction factors. Ultimately the combination of priors that yielded the strongest evidence for

193 convergence across all parameters was speciationpr $=\exp (50), \operatorname{clockratepr}=\operatorname{normal}(0.25,0.05)$,

194 and igrvarpr=exp(3), with flat beta priors on fossilizationpr and extinctionpr, and we present the

195 results from that analysis. "Sampleprob" (the percentage of extant species sampled in the

196 analysis) was set to 0.005 , as only extant Thryonomys (African cane rat) was sampled from the

197 entire sample of extant hystricognaths. The root node was constrained to fall within a uniform

198 prior on node age from $47.8 \mathrm{Ma}$ (the oldest possible age of the species in the matrix) to $55 \mathrm{Ma}$

199 (beyond which no ctenohystricans, or even demonstrable crown rodents, have been found in the

200 fossil record; e.g., Marivaux et al., 2004).

201 Two tip-dating analyses were run: in the first analysis (referred to as TD1), each tip was

202 calibrated with a uniform prior on age, employing minimum and maximum estimates based on

203 the currently accepted upper and lower bounds of magenetochrons or geological stages or ages to

204 which fossils have been assigned (i.e., in MrBayes, calibrate taxon=uniform(minimum age,

205 maximum age); see Appendix S1, which provides justification for the minimum and maximum

206 ages for each taxon). Fourteen of the species in the analysis are from the Fayum succession, and

207 we followed the magnetostratigraphic correlation of the Fayum beds to the Geomagnetic Polarity

208 Timescale that was preferred by Seiffert (2006) and Seiffert et al. (2008). In addition to topology

209 and attendant support and parameter estimates, this first analysis importantly also output point

210 age estimates for each tip species from within its uniform prior, taking into account (among other

211 things) the base clockrate and the amount of change expected along the terminal branch leading

212 to the tip. However as would be expected given such parameters, the point age estimates for

213 species from a single locality were not all the same, as most are assumed to be, given that they 
214 are from the same stratum or tightly constrained interval (also assuming that time-averaging in

215 an accumulation is negligible). Because tips from the same locality should ideally "line up" so

216 that branch lengths are not artificially long or short (thereby implying artificially slow or fast

217 rates of evolution), a second analysis (TD2) was run with the point age estimates for species

218 from each locality (i.e., the estimates calculated in TD1) averaged and used as fixed dates [i.e., in

219 MrBayes, calibrate taxon=fixed(mean age for locality based on TD1 estimates)]. For both

220 analyses, the MCMC chains were run for 50 million generations, with two independent runs,

221 each with one cold chain and three heated chains (temp=0.01), sampling every 1000 generations.

222 The first $25 \%$ of the resulting 50,000 samples were discarded as the "burn-in" period, and the

223 remaining trees were summarized using an "allcompat" (majority-rule plus compatible groups)

224 consensus tree.

\section{Bayesian ancestral reconstruction of first lower molar size in early hystricognaths}

227 We collected length and width measurements on the first lower molars of early hystricognaths in

228 our character-taxon matrix, either directly (in the case of Fayum species) or from published data

229 (in the case of species for which we only had casts), with the goal of reconstructing the evolution

230 of first lower molar area (natural log; see Dataset S4) within a Bayesian context using the

231 Continuous module in BayesTraits v. 2 (Pagel, 2002; Pagel \& Meade, 2013). We used the

232 "allcompat" consensus derived from the tip-dating analysis (TD2) described above as the input

233 tree because that analysis provided divergence dates among extinct taxa that are based on their

234 tip ages and inferred evolutionary rates, which we considered to be preferable to arbitrarily time-

235 scaled trees derived from parsimony or Bayesian analyses that do not take into account

236 evolutionary rates or amount of morphological change along internodes beyond that which is 
237 minimally required by fossil ages. We first ran 10,000,000-generation MCMC analyses of the

238 data set under random walk and directional models, with and without the phylogenetic scaling

239 parameters delta, kappa, and lambda (each considered individually), to determine which

240 model/scaling parameter combination had the highest log likelihood (based on the harmonic

241 mean in the final MCMC generation). For both the random walk model and the directional

242 model, the lambda scaling parameter was favored, but the random walk model with the lambda

243 scaling parameter was only weakly favored over the directional model with the lambda scaling

244 parameter (based on log Bayes factors), so we present results from both of those analyses. Model

245 files were created by running MCMC chains for 10,050,000 generations, with the first 50,000

246 discarded as burn-in. These model files were then employed in longer (20,050,000 generations,

247 first 50,000 discarded as burn-in) MCMC chains for ancestral state reconstructions, in which 248 ancestral values were estimated for all internal nodes in the tree.

250 RESULTS

251 Systematic Paleontology

252 Class MAMMALIA Linnaeus, 1758

253 Order RODENTIA Bowdich, 1821

254 Infraorder HYSTRICOGNATHI Tullberg, 1899

255 Parvorder PHIOMORPHA Lavocat, 1962

256 Family Incertae sedis 
257 Birkamys, new genus (Figs. 3-5, Table 1) urn:lsid:zoobank.org:act:D8D841E7-55E1-4F3A-

258 9B41-CE37F8B6F3A7

259 Type and only known species

260 Birkamys korai, new species urn:lsid:zoobank.org:act:CF09DD3A-E265-43FA-85B6-

$261 \quad$ E9868F9B8364

262 Etymology

263 Combination of birka, Arabic word for lake or swamp, in reference to the L-41 deposits and mys,

264 Greek for mouse.

265 Diagnosis

266 As for the type and only known species.

267 Birkamys korai, new species urn:lsid:zoobank.org:act:CF09DD3A-E265-43FA-85B6-

268 E9868F9B8364

269 (Figs. 3-5, Table 1)

270 Etymology

271 In honor of Professor Mahmoud Kora of Mansoura University, for his important contributions to

272 the study of stratigraphy and paleontology in Egypt.

273 Holotype

274 CGM 66000, rostrum with right and left upper incisors and $\mathrm{dP}^{3}-\mathrm{M}^{3}$ (Fig. 3; measurements in 275 Table 1). 
277 DPC 9276, left maxilla with $\mathrm{M}^{2}$ and $\mathrm{M}^{3}$ (Fig. 4E-H); DPC 15625, left maxilla with $\mathrm{M}^{1}$ (Fig. 4J-

278 L); DPC 17457, right maxilla with $\mathrm{dP}^{3}-\mathrm{M}^{3}$; DPC 22737, right mandible with $\mathrm{dP}_{4}-\mathrm{M}_{3}$ (Fig. 5).

280 Locality 41 (L-41), 46 meters above the base of the lower sequence of the Jebel Qatrani

281 Formation. The fine green claystone at L-41 contains 12\% postdepositional sodium chloride and

282 is unique among Fayum fossil quarries, most of which occur in sands and gravels. The sediments

283 at L-41 might have been laid down in a freshwater lake that was periodically flooded, resulting

284 in large accumulations of vertebrate carcasses (Simons et al. 1998). Over the last three decades,

285 work at L-41 has produced a wide variety of fish, amphibian, reptile, bird and mammal taxa.

286 There is no clear sorting of fossil mammals on the basis of size, and the locality contains not 287 only large-bodied hyracoids (Rasmussen and Gutiérrez 2010) and anthracotheriid artiodactyls, 288 but also very small primates (Simons 1997; Simons et al. 2001; Seiffert et al. 2005), 289 macroscelideans (Simons et al. 1991), tenrecoids (Seiffert and Simons 2000; Seiffert et al. 2007), 290 bats (Gunnell et al. 2008), and rodents (Holroyd, 1994; Lewis and Simons, 2006; Sallam et al. 291 2011, 2012). Hundreds of rodent specimens are known from L-41, but the only clade represented 292 is Hystricognathi, whereas both Hystricognathi and Anomaluroidea occur at the 37 Ma Locality 293 BQ-2 (Sallam et al., 2009, 2010a, b).

295 Latest part of late Eocene (latest Priabonian, 34 Ma), lower sequence of Jebel Qatrani 296 Formation, northern Egypt. 


\section{Diagnosis}

298 Birkamys korai differs from early Oligocene Phiomys andrewsi in having smaller molars; in

299 retaining deciduous premolars; in having relatively short metalophulid IIs on $\mathrm{dP}_{4}-\mathrm{M}_{3}$; in having a

300 relatively small $\mathrm{M}_{3}$ when compared to $\mathrm{M}_{2}$; and in lacking a mesostyle and mesolophule on the

301 upper molars. Differs from contemporaneous and sympatric Acritophiomys bowni in having

302 smaller teeth; in showing no evidence for replacement of deciduous premolars; in having a

303 relatively weak anterior cingulid, no metalophulid I or II, and no mesolophid or mesostylid on

$304 \mathrm{dP}_{4}$; in having no hint of an $\mathrm{M}_{1-2}$ anteroconid; in consistently lacking $\mathrm{M}_{1-2}$ mesostylids and

305 mesolophids, and having relatively short metalophulid IIs; in having relatively large $\mathrm{M}_{1-2}$

306 protoconids; in having a relatively small $\mathrm{M}_{3}$ when compared to $\mathrm{M}_{2}$; in lacking a $\mathrm{dP}^{4}$

307 mesolophule; in consistently lacking $\mathrm{M}^{1-2}$ mesostyles, mesolophules, and pericingula; in having

308 relatively large $\mathrm{M}^{1-2}$ metaconules; and in lacking enamel wrinkling and crenulation. Differs from

309 Oligocene Turkanamys hexalophus from Kenya in having smaller molars; in showing no

310 evidence for replacement of deciduous premolars; in having relatively well-developed anterior

311 cingulids on $\mathrm{M}_{1-2}$; in having a small, rather than large, metastylid on $\mathrm{M}_{1-2}$; in lacking mesostylids

312 and well-developed metalophulid IIs on $\mathrm{M}_{1-2}$; in lacking a connection of the entoconid and

313 hypoconid on the $\mathrm{M}_{1-2}$; in having a relatively small $\mathrm{M}_{3}$ when compared to $\mathrm{M}_{2}$; in lacking $\mathrm{M}^{1-2}$

314 mesostyles and mesolophules; and in lacking enamel wrinkling and crenulation. Differs from

315 "Phiomys" hammudai from the late Eocene of Libya in having smaller molars; in showing no

316 evidence for replacement of deciduous premolars; in lacking a $\mathrm{dP}_{4}$ mesolophid, mesostylid,

317 metalophulid I, and metalophulid II; in having a more distinct anterocingulid but lacking a

318 mesostylid, mesolophid, and a well-developed metalophulid II on $\mathrm{M}_{1-2}$; in having a relatively

319 small $\mathrm{M}_{3}$ when compared to $\mathrm{M}_{2}$; in lacking $\mathrm{M}^{1-2}$ mesostyles and mesolophules, and having 
320 relatively large metaconules; and in lacking enamel wrinkling and crenulation. Differs from early

321 Oligocene Neophiomys paraphiomyoides from Egypt and Libya in lacking a distinct

322 metalophulid II and having a complete ectolophid on $\mathrm{dP}_{4}$; in having a relatively small $\mathrm{M}_{3}$ when

323 compared to $\mathrm{M}_{2}$; in lacking $\mathrm{M}^{1-2}$ mesostyles, mesolophules, and posterior arms of paracones; and

324 in having relatively large $\mathrm{M}^{1-2}$ metaconules. Differs from early Oligocene "Phiomys" lavocati

325 from younger quarries in the Fayum succession in showing no evidence for replacement of 326 deciduous premolars; in having a $\mathrm{dP}_{4}$ protoconid that is more mesially placed relative to the

327 metaconid; in having $\mathrm{M}_{1-2}$ protoconids that are relatively large when compared with metaconids;

328 in having a $\mathrm{dP}^{4}$ metaloph that is connected to the metaconule, rather than distally oriented; in

329 having a $\mathrm{dP}^{4}$ mure; in having $\mathrm{M}^{1-2}$ mures and metaconules that are submerged into the mures; in

330 having anterior arms of the $\mathrm{M}^{1-2}$ hypocones that are relatively well-developed; in having an $\mathrm{M}^{1}$

331 metaloph that is connected to both the metaconule and posteroloph; and in lacking posterior arms

332 of $\mathrm{M}^{1-2}$ paracones. Differs from late Eocene Talahphiomys lavocati from Libya in having a $\mathrm{dP}_{4}$

333 protoconid that is more mesially placed relative to the metaconid; in lacking a $\mathrm{dP}_{4}$ mesostylid; in

334 having a more distinct $\mathrm{M}_{1-2}$ anterocingulid; in having a $\mathrm{dP}^{4}$ metaloph that is connected to the

335 metaconule, rather than distally oriented; in having a $\mathrm{dP}^{4}$ mure; in lacking an $\mathrm{M}^{1-2}$ mesostyle; in

336 having $\mathrm{M}^{1-2}$ mures and metaconules that are submerged into the mures; and in having an $\mathrm{M}^{2}$

337 metaloph that is connected both to the metaconule and the posteroloph. Differs from late Eocene

338 Talahphiomys libycus from Libya in having a $\mathrm{dP}^{4}$ metaloph that is connected to the metaconule,

339 rather than distally oriented; in having a $\mathrm{dP}^{4}$ mure; in lacking an $\mathrm{M}^{1-2}$ mesostyle and

340 mesolophule; in having an $\mathrm{M}^{2}$ metaloph that is connected both to the metaconule and the

341 posteroloph; in having $\mathrm{M}^{1-2}$ mures; and in lacking posterior arms of the $\mathrm{M}^{1-2}$ paracones and

342 anterior arms of the $\mathrm{M}^{1-2}$ metacones. 


\section{Description}

345 Four crushed cranial elements of Birkamys korai (Figs. 3 and 4) together document much of the

346 morphology of the rostrum, mid-cranium, and the complete upper dentition. The holotype

347 rostrum CGM 66000 (Fig. 3) was subjected to severe post-mortem distortion that has led the

348 specimen to be dorsoventrally flattened with numerous surface cracks and displacements; rather

349 than attempt physical preparation of this tiny and very fragile specimen, we figure as much as is

350 possible through volume rendering of the encasing block using high-resolution micro-CT scans

351 (Fig. 3). CGM 66000 contains the premaxillae with two upper incisors, both maxillae with the

352 entire dentition $\left(\mathrm{dP}^{3}-\mathrm{M}^{3}\right)$, and most of the frontal. The cranial parts in the hypodigm represent

353 adult individuals, two of which preserve third and fourth deciduous premolars that are worn.

354 The premaxillae are preserved in the holotype, house the two upper incisors, and form most of

355 the mediolaterally narrow and anteroposteriorly elongate rostrum and upper diastema (Fig. 3).

356 The most striking feature of the rostrum is the capacious vacuity, referred to be some as an

357 "anterior palatine fenestra" (e.g., Wood 1968), formed by the anteroposteriorly elongate and

358 confluent incisive foramina, the anterior halves of which deeply excavate, and are formed by, the

359 premaxillae. The posterior border of the incisive foramen extends posteriorly between $\mathrm{dP}^{3}$ and

$360 \mathrm{dP}^{4}$. The suture between the premaxilla and the maxilla is well-preserved. Birkamys was

361 hystricomorphous; that is, the infraorbital foramen was very large and presumably allowed for

362 the passage of a greatly expanded medial masseter that inserted on the side of the rostrum,

363 anterior to the zygomatic arch. The size and shape of the ventral margin of the infraorbital

364 foramen is most clearly preserved on DPC 9276 (Fig. 4F). On the ventral surface of the maxilla, 
365 a small masseteric tubercle is situated immediately ventral to the infraorbital foramen and

366 anterolateral to the alveolus of $\mathrm{dP}^{3}$, providing a point of origin (along with the zygomatic arch,

367 which extends laterally at the level of the alveolus of $\mathrm{dP}^{3}$ and masseteric tubercle) for the

368 superficial masseter. On the dorsal view of DPC 9276, the infraorbital fissure is relatively broad

369 and deepens anteriorly, separating the orbital process from the alveolar portion (Fig. 4G). The

370 alveolar foramen is oval in shape and lies within the medial wall of the infraorbital fissure, dorsal

371 to the $\mathrm{dP}^{3}$ alveolus. The anterior portion of the maxilla protrudes roughly at the same level as the

372 alveolar plane and preserves part of the articulation with the premaxilla. The palate is preserved

373 in the holotype and is somewhat flat, slightly lower than the alveolar plane, and broad throughout

374 its length. It houses the two major palatine foramina, which are relatively round and large, and

375 which lie at the level of the first upper molar.

376 The upper deciduous third premolar $\left(\mathrm{dP}^{3}\right)$ is generally a small peg-shaped tooth with a rounded

377 base, and abuts the mesial surface of $\mathrm{dP}^{4}$. The $\mathrm{dP}^{3}$, on both the left and right sides, is well-

378 preserved in the holotype and DPC 17457 (Figs. 3F and 4D). It has one large cusp that occupies

379 the distal portion of the crown and forms the apex of the tooth. There is a small depression on the

380 distolabial side of the former cusp.

381 The upper deciduous fourth premolar $\left(\mathrm{dP}^{4}\right)$ is roughly quadrate in shape and bears four major

382 cusps (paracone, metacone, protocone and hypocone) as well as a small metaconule (Figs. 3F

383 and 4D). The paracone is of approximately the same size and height as the metacone, and the

384 hypocone is situated at the same level as the protocone. The occlusal configuration of the crown

385 is tetralophodont, with no mesolophule. The anteroloph that forms the anterior border of the

386 tooth is low and runs labially from the protocone, parallel to the protoloph, and fuses with a

387 weakly-developed parastyle just mesial to the base of the paracone. A well-developed and 
388 transversely oriented protoloph joins the paracone and protocone. There is a small anterostyle at

389 the junction of the protocone and anteroloph. The metaloph takes a sinuous course, running

390 lingually and mesially from the metacone, connecting to the metaconule. There is a weak

391 connection with the posteroloph at its lingual portion, which together along with the hypocone

392 and its anterior arm form a small fovea at the distolingual corner of the crown. The posteroloph

393 runs labially from the hypocone, courses around the posterior margin of the tooth and connects to

394 the distal base of the metacone. A weak and poorly defined metaconule is centrally placed and

395 connected to the hypocone via the latter cusp's anterior arm, which is robust and oriented

396 mesiolabially. The mure is complete, connecting the metaconule with the mid-point, or lingual

397 part of, the protoloph. The labial wall, which is formed primarily by the posterior arm of the

398 paracone, bears a deep notch that extends to the level of the central basin, and there is a very

399 weakly developed swelling that could be a remnant of a mesostyle. The tooth lacks an endoloph,

400 and the lingual sinus (= hypoflexus) is wide, deep, and is not continuous with the central basin (=

401 mesoflexus) due to the presence of the mure.

402 The upper first molar $\left(\mathrm{M}^{1}\right)$ is the largest tooth of the upper dentition (Figs. 3F, 4D, 4L). Its

403 occlusal pattern is nearly identical to that of $\mathrm{dP}^{4}$, but differs in having relatively tall lophs and

404 cusps that are completely integrated into the four primary crests (anteroloph, protoloph,

405 metaloph, and posteroloph), and in having a relatively tall paracone when compared to the

406 metacone. The $\mathrm{M}^{2}$ occlusal surface is similar to that of $\mathrm{M}^{1}$, differing only in being relatively

407 shorter and broader. The hypocone is more labially situated with respect to the protocone.

408 The upper third molar $\left(\mathrm{M}^{3}\right)$ is smaller than $\mathrm{M}^{1-2}$ and has a relatively short lingual margin, leading

409 to a somewhat oval outline (Figs. 3F, 4D, 4H). The tooth bears a reduced metacone and

410 hypocone, which are relatively lingually and labially positioned, respectively, when compared 
411 with the same cusps on $\mathrm{M}^{1,2}$. The metaloph is weakly developed and connects the metacone and

412 the anterior arm of the hypocone. The central basin is closed by a weakly developed labial wall,

413 forming a mesofossette, and is closed lingually by a weak to well-developed mure that reaches

414 the lingual aspect of the protoloph. On DPC 17457, an outgrowth from the posterior part of the

415 protocone extends distolabially toward the anterior arm of the hypocone, forming a high and

416 continuous neo-endoloph. Together with the mure, the protoloph and neo-endoloph delimit a

417 small fovea. On DPC 9276, there is a short and low anterior arm of the hypocone that is

418 connected to the base of the metaconule. The latter is relatively well-developed and more distal

419 in position when compared with the same cusp on $\mathrm{M}^{2}$. There is a small crest running

420 longitudinally from the base of the posteroloph to connect with the metaconule distally. This

421 crest contributes to a small fovea that is also bordered by the metaconule, the hypocone and its

422 anterior arm, and the lingual part of the posteroloph. The posteroloph is relatively well-

423 developed with respect to that of $\mathrm{M}^{2}$, and courses around the posterior margin of the tooth,

424 running labially from the hypocone to form a strong connection with the metacone.

425 The mandible (Fig. 5A-D) is slender, with a partially preserved ascending ramus and a well-

426 preserved corpus. The angular process is placed lateral to the tooth row and the incisor, leaving a

427 well-developed groove between the angular process and the incisor alveolus; the mandible is

428 thus fully hystricognathous. On the lateral surface of the mandible, the ventral masseteric ridge

429 extends laterally, arising near the midpoint of the horizontal ramus and continuing posteriorly

430 toward the angular process; this ridge, which is an insertion site for the deep masseter muscle,

431 extends anteriorly as a part of the masseteric fossa, and terminates beneath the posterior portion

432 of the $\mathrm{dP}_{4}$ at roughly the same level as the mental foramen. The dorsal masseteric ridge is less

433 developed anteriorly and extends posteriorly with the coronoid process. The tip of the coronoid 
434 process is broken but it is apparently higher than the condylar process; it arises lateral to the third

435 molar, leaving a deep fossa. The mental foramen is somewhat oval and can be seen in dorsal

436 view, lying anterior to the anterior root of the $\mathrm{dP}_{4}$ and ventral to the distal portion of the

437 diastema. The diastema is deep and makes up about half the length of the horizontal ramus. The

438 posterior part of the ascending ramus is extremely fragile, and the tip of the angular process is

439 not preserved. On the medial surface of the mandible, the mandibular foramen is situated in the

440 area between the coronoid and condylar processes, on the dorsal margin of a strut that extends

441 posteriorly from the rear part of the incisor alveolus. The condylar process is slightly higher than

442 the tooth row and the tip of the incisor (which are roughly at the same level). The lower incisor is

443 well-preserved; it is oval in cross-section, with somewhat flat medial and lateral margins. The

444 anterior surface of the incisor is covered by smooth enamel that extends only to the labial

445 surface, covering about one-third of the labial side of the incisor.

446 The lower deciduous premolar $\left(\mathrm{dP}_{4}\right)$ is slightly less worn than the lower molars (Fig. 5). A

447 micro-CT scan revealed no hint of a developing p4 (Fig. 5F), suggesting that Birkamys likely did

448 not replace $\mathrm{dP}_{4}-$ a condition that occurs in later-occurring phiomorphs aside from Phiomys. The

$449 \mathrm{dP}_{4}$ is longer than it is wide, and has a somewhat rectangular outline with a wide talonid and a

450 narrow trigonid. The tooth bears five major cusps (metaconid, entoconid, protoconid, hypoconid

451 and hypoconulid). The lingual cusps are slightly smaller than the labial cusps, and the

452 hypoconulid is the smallest cusp. The protoconid extends distal to the metaconid, and has a short

453 crest running mesially from its mesiolingual portion that meets the anteroconid. A low and

454 weakly developed anterocingulid extends around the mesial margin of the tooth. The middle

455 portion of the crown is open mesially, due to the absence of the metalophulid I and II, and open

456 lingually due to the absence of the anterior arm of the entoconid and the short posterior arm of 
457 the metaconid. The ectolophid is low and attaches to the anterior arm of the hypoconid near that 458 crest's junction with the hypolophid. The entoconid is placed mesial to the hypoconid. The 459 hypoconid is connected to a distinct hypoconulid by a well-developed posterolophid that runs 460 across the distal border of the crown and does not reach the distal face of the entoconid, leaving 461 the posterior basin (=metaflexid) open lingually. The labial sinusid (=hypoflexid) is wide and 462 shallow with no ectostylid.

463 The first lower molar $\left(\mathrm{M}_{1}\right)$ is somewhat rectangular in outline and relatively broad, and bears 464 long and relatively well-developed lophs when compared with those of the $\mathrm{dP}_{4}$ (Fig. 5). The 465 mesial wall of the tooth is formed by a trenchant and concave metalophulid I that connects the 466 protoconid and metaconid. A low anterocingulid is present mesial to the protoconid. A short 467 posterior arm of the protoconid protrudes lingually; thus the tooth bears only two major basins. 468 The ectolophid is more lingually positioned than that on $\mathrm{dP}_{4}$. The posterior arm of the metaconid 469 tapers and ends near the midline of the tooth, leaving the anterior basin (=mesoflexid) open 470 lingually via a narrow valley. The hypoflexid is broad and deep.

471 The second lower molar $\left(\mathrm{M}_{2}\right)$ is the largest tooth of the lower dentition. The occlusal 472 configuration is identical to that of the first molar, but the tooth is relatively broad. The anterior 473 margin is straighter and the anterocingulid is less developed than on the $\mathrm{M}_{1}$ and $\mathrm{dP}_{4}$. The 474 occlusal pattern on the third molar is also very similar to that of $\mathrm{M}_{1-2}$, but differs in having a 475 relatively weak anterocingulid, a trigonid that is slightly broader than the talonid, a relatively 476 well-developed posterior arm of the protoconid, and a hypoconulid that is submerged into the 477 posterolophid, forming the rear lobe of the crown. 
479

480

481

482 483 484 485 486 487 488 489 490 491 492 493 494 495 496 497 498 499

\section{Cf. Birkamys (Fig. 6)}

An almost complete hemi-mandible (DPC 17995) has been recovered from L-41 that preserves the lower incisor and $\mathrm{M}_{1}$ (Fig. 6). There are few differences in the morphology of the corpus, ascending ramus, and in the position and development of the masseteric crests, but the anterior border of the ascending ramus begins to curve dorsally just posterior to the distal aspect of $\mathrm{M}_{1}$, whereas on the mandible placed in the Birkamys korai hypodigm (DPC 22737), the dorsal curvature begins at about the mid-point of $\mathrm{M}_{3}$; therefore it seems likely that the ascending ramus would have obscured $\mathrm{M}_{3}$ in lateral view on DPC 17995. The $\mathrm{M}_{1}$ preserved in DPC 17995 also differs from that in DPC 22737, notably in being longer relative to width (1.26 times longer than wide, as opposed to 1.10 times longer than wide); having a distinct, but short, posterior arm of the protoconid; in having a lower crown height and relatively thin crests; in having a more broadly open hypoflexid; and in having a metalophulid I that is mesially convex. We refrain from naming a new taxon based on this material because only one diagnostic tooth is known, but the differences between DPC 17995 and DPC 22737 suggest that this might be an additional tiny new species that could even be distinct at the generic level.

Mubhammys, new genus (Figs. 7 and 8, Table 1) urn:lsid:zoobank.org:act:BAE3043A-8B71441F-B0C3-9A0B7E6CC630

Type and only known species

Mubhammys vadumensis, new species urn:1sid:zoobank.org:act:1E6685EA-BAF3-4035-B62D0D0C486A3D46 
500 Etymology

501 Combination of mubham, Arabic word for enigmatic or mysterious, and mys, Greek for mouse.

502 Diagnosis

503 As for the type and only known species.

504 Mubhammys vadumensis, new species urn:1sid:zoobank.org:act:1E6685EA-BAF3-4035-B62D-

505 0D0C486A3D46

506 (Figs. 7 and 8, Table 1)

507 Etymology

508 From Greek vadum for shallow, in reference to the depositional environment of L-41.

509 Holotype

510 CGM 66001, a left maxilla with $\mathrm{dP}^{3-4}$ and $\mathrm{M}^{1-3}$ (Fig. 7A-B, measurements in Table 1).

511 Referred specimens: DPC 14324, left maxilla with $\mathrm{dP}^{3}-\mathrm{M}^{1}$ (Fig. 7C-H), DPC 13220, left

512 mandibular fragment with $\mathrm{dP}_{4}-\mathrm{M}_{3}$ (Fig. 8E-H), DPC 14141, left mandibular fragment with $\mathrm{dP}_{4^{-}}$

$513 \quad \mathrm{M}_{1}$ (Fig. 8A-D).

514 Type locality

515 Locality 41 (L-41).

516 Age and Formation

517 Latest part of late Eocene (latest Priabonian, 34 Ma), lower sequence of Jebel Qatrani 518 Formation, northern Egypt. 


\section{Diagnosis}

520 Relatively large basal phiomorph that shows no evidence for replacement of deciduous

521 premolars. Differs from Birkamys korai primarily in its larger size, but also in lacking a $\mathrm{dP}_{4}$

522 anteroconid; in having metalophs on $\mathrm{dP}^{4}-\mathrm{M}^{3}$ that are submerged into posterolophs; and in having

523 small $\mathrm{M}^{1-2}$ mesostyles. Differs from contemporaneous and sympatric Acritophiomys bowni in

524 showing no evidence for replacement of deciduous premolars; in lacking a distinct anteroconid, 525 mesostylid, mesolophid, metalophulid I, and metalophulid II on $\mathrm{dP}_{4}$; in lacking a mesolophid,

526 metalophulid II, and incipient anteroconid on $\mathrm{M}_{1-2}$; in having relatively large lower molar

527 protoconids when compared to metaconids; in having $\mathrm{M}^{3} / 3$ relatively small when compared with

$528 \mathrm{M}^{2} / 2$; in lacking mesolophules on $\mathrm{dP}^{4}-\mathrm{M}^{2}$; in having relatively large $\mathrm{M}^{1-2}$ metaconules; in having

$529 \mathrm{M}^{1-3}$ metalophs that are submerged into the posterolophs; and in lacking enamel wrinkling and 530 crenulation on molars. Differs from younger Metaphiomys beadnelli, also from the Fayum 531 succession, in lacking a $\mathrm{dP}_{4}$ anteroconid; in lacking a metalophulid II on $\mathrm{dP}_{4}$; in having a larger

$532 \mathrm{dP}_{4}$ hypoconulid; in having relatively large lower molar protoconids when compared to 533 metaconids; in having $\mathrm{M}^{3 / 3}$ relatively small when compared with $\mathrm{M}^{2} / 2$; in having a relatively low $534 \mathrm{dP}^{4}$ anterocingulum; in having $\mathrm{dP}^{4}-\mathrm{M}^{3}$ metalophs that are submerged into posterolophs; in 535 lacking mesolophules on $\mathrm{dP}^{4}-\mathrm{M}^{2}$; in having relatively large $\mathrm{M}^{1-2}$ metaconules; and in having no 536 posterior arm of the paracone on $\mathrm{M}^{1-2}$. Differs from Oligocene Turkanamys hexalophus from 537 Kenya in showing no evidence for replacement of deciduous premolars; in having a low 538 anterocingulid on $\mathrm{M}_{1-2}$; in having small metastylids, no mesostylids, and very weak posterior 539 arms of the protoconid on $\mathrm{M}_{1-2}$; in having relatively large lower molar protoconids when 540 compared to metaconids; in having no connection of the entoconid and hypoconid via the

541 posterolophid on $\mathrm{M}_{1-2}$; in having $\mathrm{M}^{3} / 3$ relatively small when compared with $\mathrm{M}^{2} / 2$; in having small 
542 parastyles, weak anterostyles, and no mesolophule on $\mathrm{M}^{1-2}$; in having metalophs submerged into

543 posterolophs on $\mathrm{M}^{1-3}$; and in lacking enamel wrinkling and crenulation on the molars.

545 Description

546 On the medial surface of the broken premaxilla of CGM 66001 (Fig. 7F-G) a complete right 547 upper incisor is exposed; it is short and highly arched when compared with the lower incisor. It is 548 oval in occlusal outline, with a flat medial surface and curved dorsal and lateral surfaces. In 549 lateral view, the occlusal surface is longer when compared with that of the lower incisor. The 550 pulp cavity is short and slit-shaped, and placed at the middle of the occlusal surface. A smooth 551 enamel layer covers the mesial surface of the upper incisor and extends labially to cover only 552 one-third of the labial side.

553 The maxillary morphology of Mubhammys appears to be very similar to that of Birkamys, with a 554 similar placement of the zygomatic process, and an anteroposteriorly extensive concave margin 555 of the lateral border of the incisive foramen. As in Birkamys, the posterior margin of the incisive 556 foramen would have extended posteriorly to approximately the point of $\mathrm{DP}^{4}$, and the anterior 557 margin presumably extended far into the premaxilla. Mubhammys thus shares the remarkably 558 enlarged incisive foramen morphology that is seen in Birkamys.

559 The upper deciduous third premolars $\left(\mathrm{dP}^{3}\right)$ are preserved in the holotype and DPC 14324. It is a

560 small peg-shaped tooth with a primary cusp and a rounded base, and abuts the mesial surface of $561 \mathrm{dP}^{4}$. The $\mathrm{dP}^{3}$ is less worn than the upper molars (Fig. 7A-D, H).

562 The upper deciduous fourth premolar $\left(\mathrm{dP}^{4}\right)$ has a somewhat trapezoidal outline, with a relatively 563 short lingual margin and a broad labial margin (Fig. 7A-C, H). The occlusal surface has four 
564 enlarged cusps (paracone, protocone, metacone, and hypocone), all of which are about equal in

565 size and height. The mesostyle is a distinct and isolated cusp and is situated midway between the

566 paracone and metacone along the buccal margin of the tooth. A small anterostyle is situated

567 mesiolabial to the protocone, midway along the mesial margin of the tooth. The anteroloph is

568 low and short, runs labially from the anterostyle, and courses across the mesial margin of the

569 tooth. It continues distally to end labially to the metacone, forming a cingulum around the

570 mesiolabial corner of the crown. The protoloph is a very short transverse crest, runs labially from

571 the protocone, and flares labially to meet the paracone, which is large and lacks a posterior arm.

572 Due to the absence of the posterior arm of the paracone and the anterior arm of the metacone, the

573 mesoflexus is open labially via a wide notch. The hypocone is well-developed and placed distal

574 to the protocone. The anterior arm of the hypocone is robust and runs mesiolabially to end at the

575 middle of the tooth. There is a very low and weakly developed mure, connecting the base of the

576 anterior arm of the hypocone with the protoloph. The mesolophule is absent. The metaloph is

577 robust but very short and its lingual end is submerged into the posteroloph, the latter of which

578 runs labially from the hypocone and ends at the distal base of the metacone. The posterior basin

579 (=posteroflexus) is shallow and very narrow when compared with the anterior basin

580 (=paraflexus). Distal to the anterostyle and mesial to the protocone, there is a short and low

581 anterocingulum. The labial sinus is deep and narrow. There is no ectostyle.

582 The upper first molar (Fig. 7A-C, H) has a similar occlusal morphology to that of $\mathrm{dP}^{4}$, but it is 583 larger, and the lophs and cusps are relatively well-developed. The outline of the tooth is roughly

584 square. The anteroloph has a relatively straight course and is strongly connected lingually to a 585 well-developed protocone, unlike that of $\mathrm{dP}^{4}$. The metaloph is relatively long with respect to that 586 of $\mathrm{dP}^{4}$ and turns backward where it is confluent with the posteroloph. The mesostyle is relatively 
587 well-developed and extends toward the mesoflexus via a short strut. In the holotype, the 588 metacone is broken.

589 The upper second molar is only preserved in the holotype (Fig. 7A-B) and it is strongly worn, 590 but in general appears to be similar in morphology to $\mathrm{M}^{1}$. It differs in being larger and having a 591 reduced and more labially and lingually situated hypocone and metacone (broken), respectively. 592 The metaloph is relatively long with respect to that of $\mathrm{M}^{1}$. The hypoflexus is relatively wider 593 when compared with those of $\mathrm{dP}^{4}$ and $\mathrm{M}^{1}$. The cingulum around the mesiolabial corner of the 594 tooth is absent.

595 The upper third molar (Fig. 7A-B) is heart-shaped and is smaller than all of the other upper teeth 596 aside from $\mathrm{dP}^{3}$. The anterior half of the tooth is similar to the corresponding part on $\mathrm{M}^{1-2}$, but the 597 posterior part is very worn and the metacone is broken. The tooth has a large and more 598 crestiform protocone, occuping most of the lingual portion of the crown. The hypocone is very 599 small and is relatively labial in position with respect to the protocone. The course of the 600 metaloph is uncertain due to wear.

601 The mandible is slender and hystricognathous, with its angular process placed lateral to the plane 602 of the incisor and the tooth row, leaving a well-developed groove between the angular process 603 and this plane (Fig. 8B-D, F-H). DPC 13220 (Fig. 8E-H) represents a fragment of a left 604 mandibular corpus with $\mathrm{dP}_{4}-\mathrm{M}_{3}$ and the middle part of the incisor. On the labial surface of the 605 specimen, the masseteric fossa is pronounced, ending beneath the first molar. The ventral 606 masseteric ridge extends farther mesially below the $\mathrm{dP}_{4}$ and is located lateral to the incisor and 607 teeth row. The dorsal masseteric ridge is less developed when compared to the ventral ridge and 608 extends distally along the base of the coronoid process. The groove between the tooth row and 
609 the base of the coronoid process is preserved in DPC 13220 (Fig. 8F, H). The lower incisor is

610 oval with somewhat flat medial, and slightly convex lateral, margins. A smooth and thick enamel

611 layer covers the ventral surface of the incisor and extends on both the mesial and distal sides.

612 The pulp cavity is elongate in outline and sits in the middle of the dentine layer. The mental

613 foramen is oval-shaped and relatively small and is located between the distal portion of the

614 diastema, slightly above the level of the mesial end of the ventral masseteric ridge. The diastema

615 is well-preserved in specimen DPC 14141; it is slightly deeper than the alveolar row and is as

616 long as the length of the two first teeth. The tip of the angular process, coronoid process, and

617 mandibular process are not preserved.

618 The two mandibular fragments of Mubhammys vadumensis (DPC 13220 \& DPC 14141) preserve

619 lower cheek teeth (Fig. 8). The $\mathrm{dP}_{4}$ is longer than it is wide, and has a somewhat oval outline 620 with a wide talonid and a narrow trigonid. The tooth bears a very weakly developed 621 anterocingulid mesial to the protoconid. The metalophulid I and the posterior arm of the 622 protoconid are absent, leaving the anterior basin (=anteroflexid) open mesially via a deep and 623 narrow notch. The metaconid is larger than the protoconid and is more mesially positioned. The 624 hypoconid is placed slightly posterior to the entoconid. A short anterior arm of the hypoconid 625 attaches to the hypolophid, which flares lingually along the apex of a large entoconid. The 626 ectolophid is low relative to cusp height, and joins the protoconid at the junction of the anterior 627 arm of the hypoconid and the hypolophid. The posterior arm of the metaconid slopes distally as a 628 part of the lingual wall but terminates before the midline of the crown. The anterior arm of the 629 entoconid is absent, leaving a wide notch along the lingual side of mesoflexid. There is no 630 mesoconid or mesolophid. The posterolophid is well-developed, running distolingually from the 631 hypoconid, coursing around the posterior margin of the tooth to end distal to the entoconid, 
632 leaving a wide opening on the lingual margin of the metaflexid. A well-developed hypoconulid

633 occupies the middle portion of the posterolophid and forms the very distal tip of the tooth. A

634 low, poorly developed postcingulid runs labially from the distal end of the hypoconulid. The

635 hypoflexid is wide and deep. In DPC 14141, $\mathrm{dP}_{4}$ has a well-developed cusp that abuts the

636 metaconid distally, while the mesostylid is represented by a small cuspid.

637 The first lower molar is roughly rectangular in outline and bears relatively well-developed lophs

638 and cusps; the mesial part of the tooth is slightly narrower than the distal part. An incipent and

639 low anterocingulid runs parallel to the metalophulid I; it is relatively well-developed when

640 compared with that on $\mathrm{dP}_{4}$. The metalophulid $\mathrm{I}$ is well-developed, forming the mesial border of

641 the tooth, and runs from the anterior side of the protoconid toward the mesial side of the

642 metaconid; it bears a shallow notch near its labial one-third. The posterior arm of the protoconid

643 is represented by a very small knob on the mesial part of the ectolophid. The latter is well-

644 developed and higher than that of the $\mathrm{dP}_{4}$, and connects the protoconid to the junction of the

645 hypolophid and the anterior arm of the hypoconid. The posterior arm of the metaconid is

646 relatively short when compared with that of the $\mathrm{dP}_{4}$, and only forms about one-third of the

647 lingual wall between the metaconid and the entoconid. The anterior arm of the entoconid is

648 absent, leaving the mesoflexid open via a lingual notch that is narrower than that on $\mathrm{dP}_{4}$. The

649 hypoflexid is relatively narrow, and the postcingulid that runs labially from the distal end of the

650 hypoconulid is relatively well-developed with respect to that on $\mathrm{dP}_{4}$.

651 The occlusal surface of $\mathrm{M}_{2}$ (Fig. $\left.8 \mathrm{E}-\mathrm{H}\right)$ is very similar to that of $\mathrm{M}_{1}$. The $\mathrm{M}_{2}$ differs in being 652 relatively wider and shorter, and in having a slightly broader trigonid and a longer talonid. The 653 notch of the metalophulid I is relatively deep when compared with that on $\mathrm{M}_{1}$, but still higher 654 than the anterior basin. The posterior arm of the protoconid is very short and is oriented toward 
655 the lingual wall of the tooth, but it is relatively long when compared with that on $\mathrm{M}_{1}$. The

656 hypoconulid and its postcingulid are not as well-developed at they are on $\mathrm{dP}_{4}-\mathrm{M}_{1}$.

657 The mesial portion of $\mathrm{M}_{3}($ Fig. $8 \mathrm{E}-\mathrm{H})$ is somewhat similar to the corresponding part of $\mathrm{M}_{1}$ and

$658 \mathrm{M}_{2}$. The $\mathrm{M}_{3}$ differs from the rest of the lower dentition in being relatively small, and in having a 659 triangular outline. The trigonid is relatively large when compared with the talonid. The posterior 660 arm of the protoconid is relatively long and is oriented toward the entoconid, which is reduced in 661 size. The hypolophid is short and the hypoconid flares with the posterolophid distally, forming 662 the posterior margin of the tooth. The hypoconulid is absent. The anterior arm of the entoconid is 663 present, leading to a narrow and deep notch on the lingual wall; the mesoflexid is closed 664 lingually, forming a mesofossettid. The postcingulid is absent, and the anterior arm of the 665 hypoconid is very short.

666

667 Comparisons

668 The contemporaneous and sympatric L-41 species of Birkamys and Mubhammys are quite 669 different in tooth and mandible size (Fig. 9), but are very similar in the occlusal morphology. $B$. 670 korai is the smallest known hystricognathous rodent from the Paleogene of Africa, and the first 671 lower molar area of M. vadumensis is 3.5 times that of B. korai. The lower dentition of Birkamys 672 is similar to that of Mubhammys in lacking metalophulid I and II on $\mathrm{dP}_{4}$, and in having a short 673 posterior arm of the protoconid on $\mathrm{M}_{1}$ and a more robust posterior arm of the protoconid on the 674 last two molars that never reaches the lingual wall. Moreover the upper dentition of Birkamys is 675 similar to that of Mubhammys in lacking the connection between the metacone and the anterior 676 arm of the hypocone; instead the metaloph is directed distally and submerged into the 
677 posteroloph. The lower molars of Birkamys differ from those of Mubhammys in lacking the

678 postcingulid, having a relatively robust metalophulid I on the lower molars, and in having a

679 relatively short $\mathrm{M}_{1}$. Birkamys also lacks the $\mathrm{M}^{2}$ mesostyle that is present in Mubhammys.

680 Furthermore, when compared with that of Mubhammys, the $\mathrm{dP}_{4}$ of Birkamys is relatively long,

681 has a crest that runs mesially from the protoconid, has a well-developed anterocingulid, and a

682 large protoconid when compared with the metaconid; Mubhammys has a relatively large

683 metaconid. The $\mathrm{M}^{3}$ of Mubhammys is heavily worn, which makes it difficult to compare it with

684 that of Birkamys.

685 Birkamys and Mubhammys share a number of dental features with early Oligocene members of 686 the genera Phiomys and Neophiomys (Coster et al., 2012b; Holroyd, 1994; Wood 1968) that were

687 presumably present in the last common ancestor that these taxa shared with all later phiomorphs.

688 The type species of Phiomys (Phiomys andrewsi) differs from Birkamys in being larger, having a

689 well-developed metalophulid II, in replacing the $\mathrm{dP}_{4}$, and in having a relatively narrow anterior

690 portion of $\mathrm{dP}_{4}$. When compared with Mubhammys, the lower teeth of $P$. andrewsi are smaller,

691 with a relatively well-developed anterocingulid. The lower molars of Birkamys differ from those

692 of Neophiomys from the early Oligocene Fayum Quarry G (Coster et al., 2012b; Wood 1968) in

693 their small size, in having a well-developed metalophulid I, a relatively weak anterocingulid, and

694 a relatively long $\mathrm{dP}_{4}$ that has the anteroconid connected to the protoconid. Furthermore, the $\mathrm{M}^{2}$

695 of Birkamys differs from that of Neophiomys in lacking a mure, a mesolophule, and a metaloph

696 that is connected with both the posteroloph and mesolophule. Neophiomys is similar to

697 Mubhammys in having an $\mathrm{M}_{1}$ that is the longest tooth of the lower dentition, in the development

698 of the posterior arm of the protoconid, and in having an anterocingulid, but differs in its small

699 size, interrupted metalophulid $\mathrm{I}$, and well-developed anterocingulids that are present on $\mathrm{M}_{3}$. 
700 Furthermore, the $\mathrm{dP}_{4}$ of Neophiomys differs from that of Mubhammys in having an anteroconid

701 and a long posterior arm of the protoconid that forms a complete metalophulid II. The upper

702 dentition of Neophiomys differs from that of Mubhammys in having a double (mesial and distal)

703 connection of the metaloph on $\mathrm{M}^{1}$, as well as a well-developed mure and mesostyle. When

704 compared to Birkamys, the lower teeth of "Phiomys aff. paraphiomyoides" from the early

705 Oligocene Fayum Quarry I are larger, and there is a small cusp on the anterocingulid of $\mathrm{M}_{1-2}$.

706 The $\mathrm{dP}_{4}$ of "Phiomys aff. paraphiomyoides" also shows some characters that differ from those of

707 Birkamys, such as being relatively short and in having a complete metalophulid II and a distinct

708 anteroconid. The lower cheek teeth of Mubhammys show a great similarity to those of "Phiomys

709 aff. paraphiomyoides", differing only in having a $\mathrm{dP}_{4}$ that lacks metalophulid II, and in having a

710 relatively long $\mathrm{M}_{1}$ with deep lingual notches, relatively well-developed postcingulids, and in

711 lacking a small cusp on the weak anterocingulid.

712 "Phiomys" lavocati (Wood 1968) is roughly the same size as Birkamys korai, but has a more

713 robust mandible that bears a more ventral position of the mental foramen, as well as a relatively

714 short diastema. The lower teeth of "Phiomys" lavocati differ from those of Birkamys in being

715 broader and shorter, having relatively weak metalophulid I and II, in lacking anterocingulids, and

716 in having mesoflexids and metaflexids that are closed lingually. The lower deciduous premolar

717 of "Phiomys" lavocati is also relatively short, and has a relatively narrow trigonid and wide

718 talonid, a relatively well-developed ectolophid, and an anteroconid. The $\mathrm{dP}_{4}$ protoconid of

719 "Phiomys" lavocati is more distally positioned with respect to the metaconid, and the

720 anterocingulid is more labially placed. The upper second molar of "Phiomys" lavocati differs

721 from that of Birkamys in having a relatively reduced and more lingually positioned metacone; a

722 metaloph that is poorly developed and oriented toward the metaconule; a hypocone that is equal 
723 in size to the protocone and less labially postioned; an anteroloph that is relatively well-

724 developed; a high labial wall that closes the mesoflexus labially; a mesostyle that is integrated

725 into the labial wall, but still recognizable; an enterostyle that abuts the hypocone, and a mure

726 extending from the metaconule to contact the posterior portion of the protoloph.

727 The lower molars of "Phiomys" cf. lavocati from the early Oligocene of Oman (Thomas et al. 728 1989) are similar to those of Birkamys in having an anterocingulid and short posterior arm of the

729 protoconid, and a lingually closed mesoflexid on $\mathrm{M}_{3}$. But the only upper molar from that locality 730 shows significant differences when compared with that of Birkamys, such as the presence of a 731 complete mure, an interrupted mesolophule, a metaloph that is connected to both the metaconule 732 and posteroloph, a labial wall that closes the mesoflexus, and a mesostyle. Furthermore the first 733 lower molar of "Phiomys" cf. lavocati has both a well-developed postcingulid and a lingual wall, 734 and the posterior arm of the protoconid protrudes from the middle of the ectolophid, rather than 735 from the protoconid as in Birkamys.

736 The diminutive species Phiocricetomys minutus, from Fayum Quarry I, differs from Birkamys in 737 exhibiting strong distal reduction of the cheek teeth (i.e., loss of $\mathrm{M}_{3}$ ), having relatively rounded 738 cusps, no metalophulid II, and an anterior end of the masseteric fossa that extends as far forward 739 as the anterior end of the premolars. The mental foramen is placed beneath this ridge in 740 Phiocricetomys, whereas in Birkamys the anterior end of the masseteric fossa lies just below the 741 mental foramen. Phiocricetomys also has a cingulid that courses all the way around the labial 742 surface of $\mathrm{M}_{1}$, and a strong anterocingulid that bears an anteroconid and some small accessory 743 cusps. On the $\mathrm{dP}_{4}$ of Phiocricetomys, the metaconid and its posterior arm are more mesially 744 positioned with respect to the protoconid, the anteroconid is well-developed, the metalophulid I 745 is interrupted labially, the hypolophid is absent, the hypoconulid is well-developed and relatively 
746 large, with a posterior cingulid, and the posterolophid is very weak. The $\mathrm{M}_{2}$ of Phiocricetomys

747 has a reduced entoconid, and a protoconid that is concave mesially and convex distally. The

748 hypolophid is absent and the posterolophid is incipient, with no hypoconulid.

749 Contemporaneous Acritophiomys bowni (Sallam et al. 2012) is the same size as Mubhammys

750 vadumensis, but it differs in replacing its deciduous premolars and in having well-developed

751 mesolophules, double connections of the metaloph, complete mures, and relatively long lophs on

752 the upper molars, while the lower molars bear well-developed posterior arms of the protoconids

753 that approximate the lingual margins of the crowns. Moreover, the $\mathrm{dP}_{4}$ of $A$. bowni differs than

754 that of $M$. vadumensis in having a well-developed anterocingulid, a complete posterior arm of the

755 protoconid and a well-developed mesolophid, mesostylid, and ectostylid.

756

757

758

759

760

761

762

763

764

765

766

767

Birkamys and Mubhammys differ from the primitive hystricognaths Protophiomys and Waslamys

from the earliest late Eocene ( $\sim 37 \mathrm{Ma})$ of the Fayum area (Sallam et al, 2009) in retaining deciduous premolars, having no mesolophid or mesoconid on $\mathrm{dP}_{4}$, in having lingually open mesoflexids on the lower molars, and, on the upper molars, lacking endolophs, mesolophules, and labial walls; Birkamys and Mubhammys also have $\mathrm{M}^{2}$ metalophs that are oriented distally, meeting the posterolophs.

In addition to its small size, Birkamys korai shares some dental features with Kahawamys mbeyaensis from the late Oligocene of the Rukwa Rift Basin in Tanzania (Stevens et al. 2009), such as a more centrally positioned ectolophid, a relatively mesial position of the entoconid with respect to the hypoconid, and a crest extending distally from the $\mathrm{dP}_{4}$ anteroconid to connect with the protoconid. The lower molars of Birkamys differ from those of Kahawamys in lacking an anterior arm of the entoconid, having relatively short and lingually open metaflexids, relatively 
768 distinct posterior arms of the protoconids that increase in length distally, anterocingulids on all

769 molars, and a $\mathrm{dP}_{4}$ that is relatively wide, with a taller trigonid.

770 The extant cane rat Thryonomys resembles Birkamys in retaining deciduous premolars thoughout

771 its life, but in addition to being much larger in size, differs from Birkamys and Mubhammys in

772 having relatively short and hypsodont crowns, no anterocingulids or posterior arms of the

773 protoconids on lower teeth, and in having a complete metalophulid I and a mesolophid in $\mathrm{dP}_{4}$.

774 Furthermore, the $\mathrm{M}^{2}$ of Thryonomys differs from that of Birkamys and Mubhammys in having a

775 complete mure and in lacking a metaconule. The $\mathrm{M}^{3}$ of Thryonomys differs from that of

776 Birkamys in lacking a neo-endoloph, a metaloph and a well-developed metaconule.

777

778 Phylogenetic analysis

779 Parsimony analysis

780 Parsimony analysis in PAUP $4.0 \mathrm{~b} 10$ with all characters equally weighted returned 10 equally

781 parsimonious trees of length 907, the strict consensus of which is shown in Fig. 10A. In all trees,

782 Birkamys and Mubhammys are nested deep within Phiomorpha as the sister taxon of extant

783 Thryonomys, with the sister group of the Birkamys-Mubhammys-Thryonomys clade containing

784 early Oligocene "Paraphiomys" simonsi and Miocene Paraphiomys and Paraulacodus. With the

785 placement of Canaanimys (late middle Eocene of Peru) taken to indicate the divergence of

786 Caviomorpha from Phiomorpha, there is a pectinate sequence of basal phiomorphs that includes

787 "Phiomys" hammudai and Turkanamys as its most basal members, followed sequentially by

788 Acritophiomys, Prepomonomys, Phiomys, Neophiomys, Metaphiomys, and Diamantomys.

789 Birkamys and Mubhammys are placed as sister taxa with strong support (bootstrap support (BS) 
$790=82$ ). Among derived hystricognaths, the only other clade that was supported by BS $>50$ was

791 Canaanimys + Gaudeamus (late Eocene and early Oligocene of Africa) (BS=62), Gaudeamus

792 (BS=99), and a Gaudeamus clade that excludes late Eocene Gaudeamus aslius (BS=83).

793 Elsewhere in the tree, the oldest African hystricognath, "Protophiomys" tunisiensis, is placed as

794 the sister species of the phiocricetomyines Talahphiomys, "Phiomys" lavocati, and

795 Phiocricetomys. The next-oldest species from northern Africa, from Locality BQ-2

796 (Protophiomys aegyptensis and Waslamys) and Bir el-Ater (Protophiomys algeriensis) are placed

797 outside of the Phiomorpha-Caviomorpha clade, with $P$. algeriensis being the sister taxon of

798 derived Asian "baluchimyines", Waslamys forming a clade with "Protophiomys"

799 durattalahensis, and Protophiomys aegyptensis intervening along the phiomorph-caviomorph

800 stem between the divergences of the "P." tunisiensis-phiocricetomyine clade and the Waslamys-

801 "P." durattalahensis clade.

802 Parsimony analysis of the same data set with transitions between "fixed" and polymorphic states

803 scaled to be equal to a half-step, rather than a full step (so that transitions between "fixed" states

804 are equal to a single step) recovered 119 equally parsimonious trees of length 595 . The strict

805 consensus of these trees was largely unresolved (Fig. 10B), with only a Confiniummys-

806 Ottomania clade, a Gaudeamus clade, a Bugtimys-Hodsahibia clade, a phiocricetomyine clade,

807 and a Birkamys-Mubhammys clade being retained within Hystricognathi in the strict consensus.

808 Notably, the sister-group relationship of Birkamys, Mubhammys, and extant Thyronomys

809 recovered when all characters are equally weighted was not consistently recovered under the

810 alternative weighting scheme; a maximum agreement subtree (Fig. 10C) excluded Thryonomys

811 entirely and placed Birkamys and Mubhammys as the sister group of early Oligocene

812 "Paraphiomys" simonsi and Miocene Paraphiomys. The maximum agreement subtree is also 
813 consistent with the strict consensus derived from parsimony analysis with all characters equally

814 weighted (Fig. 10A).

815

816 Bayesian phylogenetic analysis

817 As in the parsimony analyses, the "allcompat" (majority-rule plus compatible groups) consensus

818 derived from the Bayesian analysis (Fig. 11) recovered a Birkamys-Mubhammys clade, with

819 moderate support (posterior probability $(\mathrm{PP})=0.68$ ), but this clade was not deeply nested within

820 Phiomorpha, instead being the sister group of a well-supported $(\mathrm{PP}=0.91)$ clade containing

821 Oligocene (Metaphiomys, "Paraphiomys" simonsi) and Miocene (Diamantomys, Paraphiomys,

822 Paraulacodus) species, as well as a Thryonomys-Prepomonomys clade. This result is completely

823 consistent with the maximum agreement subtree derived from the parsimony analysis in which

824 transitions between "fixed" and polymorphic states were scaled to a half-step. Also as in the

825 parsimony analysis, the most basal phiomorphs are "Phiomys" hammudai and Turkanamys,

826 followed by the sequentially more crownward genera Acritophiomys, Phiomys, and Neophiomys.

827 The arrangement of species along the pectinate stem at the base of Phiomorpha in the allcompat

828 tree is supported by PPs in the range of 0.49-0.56. Canaanimys and Gaudeamus form a well-

829 supported clade ( $\mathrm{PP}=0.99)$, and " $P$." tunisiensis is again placed as the sister taxon of

830 phiocricetomyines, but with very weak support $(\mathrm{PP}=0.36)$. There is strong support $(\mathrm{PP}=0.91)$

831 for a clade containing African species, Canaanimys, and advanced "baluchimyines" to the

832 exclusion of basal "baluchimyines" (Baluchimys ganeshaper, Baluchimys krabiense,

833 Confinniumys, Lindsaya, Ottomania), but relationships among the basal members of the clade

834 (Protophiomys, Waslamys) in the allcompat tree are only weakly supported $(\mathrm{PPs}=0.25-0.5)$. 
Tip-dating analysis with the fossilized birth-death prior

837 The "allcompat" consensus summarizing the 50,000 post-burn-in trees from the tip-dating 838 analysis of the 118-character matrix with broad uniform priors on tip ages (i.e., analysis TD1, see 839 Fig. S2) provided tip estimates that were averaged on a locality-by-locality basis for analysis 840 TD2. These averages allowed for the ordering of localities from oldest to youngest as follows 841 (Fig. 12, see Table 2 for 95\% HPD): Subathu "Zone VIII” (India), 45.8 Ma; Khaychin II-III-IV 842 (Mongolia), 43.5 Ma; Rencun Member (China), 41.0 Ma; Djebel el Kébar (Tunisia), 39.2 Ma; 843 Birket Qarun Locality 2 (Egypt), 37.3 Ma; Bir el-Ater (Nementcha, Algeria), 37.3 Ma; Dur at-

844 Talah DT1 (Libya), 36.2 Ma; Dur at-Talah DT2 (Libya), 35.9 Ma; Fayum Locality 41 (Egypt), 845 34.4 Ma; Fayum Quarries A and B (Egypt), 33.8 Ma; Krabi Bang Mark Pit (Thailand), 33.5 Ma; 846 Lokone (Kenya), 31.9 Ma; Hsanda Gol (Mongolia), 32.0 Ma; Y-GSP 417 (Pakistan), 31.6 Ma; 847 Süngülü (Turkey), 32.1 Ma; Fayum Quarry E (Egypt), 32.0 Ma; Fayum Quarry G (Egypt), 30.8 848 Ma; Paali Nala C2 (Pakistan), 29.9 Ma; Fayum Quarries I and M (Egypt), 29.6 Ma; and Silica 849 North (Namibia), 25.7 Ma.

850 The resulting "allcompat" tree from analysis TD2, with tips fixed to the mean dates above (Fig. 851 13; see Fig. S3 and Dataset S5 for absolute median rates for each branch), is effectively the same 852 as that from TD1 [Fig. S2; the sole difference being that Acritophiomys joins "Phiomys" 853 hammudai, with very low probability $(\mathrm{PP}=0.30)$ ], but shows some notable differences from that 854 based on the standard Bayesian analysis; few of the different placements are supported by high 855 posterior probabilities, however. In contrast to the Bayesian allcompat consensus, the tip-dating 856 allcompat 1) places Birkamys and Mubhammys in a slightly more basal position in phiomorph 857 phylogeny, being the sister group of all younger phiomorphs aside from Phiomys; 2) shows 
858 much stronger support for the monophyly of progressively more nested phiomorph clades that

859 include Turkanamys, "Phiomys" hammudai, and Acritophiomys (TD1 PP=0.90, TD2 PP=0.92,

860 standard Bayesian $\mathrm{PP}=0.55$ ), Phiomys (TD1 $\mathrm{PP}=0.90$, TD2 $\mathrm{PP}=0.91$, standard Bayesian

$861 \mathrm{PP}=0.49$ ), and Birkamys-Mubhammys (TD1 $\mathrm{PP}=0.94$, TD2 $\mathrm{PP}=0.96$, standard Bayesian

$862 \mathrm{PP}=0.50) ; 2$ ) the sole undoubted caviomorph in the matrix (Canaanimys) in a particularly basal

863 position, and with no special relationship to Gaudeamus, in strong contrast to the Bayesian

864 analysis that supported a Canaanimys-Gaudeamus clade with a posterior probability of $0.99 ; 3$ )

865 Tsaganomys and "basal baluchimyines" form a well-supported clade (TD1 PP=0.87, TD2

$866 \mathrm{PP}=0.92$ ) rather than a paraphyletic stem with respect to African and South American

867 hystricognaths (as found in both the standard Bayesian and parsimony analyses). Despite the

868 differences in overall branching sequence between the tip-dating allcompat consensus and the

869 standard Bayesian allcompat consensus, in the former the only higher-level clades that are

870 supported by posterior probabilities $>0.5$ are Phiocricetomyinae (TD1 $\mathrm{PP}=0.93$, TD2 $\mathrm{PP}=0.94$ ), a

871 clade of "advanced" baluchimyines (TD1 PP=0.94, TD2 PP=0.98), Gaudeamuridae (TD1 and

872 TD2 PP=1.0), and the clade including "phiomyids" and derived phiomorphs (TD1 PP=0.90, TD2

$873 \mathrm{PP}=0.92$ ). As such, the interrelationships among those clades, Canaanimys, Waslamys and the

874 various species assigned to the genus Protophiomys are not well-resolved, though support for a

875 "Protophiomys" tunisiensis-Phiocricetomyinae clade increases to $\mathrm{PP}=0.52$ in analysis TD2.

876 Evolutionary rates (calculated for each branch as number of changes per site per Ma by

877 multiplying the median rate for the branch in the allcompat consensus by the median estimate for

878 the base clockrate that is output in the MrBayes *.pstat file; see Beck and Lee, 2014) are fairly

879 consistent across most nodes in the tree, with the most striking accelerations being along the

880 branches leading to Canaanimys and to the Birkamys-Mubhammys clade. The split between 
881 Caviomorpha and Phiomorpha (the latter in this case including basal baluchimyines and 882 Tsaganomys) is estimated to have occurred at either $43.5 \mathrm{Ma}$ (TD1) or 43.2 (TD2), and the

883 largely African clade containing phiocricetomyines, gaudeamurids, and undoubted phiomorphs 884 is estimated to have appeared at either $41.8 \mathrm{Ma}$ (TD1) or $41.5 \mathrm{Ma}$ (TD2). The advanced 885 phiomorph clade that includes all species showing no evidence for $\mathrm{P}^{4} / 4$ eruption (i.e., the clade 886 including Birkamys and Mubhammys but excluding Phiomys) is estimated to have appeared at $887 \quad 35.1 \mathrm{Ma}$ in both TD1 and TD2.

\section{Evolution of $M_{1}$ size among early hystricognaths}

890 With $\ln \mathrm{M}_{1}$ area treated as a continuous variable evolving on the pruned tip-dating "allcompat" 891 tree from TD2 (Fig. S4), the directional and random walk models (both with a lambda scaling 892 parameter) returned similar log likelihoods, with little basis for preferring one model over the

893 other. In Figure 14, we present the results of runs based on both models, with mean estimates for 894 ancestral nodes from each model represented by single points and the intervening space infilled 895 to reflect differences in the mean estimates (see Dataset S6 for means and upper and lower 95\% 896 HPD for each node reconstructed).

897 While the two models leave considerable uncertainty about the mean $\mathrm{M}_{1}$ area estimate along the 898 stem leading to the African hystricognath radiation, the estimate for that group's common 899 ancestor is well-constrained, with the random walk model recovering a mean estimate of 2.86 $900 \mathrm{~mm}^{2}$ and the directional model a mean estimate of $2.69 \mathrm{~mm}^{2}$ - i.e., about the size of

901 Protophiomys aegyptensis from Locality BQ-2, and a little bit larger than the oldest Afro-

902 Arabian hystricognath, "Protophiomys" tunisiensis (Marivaux et al., 2014). From this point of 
903 origin for African hystricognaths, there is an immediate size-related divergence between 904 phiocricetomyines (here including "Protophiomys" tunisiensis) and the lineage leading to 905 derived phiomorphs. Phiocricetomyines decrease in size at a fairly constant rate through time, 906 finally terminating with the diminutive early Oligocene species Phiocricetomys minutus. There is

907 little change leading to the initial divergence of Protophiomys sensu stricto, with slight increases 908 in $\mathrm{M}_{1}$ area along the lineages leading to gaudeamurids, "Phiomys" hammudai, and Turkanamys, 909 but in the early Priabonian a dwarfing event is implied, paralleling the trend seen in 910 phiocricetomyines, along a trajectory that ultimately leads to the tiny species Phiomys andrewsi.

911 There is a reconstructed reversal of that trend in the Priabonian, close to the point of origin of the

912 Birkamys-Mubhammys clade and the reconstructed acquisition of $\mathrm{P}^{4} / 4$ suppression, followed by

913 gradual increases in size through the early Oligocene with the evolution of more derived and

914 deeply nested phiomorphs (e.g., Metaphiomys). Given the trends reconstructed here, the small

915 size of Neophiomys is, like Phiomys, also reconstructed as having been due to dwarfing, rather

916 than retention of ancestral small size. Most remarkable in these size trends is the rapid 917 divergence of Birkamys and Mubhammys from a common ancestor into dramatically different

918 size categories, along trajectories that are almost horizontal on the size change versus time plot,

919 showing that major change in size has occurred over only a very short period of time (note,

920 though, that the implied change along the Birkamys branch appears somewhat exaggerated due to

921 the use of logarithmically transformed variables). The upper and lower 95\% HPDs for most 922 ancestral estimates are quite broad (see Dataset S6), but the 95\% HPD for the common ancestor 923 of all Afro-Arabian hystricognaths (random walk model, 0.3205-1.8077; directional model, $9240.2243-1.7649)$ nevertheless clearly excludes values in the range of Birkamys korai. 
926 Discussion

927 Origin and evolution of the Birkamys-Mubhammys clade

928 The placement of Birkamys and Mubhammys as the exclusive sister taxa of extant Thryonomys in

929 the maximum parsimony analysis in which all characters were equally weighted must be

930 considered highly unlikely given the numerous extensive ghost lineages that the topology implies

931 throughout phiomorph phylogeny (Fig. 15). When tips are scaled to the age estimates provided

932 by the TD1 tip-dating analysis, and internodes are arbitrarily separated by $1 \mathrm{Ma}$, the strict

933 consensus derived from the parsimony analysis with all characters equally weighted requires a

934 total of $422.7 \mathrm{Ma}$ along all branches (Fig. 15A, calculated in Mesquite 2.75 ("sum of branch

935 lengths"); Maddison and Maddison, 2011), while the standard Bayesian allcompat tree, which

936 places Birkamys and Mubhammys much more basally in phiomorph phylogeny, provides a

937 significant reduction in overall time required (Fig. 15B, 357.4 Ma). However the placement of

938 Thryonomys as the sister taxon of a Birkamys-Mubhammys clade in the unweighted parsimony

939 analysis is not well-supported, and is sensitive to weighting of ordered characters; the maximum

940 agreement subtree calculated from all trees recovered when transitions between "fixed" and

941 polymorphic states are scaled to be a half-step rather than a full step does not include a

942 Birkamys-Mubhammys-Thryonomys clade, and is entirely consistent with the Bayesian allcompat

943 tree. When compared to the standard Bayesian allcompat tree, the tip-dating allcompat tree from

944 TD2 requires only $45 \%$ of the total time accumulated across all branches (Fig. 15D, 159.4 Ma

945 total). This tip-dating tree has several zones with very rapid divergences and short internodes, but

946 even if branch lengths of terminal taxa and internodes are set to 0 in the parsimony tree (Fig.

947 15C), it still requires $125 \%$ more time (198.7 Ma versus $159.4 \mathrm{Ma}$ ) than the TD2 tip-dating tree. 
948 Taken together, the phylogenetic and morphometric analyses presented here suggest that

949 Birkamys and Mubhammys are members of a previously unrecorded late Eocene African lineage

950 of early phiomorph rodents that diverged dramatically in size following a rapid change in tooth

951 morphology in the later Eocene. The tip-dating analyses recovered particularly high evolutionary

952 rates along the stem leading to the Birkamys-Mubhammys clade (Fig. 12), but ancestral

953 reconstructions of $\mathrm{M}_{1}$ area indicate only a slight size decrease along this branch; instead the most

954 dramatic size change is the rapid dwarfing event that is reconstructed along the branch leading to

955 Birkamys. This pattern suggests that a relatively rapid change in dental morphology (overall

956 simplification, involving the loss or reduction of transverse crests) might have facilitated, or

957 driven, Birkamys' expansion into a new niche space that was either unoccupied during the latest

958 Eocene in this particular part of Africa, or that overlapped with the niche spaces of

959 phiocricetomyines (small members of which have been recovered at L-41; descriptions currently

960 in preparation).

961 The dwarfing event implied for the Birkamys lineage also suggests that the suppression of $\mathrm{P}^{4} / 4$

962 development and eruption likely first occurred at a body size larger than that of the tiny species

963 B. korai, perhaps in populations with individuals that were about the size of Protophiomys

964 aegyptensis or Pr. algeriensis. Given the ancestral reconstructions depicted in Fig. 14, initial

965 suppression, however, would have evolved following an earlier, less dramatic, late Eocene

966 dwarfing event from somewhat larger ancestors. After the Eocene-Oligocene boundary, members

967 of the clade that evolved suppression subsequently undergo a steady increase in $\mathrm{M}_{1}$ size. Wood

968 (1968) suggested that in early phiomorphs the $\mathrm{P}^{4} / 4$ might have "lagged in the race to become

969 molariform" (p. 84), perhaps due to the longer retention of $\mathrm{dP}^{4} / 4$ in basal stem phiomorphs, and

970 that life-long retention of $\mathrm{dP}^{4} / 4$ would have been advantageous if selection favored individuals 
971 with increased capacity for grinding across the post-diastemal dentition. The dwarfing event

972 reconstructed prior to the evolution of $\mathrm{P}^{4} / 4$ suppression opens up the possibility that $\mathrm{dP}^{4} / 4$

973 retention might have first evolved in populations that were somewhat neotenous relative to their

974 ancestors -- i.e, containing individuals whose growth trajectories (including the timing of dental

975 eruption) had been truncated, so that replacement of $\mathrm{dP}^{4} / 4$ ultimately never occurred. Only after

$976 \mathrm{P}^{4} / 4$ suppression had been effectively "fixed" might there have then been selection for the

977 increased hypsodonty of all unreplaced teeth in various Oligocene lineages. Given the presence

978 of what might be yet another tiny phiomorph species at L-41 (cf. Birkamys, Fig. 6), however, it is

979 also possible that the $M_{1}$ size change scenario presented in Fig. 14 is overly simplistic; the

980 hypothesis presented here will have to be tested with the recovery of additional species from late

981 Eocene sites throughout Africa and Arabia.

982

983 Broader implications of tip-dating topologies for early hystricognath evolution

984 The parsimony, standard Bayesian, and tip-dating analyses all congruently supported a

985 phiomorph clade that includes as its most basal members late Eocene Acritophiomys and

986 "Phiomys" hammudai and Oligocene Turkanamys hexalophus. In the parsimony and standard

987 Bayesian analyses, this clade was found to be the sister taxon of Caviomorpha - i.e., either a

988 Gaudeamuridae+Caviomorpha clade (parsimony with all characters equally weighted) or a

989 Gaudeamuridae+Caviomorpha+Waslamys+"Protophiomys" durattalahensis clade (standard

990 Bayesian). In the tip-dating analysis, the caviomorph Canaanimys was not placed with

991 gaudeamurids, and in fact was placed as the most basal of all hystricognaths, though with very

992 weak support for its exclusion from more nested positions. One of the more remarkable 
993 topological rearrangements in the tip-dating analyses was the placement of primitive

994 "baluchimyines" (Baluchimys, Confiniummys, Lindsaya, Ottomania) in a well-supported clade

995 with early Oligocene Tsaganomys. This result is not entirely surprising, because the evidence for

996 the paraphyly of the group with respect to derived hystricognaths is weak in the parsimony and

997 standard Bayesian analyses (Figs. 10 and 11), and furthermore the paraphyly of the group

998 requires extensive ghost lineages (Fig. 15) and presumably very low rates of evolution along

999 terminal branches. However it is surprising that the monophyly of the group could be strongly

1000 supported ( $\mathrm{PP}=0.92$ in the TD2 analysis) given these conditions. "Advanced" baluchimyines

1001 (Bugtimys, Hodsahibia, Lophibaluchia) are nested within the African hystricognath radiation

1002 across all analyses, implying an African origin for that clade and a dispersal to Asia, which is

1003 estimated to have occurred in the middle or late Eocene by the tip-dating analyses. However

1004 while this topological result is strongly supported by the standard Bayesian analysis, it is not

1005 well-supported in either the parsimony or tip-dating analyses.

1006

1007 Telling time with rodent teeth: implications of tip estimates for the chronology of Paleogene

1008 hystricognath-bearing sites

1009 In the absence of radioisotopically datable rocks, terrestrial mammal faunas from spatially and/or

1010 temporally isolated horizons can be extraordinarily difficult to date. The magnitude of the

1011 difficulty is proportional to the intensity of sampling of that temporal interval elsewhere on a

1012 landmass; if many other faunas of different ages bracket a fauna of interest, it is more likely that

1013 the same species will be recovered from multiple localities, and, in such cases, standard

1014 biochronology based on first/last appearances can be used to order localities, using for instance 
1015 Appearance Event Ordination (Alroy, 1994). In the Paleogene of Afro-Arabia, sampling of the

1016 terrestrial mammal record has been so limited, and so patchy in space and time, that it is very

1017 rare for localities to show overlapping species (Seiffert, 2006, 2010; Coster et al., 2012). The

1018 taxonomy that workers choose to use can further obfuscate the situation; i.e., if newly discovered

1019 fossils are uncritically assigned to new species, there will be no species overlap for

1020 biochronological analysis.

1021 These conditions have led to an unfortunate situation in which ordering of sites in the Paleogene

1022 of Africa is more often than not based on assumption-laden "stage of evolution" arguments that

1023 compare species from two localities and determine that one is older than the other because

1024 species A is "more primitive" than species B, or species B is of a more "advanced evolutionary

1025 stage" than species A. For instance, in attempting to determine the age of the Dur at-Talah

1026 localities in Libya that yielded some of the species included in our analysis, Jaeger et al. (2010a)

1027 argued that "Protophiomys is a primitive representative of the phiomyid African radiation and it

1028 is represented in Dur At-Talah by a slightly more derived species (Pr.durattalahensis) than that

1029 of Nementcha (Pr. algeriensis), thereby suggesting a younger age for the Dur At-Talah deposits"

1030 and that "the L41 rodent assemblage (Holroyd, 1994) contains more derived species than that of

1031 Dur at-Talah" (p. 211), leading them to argue that Dur at-Talah is also older than L-41. Sallam et

1032 al. (2012, p. 297) argued that ""Phiomys" hammudai from Dur at-Talah is perhaps slightly more

1033 primitive than Acritophiomys from L-41, but nevertheless is clearly more derived than the

1034 hystricognaths from BQ-2 (Waslamys attiai and Protophiomys aegyptensis)" in suggesting that

1035 Dur at-Talah is probably intermediate in age between L-41 and BQ-2.

1036 Though such assessments might be based on compelling background information, the evidence

1037 and assumptions underlying the arguments are rarely explicit. On the broadest level, in the 
1038 absence of a phylogenetic analysis, the comparison of the characters of species A with those of

1039 species B assumes that the two species are closely related and that the characters in question are

1040 homologous; it further assumes the evolutionary trajectory of the features, and that the presence

1041 of a presumed apomorphy in species B indicates that that feature has appeared more recently in

1042 time than the presumed plesiomorphic state in species A. These arguments thus also make

1043 assumptions about rates of evolution - they assume that a (presumed) plesiomorphic taxon

1044 species A is likely to be temporally older than a (presumed) apomorphic taxon species B because

1045 the reverse arrangement would imply relatively slow evolutionary rates in species A (i.e., stasis)

1046 and fast evolutionary rates in species B. It might even be assumed that the presence of a

1047 presumed apomorphy in species B implies that a certain amount of speciation must have

1048 occurred along the lineage leading to species B to account for that amount of change.

1049 Bayesian tip-dating with the fossilized birth-death prior takes into account the important

1050 background information that must underlie these "stage of evolution" arguments — ages of

1051 related species, phylogenetic relationships among those species, rates of evolution, and patterns

1052 in speciation and fossilization — but in a much more explicit, objective, and replicable manner.

1053 Here we suggest that Bayesian tip-dating analysis with the fossilized birth-death prior is thus not

1054 only of use for dating internal nodes, but can also reasonably be "turned on its head" to provide

1055 age estimates for temporally poorly-constrained tips that have been assigned broad uniform

1056 priors on tip age — i.e., taking into account multiple biochronologically-relevant parameters to

1057 determine both phylogenetic position and the most likely point in time at which a morphological

1058 pattern would likely be present, given its broad uniform prior on age, its phylogenetic position, 1059 and the base clock rate of the tree. 
1060 One possible concern with this approach is that age estimates for species will simply fall near the

1061 middle of their uniform age priors. Our results clearly indicate that this is not the case. A

1062 particularly striking example is provided by Prepomonomys bogenfelsi, a species of contested

1063 age from the Sperrgebiet area of Namibia (Pickford et al., 2008). P. bogenfelsi and the other

1064 mammals from the Sperrgebiet Silica North locality were first described as Lutetian (early

1065 middle Eocene) in age (Pickford et al., 2008) and later as Bartonian (late middle Eocene)

1066 (Pickford et al., 2014), but multiple authors (Coster et al., 2012; Marivaux et al., 2014), including

1067 Pickford et al. (2008) themselves, have noted that the species from Silica North are similar to

1068 Miocene species from east Africa. Pickford et al. (2008) even placed some of the Silica North

1069 species in, or close to, otherwise exclusively Miocene phiomorph genera (Apodecter, cf.

1070 Bathyergoides). If the Silica North specimens are Bartonian in age as Pickford et al. (2014)

1071 suggest, their taxonomic identifications as Apodecter and cf. Bathyergoides would require $\sim 17-$

1072 21-million-year-old temporal extensions for these genera far back into the Eocene, into time

1073 intervals when crown hystricognaths were (given a direct reading of the fossil record) only just

1074 starting to diversify. However with our very conservative and broad 20-47 Ma uniform age prior

1075 on Prepomonomys, the TD1 analysis favored an age of $25.7 \mathrm{Ma}$ (late Oligocene), i.e., far into the

1076 youngest part of the age prior, with a 95\% HPD interval (20.0-30.41 Ma) that excludes most of

1077 the early Oligocene, and the Eocene entirely. Based solely on the fossils that have been described

1078 from Silica North and Silica South thus far (Pickford et al., 2008), and the strongly conflicting

1079 information provided by middle and late Eocene hystricognaths in northern Africa (Jaeger et al.,

1080 1985, 2010a; Marivaux et al., 2014; Sallam et al., 2009, 2011, 2012), a late Oligocene age would

1081 appear to us to make better sense of the rodent fauna from these localities, and could also explain

1082 why Silica North would have a relatively derived rodent fauna without any of the immigrant 
1083 mammals that are thought to have arrived in Africa near the Oligocene-Miocene boundary

1084 (Rasmussen and Gutiérrez, 2009). The recently described mammals from the Eocliff and Eoridge

1085 sites (e.g., Pickford, 2015a, b), also in the Sperrgebiet area and also considered to be of

1086 Bartonian age by Pickford et al. (2014), are in our opinion also consistent with a late Oligocene

1087 age; the Eocliff tenrecoids (Pickford, 2015a) are morphologically intermediate between early

1088 Miocene species and those known from the late Eocene and Oligocene of Egypt (Seiffert and

1089 Simons, 2000; Seiffert et al., 2007; Seiffert, 2010), while the presence of a derived

1090 anthracotheriid artiodactyl (Pickford, 2015b) - an immigrant clade that has never been found at

1091 any of the earliest Priabonian Birket Qarun localities in the Fayum, and first appear in the Dir

1092 Abu Lifa Member of the stratigraphically younger Qasr el-Sagha Formation — strongly supports

1093 a maximum age of latest Priabonian for Eocliff, and more clearly an Oligocene age.

1094 Similarly, Asian "baluchimyines" and Turkanamys have relatively old (early Oligocene) mean

1095 estimates within the broad (Oligocene-wide) uniform limits of their age priors. "Baluchimyine"

1096 species from the lower part (Bugti Member) of the Chitarwata Formation of Pakistan were

1097 initially thought to be early Miocene in age (Flynn, 1986), but there is now agreement that this

1098 unit is Oligocene, though estimates for its maximum age range from the early Oligocene into the

1099 late Oligocene (Lindsay et al., 2005; Metais et al., 2013). In the case of the five Chitarwata

1100 Formation "baluchimyine" species (of 12 known) sampled in this analysis, the resulting mean

1101 estimates (31.57 Ma for Y-GSP 417 and 29.9 Ma for Paali Nala C2) are consistent with the early

1102 Oligocene estimates of Welcomme et al. (2001) and Metais et al. (2013) based on

1103 biochronological interpretation of multiple vertebrate lineages. The mean age estimates for three

1104 species from Y-GSP 417 (as output in the MrBayes ".vstat" file) are tightly constrained at 31.7

1105 Ma (28.1-33.9 Ma 95\% HPD) for Baluchimys ganeshapher, 31.7 Ma (28.2-33.9 Ma 95\% HPD) 
1106 for Lindsaya derabugtiensis, and 31.3 Ma (27.1-33.9 Ma 95\% HPD) for Lophibaluchia

1107 pilbeami, while Bugtimys zafarullahi and Hodsahibia gracilis from Paali Nala C2 were

1108 estimated to be 30.2 Ma (25.6-33.9 Ma 95\% HPD) and 29.6 Ma (24.9-33.9 Ma 95\% HPD),

1109 respectively. Lindsay et al. (2005) suggested that the baluchimyine-bearing base of the

1110 Chitarwata Formation is likely to be either $\sim 29.8 \mathrm{Ma}$ or $\sim 25.8$, and of these options our data

1111 support the former interpretation. Two other "baluchimyines" in the analysis, Confiniummys and

1112 Ottomania from Süngülü in Turkey, were thought to be close in age to the Eocene-Oligocene

1113 boundary (de Bruijn et al., 2003), but here were estimated to be about two million years younger

1114 (32.1 Ma), despite broad uniform priors extending from the end of the Oligocene (23 Ma) all the

1115 way back to the beginning of the late Eocene (37.8 Ma). Given the age estimates provided by the

1116 tip-dating analysis, Baluchimys krabiense from the Bang Mark Pit in Krabi, Thailand (Marivaux

1117 et al., 2000) would be the oldest "baluchimyine" from Asia at 33.5 Ma (31.6-35.0 Ma 95\%

1118 HPD). Finally, the 31.9 Ma (28.3-33.9 Ma 95\% HPD) estimate that Turkanamys hexalophus

1119 provides for the Lokone Hill sites in the Turkana Basin of Kenya is consistent with the broad late

1120 early to late Oligocene age suggested by Ducrocq et al. (2010). Seiffert (2012) suggested that the

1121 Lokone Hill sites were close in age to the boundary between the early and late Oligocene ( 28

1122 Ma).

1123 Finally, our analysis has implications for the age of the Dur at-Talah faunas DT1 and DT2,

1124 which have been described by Jaeger et al. (2010a, b) on "stage of evolution" grounds as being

1125 late middle Eocene (Bartonian) in age, but were instead considered to be late Eocene

1126 (Priabonian) by Sallam et al. (2012), Antoine et al. (2012), and Marivaux et al. (2014). Both of

1127 these faunas present interesting problems in that they preserve remains of primitive species

1128 ("Protophiomys" durattalahensis at DT-1 and "Protophiomys" aff. durattalahensis at DT-2) that 
1129 resemble Waslamys from BQ-2, combined with phiocricetomyines [Talahphiomys libycus (DT-

1130 1) and Talahphiomys lavocati (DT-2)] that have no relatives at BQ-2, and that more closely

1131 resemble species from the Oligocene levels of the Jebel Qatrani Formation. "Phiomys"

1132 hammudai from DT-1 shares derived features with Acritophiomys from the latest Eocene L-41

1133 locality, as well as more derived phiomorphs from younger Fayum levels, and is not known from

1134 BQ-2. It is perhaps not surprising, then, that the tip estimates for the species from these localities

1135 are the most disparate of all in the analysis: the "Protophiomys" species are assigned mean

1136 estimates of $37.6 \mathrm{Ma}$ (durattalahensis) and 38.2 Ma (aff. durattalahensis), which are in line with

1137 Jaeger et al.'s (2010a) late middle Eocene estimates, while the other Dur at-Talah species are

1138 estimated to be considerably younger: "Phiomys" hammudai is assigned a mean estimate of 35.6

1139 Ma (1.7 Ma younger than the overall mean estimate for BQ-2), and Talahphiomys species are

1140 estimated to be even younger (35.3 Ma for T. libycus and 33.6 Ma for T. lavocati). Ultimately,

1141 the mean estimates based on all species are 36.2 Ma for DT-1 (3 species) and 35.9 Ma for DT-2

1142 (2 species) - i.e., intermediate in age between BQ-2 and L-41, as was argued by Sallam et al.

1143 (2012) and Seiffert (2012). The mean estimates for the ages of DT-1 and DT-2 do not require

1144 particularly fast or slow rates and are broadly consistent with adjacent branches (Fig. 13).

1145 We would not argue that this method should be used in place of traditional biochronological

1146 methods that can be employed on landmasses with better sampling and sufficient species

1147 overlap, but it is certainly a more rigorous and repeatable approach than the data-free and

1148 assumption-laden "stage of evolution" arguments that have otherwise been applied to the

1149 ordering of terrestrial mammal sites in the very sparsely sampled Afro-Arabian Paleogene. We

1150 would expect this method to converge on increasingly robust age estimates as evidence is

1151 brought to bear from multiple biochronologically useful clades, and to be most useful when there 
1152 are long and relatively well-dated reference sections available — for instance, in the case of

1153 Paleogene hystricognaths, the ability to integrate relatively tight age priors for species from the

1154 long Fayum succession undoubtedly helps to constrain several key parameters that in turn

1155 constrain estimates for poorly-constrained tips.

1156

1157 Incisive foramina of early phiomorphs

1158 The most striking feature of the rostrum of Birkamys is the great enlargement of the apparently

1159 confluent incisive foramina, most clearly seen on the holotype specimen (CGM 66000, Fig. 3B)

1160 but also evident from the anteroposteriorly elongate, concave, and smooth lateral borders of the

1161 foramen on isolated maxillae [DPC 9276 (Fig. 4E) and DPC 15625 (Fig. 4B)]. The same pattern

1162 holds for the one maxilla of Mubhammys that preserves this area (Fig. 7C). An anteroposteriorly

1163 enlarged incisive foramen was also identified in Metaphiomys by Wood (1968, his Fig. 6) and

1164 referred to as an "anterior palatine fenestra"; of this, he noted (pp. 51-52) that "ventrally, the

1165 anterior palatine fenestrae are large and not sunk into a palatal depression as much as in

1166 Petromus or Thryonomys, although there is a shallow depression lateral to the fenestra (fig. 6D),

1167 within which the fenestrae lie, which suggests the initial stages of a Petromus type of

1168 modification. The palatine fenestra is more rounded anteriorly than in the recent genera. No

1169 suggestion of an interpremaxillary foramen is present in any of the genera, although there is a

1170 paired foramen at the anterior end of the anterior palatine fenestra in Petromus and Thryonomys

1171 not seen in Metaphiomys. Posteriorly, there is a broad depression extending as far back as the

1172 anterior end of $\mathrm{dP}^{4}$ (Fig. 6A, 16), which seems to be identical to the deep fossa that contains the

1173 anterior palatine fenestrae in Petromus and Thryonomys." With the recovery of fairly complete, 
1174 but crushed, crania of Acritophiomys and Gaudeamus from L-41 (Sallam et al., 2011, 2012), it is

1175 now clear that enlarged incisive foramina are also present in those genera. The only known

1176 maxilla of Waslamys is not well-preserved, but appears to have a smooth margin anterior to the

$1177 \mathrm{P}^{4}$ that is similar to that of Birkamys (Fig. 16A). Among early Miocene taxa, similarly enlarged

1178 foramina are seen in Lavocatomys aequatorialis (Fig. 16F), Simonimys genovefae (Fig. 16H) and

1179 Paraphiomys stromeri. Diamantomys leuderitzi appears to have confluent foramina, but they are

1180 mediolaterally narrow and bordered by ventrally protruding flanges (Lavocat, 1973), perhaps

1181 correlated with the anteroposterior elongation of this region of the cranium. Kenyamys mariae

1182 also has more restricted foramina that are separated by a midline bony partition (Lavocat, 1973).

1183 In strong contrast, the incisive foramina of the Miocene bathyergoid Renefossor songhorensis are

1184 very small (Fig. 16C), and are either absent or tiny in Proheliophobius leakeyi (Fig. 16G).

1185 Among early Miocene bathyergoids, the foramina of Efeldomys loliae from Namibia (Mein \&

1186 Pickford, 2008) appear to be the largest relative to tooth size (unless their apparent size is due to

1187 breakage), but are still much smaller than those of the L-41 species.

1188 From these observations the question arises as to whether the very enlarged foramina of

1189 Acritophiomys, Birkamys, Gaudeamus, and Mubhammys are primitive within Phiomorpha (or

1190 possibly even at some more inclusive level within Hystricognathi), or instead a synapomorphy of

1191 Thryonomyoidea (Petromus-Thryonomys) relative to Bathyergoidea, in which case Efeldomys

1192 and Renefossor retain the ancestral condition within Phiomorpha. The molecular divergence

1193 estimates of Patterson and Upham (2014) place the thryonomyoid-bathyergoid divergence at

$119436.3 \mathrm{Ma}$, but the divergence of gaudeamurids from other hystricognaths in the matrix is

1195 estimated by the tip-dating analyses to have occurred $39 \mathrm{Ma}$; assuming homology, this suggests

1196 an origin for such enlarged foramina well into the middle Eocene. There is no clear fossil record 
1197 of the hystricid lineage before the Miocene, but, as in extant species, the late Miocene form

1198 “Hystrix” gansuensis has restricted foramina (Wang \& Qiu, 2002). Early Oligocene Tsaganomys,

1199 which is aligned with "baluchimyines" in the tip-dating analysis, has restricted foramina as well

1200 (Bryant \& McKenna, 1995). Among early caviomorphs, Incamys bolivianus has enlarged

1201 foramina, while Branisamys luribayensis does not (Patterson \& Wood, 1983; their Figs. 14 and

1202 23). Unfortunately the origin of this distinctive feature cannot be adequately addressed without a

1203 matrix that samples more comprehensively from living and extinct ctenohystricans, but the

1204 recognition of the early ubiquity of this feature provides an interesting and easily identifiable

1205 new piece of evidence that will no doubt be of great importance for ongoing efforts to unravel

1206 early hystricognath phylogeny.

1207 The broader question of the functional and behavioral implications of such variation will require

1208 much more research into the morphology of extant hystricognaths. The morphology seen in early

1209 phiomorphs might relate in some way to both the peculiar position of the vomeronasal organ of

1210 rodents, which opens anterior to the incisive foramina (Wöhrmann-Repenning, 1982; Giere et al.,

1211 1999), and the unique transformations of the rostral nasal skeleton and soft tissue structures of

1212 hystricognaths (Mess, 1999). For instance, Mess (1999) found that extant non-bathyergoid

1213 hystricognaths lacked fusion of the processus lateralis ventralis and the lamina tranversalis

1214 anterior, leading to a non-continuous rostral nasal floor, and that the nasal septum forms a

1215 ventrally protruding keel onto which facial musculature inserts; she suggested that this

1216 morphology could lead to increased mobility of the rostral nasal skeleton in these forms. In

1217 contrast, bathyergoids have a continuous rostral nasal floor and much smaller incisive foramina;

1218 of interest in this regard is the observation that among the bathyergoid phiomorphs, the naked 
1219 mole-rat Heterocephalus has a very small vomeronasal organ, perhaps relating to eusociality

1220 (Smith et al., 2007).

1221

\section{Conclusions}

1223 The late Eocene genera described here, Birkamys and Mubhammys, further expand the 1224 morphological diversity observable in the terminal Eocene radiation of Afro-Arabian 1225 hystricognaths, and provide the first compelling evidence for a key phiomorph synapomorphy — 1226 suppression of $\mathrm{P}^{4} / 4$ eruption - having evolved by the latest Eocene. In their lower molar 1227 morphology, Birkamys and Mubhammys show considerable similarity to members of the genus 1228 Phiomys; this shared morphology likely would have characterized the late Eocene-aged last 1229 common ancestor of the phiomorph clade that contains Birkamys, Mubhammys, and Phiomys.

1230 The combined evidence from phylogenetic analysis and estimation of ancestral sizes of the first 1231 lower molar across early hystricognaths imply that Birkamys and Mubhammys underwent 1232 exceedingly rapid divergence in tooth size in the latest Eocene; the reasons for such a dramatic 1233 change are unclear. Cranial evidence from Birkamys, Mubhammys, and several Fayum and early 1234 Miocene has unexpectedly revealed that greatly enlarged incisive foramina are likely to be an 1235 ancient feature of phiomorph rodents, and possibly synapomorphic at an even more inclusive 1236 level within Hystricognathi.

\section{Institutional abbreviations}

1239 CGM Egyptian Geological Museum, Egypt

1240 DPC Duke Lemur Center Division of Fossil Primates 
1241 MUVP Mansoura University Vertebrate Paleontology Center

1242

1243 ACKNOWLEDGMENTS

1244 We thank G. Gunnell, P. Chatrath, and C. Riddle for access to the fossil collection at the

1245 Division of Fossil Primates, Duke Lemur Center, F.K. Manthi for access to Miocene phiomorphs

1246 at the National Museums of Kenya, and M. Abdel Ghany and A.H. Sileem for access to

1247 specimens at the CGM. J. Thostenson (Duke) and P.M. O’Connor (Ohio University) provided

1248 access to micro-CT scanning facilities. M.E. Frenkel helped with SEM facilities housed at the

1249 American Museum of Natural History. We thank L. Marivaux and M.E. Pérez for their helpful

1250 reviews of the manuscript, and A. Hammond, J. Herrera, and N. Stevens for helpful discussion.

1251 We thank the staff of the Egyptian Mineral Resources Authority and the Egyptian Geological

1252 Survey for facilitating our work in the Fayum area. This is Duke Lemur Center publication \# 12531313. 
1255 References

1256 Alroy J. 1994. Appearance event ordination: a new biochronologic method. Paleobiology 20: $1257 \quad 191-207$.

1258 Antoine P-O, Marivaux L, Croft DA, Billet G, Ganerød M, Jaramillo C, Martin T, Orliac MJ, 1259 Tejada J, Altamirano AJ, Duranthon F, Fanjat G, Rousse S, and Gismondi RS. 2012. 1260 Middle Eocene rodents from Peruvian Amazonia reveal the pattern and timing of 1261 caviomorph origins and biogeography. Proceedings of the Royal Society B: Biological $1262 \quad$ Sciences 279:1319-1326.

1263 Beck RMD, and Lee MSY. 2014. Ancient dates or accelerated rates? Morphological clocks and 1264 the antiquity of placental mammals. Proceedings of the Royal Society B: Biological $1265 \quad$ Sciences 281:20141278. 10.1098/rspb.2014.1278.

1266 Bryant JD, and McKenna MC. 1995. Cranial anatomy and phylogenetic position of Tsaganomys 1267 altaicus (Mammalia: Rodentia) from the Hsanda Gol Formation (Oligocene), Mongolia. 1268 American Museum Novitates 3156:1-15.

1269 Close RA, Friedman M, Lloyd GT, and Benson RBJ. 2015. Evidence for a mid-Jurassic adaptive radiation in mammals. Current Biology 25:2137-2142.

1271 Coster P, Benammi M, Lazzari V, Billet G, Martin T, Salem M, Bilal AA, Chaimanee Y, 1272 Schuster M, Valentin X, Brunet M, and Jaeger J-J. 2010. Gaudeamus lavocati sp. nov. 1273 (Rodentia, Hystricognathi) from the early Oligocene of Zallah, Libya: first African 1274 caviomorph? Naturwissenschaften 97:697-706. 
1275 Coster P, Benammi M, Mahboubi M, Tabuce R, Adaci M, Marivaux L, Bensalah M, Mahboubi

1276 S, Mahboubi A, Mebrouk F, Maameri C, and Jaeger J-J. 2012a. Chronology of the

1277 Eocene continental deposits of Africa: Magnetostratigraphy and biostratigraphy of the El

1278 Kohol and Glib Zegdou Formations, Algeria. Geological Society of America Bulletin $1279 \quad 124: 1590-1606$.

1280 Coster P, Benammi M, Salem M, Bilal AA, Chamanee Y, Valentin X, Brunet M, and Jaeger J-J. $12812012 \mathrm{~b}$. New hystricognathous rodents from the early Oligocene of central Libya (Zallah 1282 Oasis, Sahara Desert): Systematic, phylogenetic, and biochronologic implications. Annals 1283 of the Carnegie Museum 80:239-259.

1284 de Bruijn H, Ünay E, Saraç G, and Yülmaz A. 2003. A rodent assemblage from the Eo/Oligocene 1285 boundary interval near Süngülü, Lesser Caucasus, Turkey. Coloquios de Paleontología $1286 \quad 1: 47-76$.

1287 Dembo M, Matzke NJ, Mooers AØ, and Collard M. 2015. Bayesian analysis of a morphological 1288 supermatrix sheds light on controversial fossil hominin relationships. Proceedings of the

Ducrocq S, Boisserie J-R, Tiercelin J-J, Delmer C, Garcia G, Manthi FK, Leakey MG, Marivaux Royal Society B: Biological Sciences 282:20150943. L, Otero O, Peigné S, Tassy P, and Lihoreau F. 2010. New Oligocene Vertebrate Localities from Northern Kenya (Turkana Basin). Journal of Vertebrate Paleontology 30:293-299.

Flynn LJ, Jacobs LL, and Cheema IU. 1986. Baluchimyinae, a new ctenodactyloid rodent 1295 subfamily from the Miocene of Baluchistan. American Museum Novitates 2841:1-58. 
1296 Giere P, Freyer C, and Zeller U. 1999. Opening of the mammalian vomeronasal organ with

1297 respect to the Glires hypothesis: A cladistic reconstruction of the therian morphotype.

1298 Mitteilung aus dem Museum für Naturkunde in Berlin, Zoologische Reihe 75: 247-255.

1299 Gradstein F, Ogg JG, Schmitz M, and Ogg G. 2012. The Geological Time Scale 2012.

$1300 \quad$ Amsterdam: Elsevier.

1301 Gunnell GF, Simons EL, and Seiffert ER. 2008. New bats (Mammalia: Chiroptera) from the late 1302 Eocene and early Oligocene, Fayum Depression, Egypt. Journal of Vertebrate 1303 Paleontology 28:1-11.

1304 Holroyd PA. 1994. An Examination of Dispersal Origins for Fayum Mammalia. Ph.D. 1305 Dissertation, Duke University.

1306 Huelsenbeck JP, Ronquist F, and Teslenko M. 2015. Command Reference for MrBayes ver. 1307 3.2.5. http://mrbayes.sourceforge.net.

1308 Huchon D, Chevret P, Jordan U, Kilpatrick CW, Ranwez V, Jenkins PD, Brosius J, and Schmitz J. 2007. Multiple molecular evidences for a living mammalian fossil. Proceedings of the National Academy of Sciences, U.S.A. 104: 7495-7499.

1311 Jaeger J-J, Denys C, and Coiffait B. 1985. New Phiomorpha and Anomaluridae from the late

1312 Eocene of north-west Africa: Phylogenetic implications. In: Luckett WP, and 1313 Hartenberger J-L, eds. Evolutionary Relationships among Rodents - A Multidisciplinary 1314 Analysis. New York: Plenum Press, 567-588.

1315 Jaeger J-J, Marivaux L, Salem M, Bilal AA, Benammi M, Chaimanee Y, Duringer P, Marandat 1316 B, Metais E, Schuster M, Valentin X, Brunet M. 2010a. New rodent assemblages from 
1317 the Eocene Dur at-Talah escarpment (Sahara of central Libya): systematic, 1318 biochronological, and palaeobiogeographical implications. Zoological Journal of the 1319 Linnean Society 160:195-213.

1320 Jaeger J-J, Beard KC, Chaimanee Y, Salem M, Benammi M, Hlal O, Coster P, Bilal AA, 1321 Duringer P, Schuster M, Valentin X, Marandat B, Marivaux L, Metais E, Hammuda O, 1322 and Brunet M. 2010b. Late middle Eocene epoch of Libya yields earliest known radiation 1323 of African anthropoids. Nature 467:1096-1103.

1324 Lavocat R. 1973. Les rongeurs du Miocène d'Afrique Orientale, Miocène inférieur. Mémoires et 1325 Travaux de l'Institut de Montpellier de l'Ecole Pratique des Hautes Etudes 1:1-284

1326 Lewis PJ, and Simons EL. 2006. Morphological trends in the molars of fossil rodents from the 1327 Fayum Depression, Egypt. Palaeontologica Africana 42:37-42.

1328 Lewis PO. 2001. A likelihood approach to estimating phylogeny from discrete morphological character data. Systematic Biology 50:913-925.

1330 Lindsay EH, Flynn LJ, Cheema IU, Barry JC, Downing K, Rajpar AR, and Raza SM. 2005. Will 1331 Downs and the Zinda Pir Dome. Palaeontologia Electronica 8:19A.

1332 Maddison WP and Maddison DR. 2011. Mesquite: a modular system for evolutionary analysis. $1333 \quad$ Version 2.75.

1334 Marivaux L, Benammi M, Ducrocq S, Jaeger J-J, and Chaimanee Y. 2000. A new baluchimyine rodent from the Late Eocene of the Krabi Basin (Thailand): palaeobiogeographic and 1336 biochronologic implications. Comptes Rendus de l'Académie des Sciences Paris, IIA 1337 $331: 427-433$. 
1338 Marivaux L, Vianey-Liaud M, Welcomme J-L, and Jaeger J-J. 2002. The role of Asia in the 1339 origin and diversification of hystricognathous rodents. Zoologica Scripta 31:225-239.

1340 Marivaux L, Vianey-Liaud M, and Jaeger JJ. 2004. High-level phylogeny of early Tertiary 1341 rodents: dental evidence. Zoological Journal of the Linnean Society 142:105-134.

1342 Marivaux L, Lihoreau F, Manthi FK, and Ducrocq S. 2012. A new basal phiomorph (Rodentia, 1343 Hystricognathi) from the late Oligocene of Lokone (Turkana Basin, Kenya). Journal of $1344 \quad$ Vertebrate Paleontology 32:646-657. 10.1080/02724634.2012.657318

1345 Marivaux L, Essid E, Marzougui W, Ammar H, Adnet S, Marandat B, Merzeraud G, Tabuce R, and Vianey-Liaud M. 2014. A new and primitive species of Protophiomys (Rodentia, Hystricognathi) from the late middle Eocene of Djebel el Kébar, Central Tunisia.

Meredith RW, Janečka JE, Gatesy J, Ryder OA, Fisher CA, Teeling EC, Goodbla A, Eizirik E, Simão TLL, Stadler T, Rabosky DL, Honeycutt RL, Flynn JJ, Ingram CM, Steiner C, Williams TL, Robinson TJ, Burk-Herrick A, Westerman M, Ayoub NA, Springer MS, and Murphy WJ. 2011. Impacts of the Cretaceous Terrestrial Revolution and KPg

1354 Mess A. 1999. The rostral nasal skeleton of hystricognath rodents: evidence on their 1355 phylogenetic relationships. Mitteilung aus dem Museum für Naturkunde in Berlin, Zoologische Reihe 75: 19-35.

Métais G, Antoine P-O, Baqri SRH, Crochet J-Y, De Franceschi D, Marivaux L, and Welcomme J-L. 2013. Lithofacies, depositional environments, regional biostratigraphy and age of the 

Sciences 34:154-167.

1361 Pagel M. 2002. User's manual for Continuous. Department of Animal and Microbial Sciences, 1362 University of Reading, Reading, U.K.

1363 Pagel M, Meade A. 2013. BayesTraits v2 manual. Department of Animal and Microbial 1364 Sciences, University of Reading, Reading, U.K.

1365 Patterson B, and Wood AE. 1982. Rodents from the Deseadan Oligocene of Bolivia and the 1366 relationships of the Caviomorpha. Bulletin of the Museum of Comparative Zoology 149: $1367 \quad 371-543$.

1368 Patterson BD, and Upham NS. 2014. A newly recognized family from the Horn of Africa, the Heterocephalidae (Rodentia: Ctenohystrica). Zoological Journal of the Linnean Society

Pickford M, Senut B, Morales J, Mein P, and Sánchez IM. 2008. Mammalia from the Lutetian of Namibia. Memoirs of the Geological Survey of Namibia 20:465-514.

1373 Pickford M, Senut B, Mocke H, Mourer-Chauviré C, Rage J-C, and Mein P. 2014. Eocene aridity in southwestern Africa: timing of onset and biological consequences. Transactions of the Royal Society of South Africa 69:139-144.

Pickford M. 2015a. Late Eocene Potamogalidae and Tenrecidae (Mammalia) from the 159. 
1379 Pickford M. 2015b. Bothriogenys (Anthracotheriidae) from the Bartonian of Eoridge, Namibia. 1380 Communications of the Geological Survey of Namibia 16: 222-229.

1381 Rasmussen DT, and Gutiérrez M. 2010. Hyracoidea. In: Sanders WJ, and Werdelin L, eds. 1382 Cenozoic Mammals of Africa. Berkeley: University of California Press, 123-145.

1383 Ronquist F, Klopfstein S, Vilhelmsen L, Schulmeister S, Murray DL, and Rasnitsyn AP. 2012a. A total-evidence approach to dating with fossils, applied to the early radiation of the Hymenoptera. Systematic Biology 61:973-999.

Ronquist F, Teslenko M, van der Mark P, Ayres DL, Darling A, Höhna S, Larget B, Liu L, Suchard MA, and Huelsenbeck JP. 2012b. MrBayes 3.2: efficient Bayesian phylogenetic inference and model choice across a large model space. Systematic Biology 61:539-542.

Sallam HM, Seiffert ER, Steiper ME, and Simons EL. 2009. Fossil and molecular evidence constrain scenarios for the early evolutionary and biogeographic history of hystricognathous rodents. Proceedings of the National Academy of Sciences, U.S.A. 106:

Sallam HM, Seiffert ER, and Simons EL. 2010a. A highly derived anomalurid rodent (Mammalia) from the earliest late Eocene of Egypt. Palaeontology 53:803-813. from the earliest late Eocene of Egypt: Phylogenetic and biogeographic implications. Journal of Vertebrate Paleontology 30:1579-1593. 
1398 Sallam HM, Seiffert ER, and Simons EL. 2011. Craniodental morphology and systematics of a 1399 new family of hystricognathous rodents (Gaudeamuridae) from the late Eocene and early $1400 \quad$ Oligocene of Egypt. PLoS ONE 6:e16525.

1401 Sallam HM, Seiffert ER, and Simons EL. 2012. A basal phiomorph (Rodentia, Hystricognathi) 1402 from the late Eocene of the Fayum Depression, Egypt. Swiss Journal of Palaeontology $1403 \quad 131: 283-301$.

1404 Seiffert ER. 2006. Revised age estimates for the later Paleogene mammal faunas of Egypt and 1405 Oman. Proceedings of the National Academy of Sciences, U.S.A. 103:5000-5005.

1406 Seiffert ER. 2010. The oldest and youngest records of afrosoricid placentals from the Fayum Depression of northern Egypt. Acta Palaeontologica Polonica 55: 599-616.

1408 Seiffert ER. 2012. Early primate evolution in Afro-Arabia. Evolutionary Anthropology 21:239253.

1410 Seiffert ER, and Simons EL. 2000. Widanelfarasia, a diminutive placental from the late Eocene 1411 of Egypt. Proceedings of the National Academy of Sciences, U.S.A. 97:2646-2651.

1412 Seiffert ER, Simons EL, Ryan TM, and Attia Y. 2005. Additional remains of Wadilemur 1413 elegans, a primitive stem galagid from the late Eocene of Egypt. Proceedings of the $1414 \quad$ National Academy of Sciences, U.S.A. 102:11396-11401.

1415 Seiffert ER, Simons EL, Ryan TM, Bown TM, and Attia Y. 2007. New remains of Eocene and 1416 Oligocene Afrosoricida (Afrotheria) from Egypt, with implications for the origin(s) of 1417 afrosoricid zalambdodonty. Journal of Vertebrate Paleontology 27:963-972. 
1418 Seiffert ER, Bown TM, Clyde WC, and Simons EL. 2008. Geology, paleoenvironment, and age

1419 of Birket Qarun Locality 2 (BQ-2), Fayum Depression, Egypt. In: Fleagle JG, and Gilbert

1420 CC, eds. Elwyn L Simons: A Search for Origins. New York: Springer, 71-86.

1421 Simons EL. 1997. Discovery of the smallest Fayum Egyptian primates (Anchomomyini, 1422 Adapidae). Proceedings of the National Academy of Sciences, U.S.A. 94:180-184.

1423 Simons EL, Cornero S, and Bown TM. 1998. The taphonomy of fossil vertebrate Quarry L-41, 1424 Upper Eocene, Fayum Province, Egypt. In Proceedings of the Geological Survey of 1425 Egypt Centennial. Cairo, Egypt: Egyptian Geological Survey and Mining Authority. p 1426 785-791.

1427 Simons EL, Holroyd PA, and Bown TM. 1991. Early Tertiary elephant shrews from Egypt and the origin of the Macroscelidea. Proceedings of the National Academy of Sciences, U.S.A. 58:9734-9737.

Simons EL, Seiffert ER, Chatrath PS, and Attia Y. 2001. Earliest record of a parapithecid anthropoid from the Jebel Qatrani Formation, northern Egypt. Folia Primatologica 72:316-331.

Singleton G, Dickman CR, and Stoddart DM. 2006. Rodents. In: MacDonald DW (ed) The Encylopedia of Mammals. Oxford University Press, Oxford, pp 128-137.

1435 Smith TD, Bhatnagar KP, Dennis JC, Morrison EE, and Park TJ. 2007. Growth-deficient 1436 vomeronasal organs in the naked mole-rat (Heterocephalus glaber). Brain Research 1437 1132: 78-83. 
1438 Stevens NJ, Holroyd PA, Roberts EM, O'Connor PM, and Gottfried MD. 2009. Kahawamys 1439 mbeyaensis (n. gen., n. sp.) (Rodentia: Thryonomyoidea) from the late Oligocene Rukwa 1440 Rift Basin, Tanzania. Journal of Vertebrate Paleontology 29:631-634.

1441 Swofford DL. 2002. PAUP* Phylogenetic Analysis Using Parsimony (*and Other Methods), $1442 \quad$ Version 4. Sunderland, MA: Sinauer Associates.

1443 Thomas H, Roger J, Sen S, Boudillon-de-Grissac C, and Al-Sulaimani Z. 1989. Découverte de 1444 vertébrés fossiles dans l'Oligocène inférieur du Dhofar (Sultanat d'Oman). Geobios $1445 \quad 22: 101-120$.

1446 Wang B-Y, Qui Z-X. 2002. A porcupine from late Miocene of Linxia Basin, Gansu, China. $1447 \quad$ Vertebrata Palasiatica 40: 22-33.

1448 Welcomme J-L, Benammi N, Crochet J-Y, Marivaux L, Metais G, Antoine P-O, and Baloch I. 2001. Himalayan Forelands: palaeontological evidence for Oligocene detrital deposits in the Bugti Hills (Balochistan, Pakistan). Geological Magazine 138:397-405.

1451 Wöhrmann-Repenning A. 1982. Vergleichend anatomische Untersuchungen an Rodentia. Phylogenetische Überlegungen über die Beziehungen der Jacobsonschen Organe zu den Ductus nasopalatini. Zoologischer Anzeiger 209: 33-46.

1454 Wood AE. 1968. Early Cenozoic mammalian faunas, Fayum Province, Egypt, Part II: the African Oligocene Rodentia. Peabody Museum Bulletin 28:23-205.

1456 Wood AE, Wilson RW. 1936. A suggested nomenclature for the cusps of the cheek teeth of 1457 rodents. Journal of Paleontology 10:388-391. 
1459

1460 


\section{1}

Major fossil localities in the Fayum Depression of northern Egypt

Left, stratigraphic positions and age estimates for major mammal-bearing fossil localities in the Fayum succession, and approximate position of Eocene-Oligocene boundary, following Seiffert (2006). Upper right, map of northern Egypt showing common landmarks and localities near the Fayum Depression. Lower right, map of the Fayum area showing the approximate position of Locality 41 (L-41), which occurs near the middle of the section approximately midway between the oldest rodent-bearing fossil locality (BQ-2) and the youngest rodent-bearing fossil localities (I\&M). Modified after Bown and Kraus (1988). 

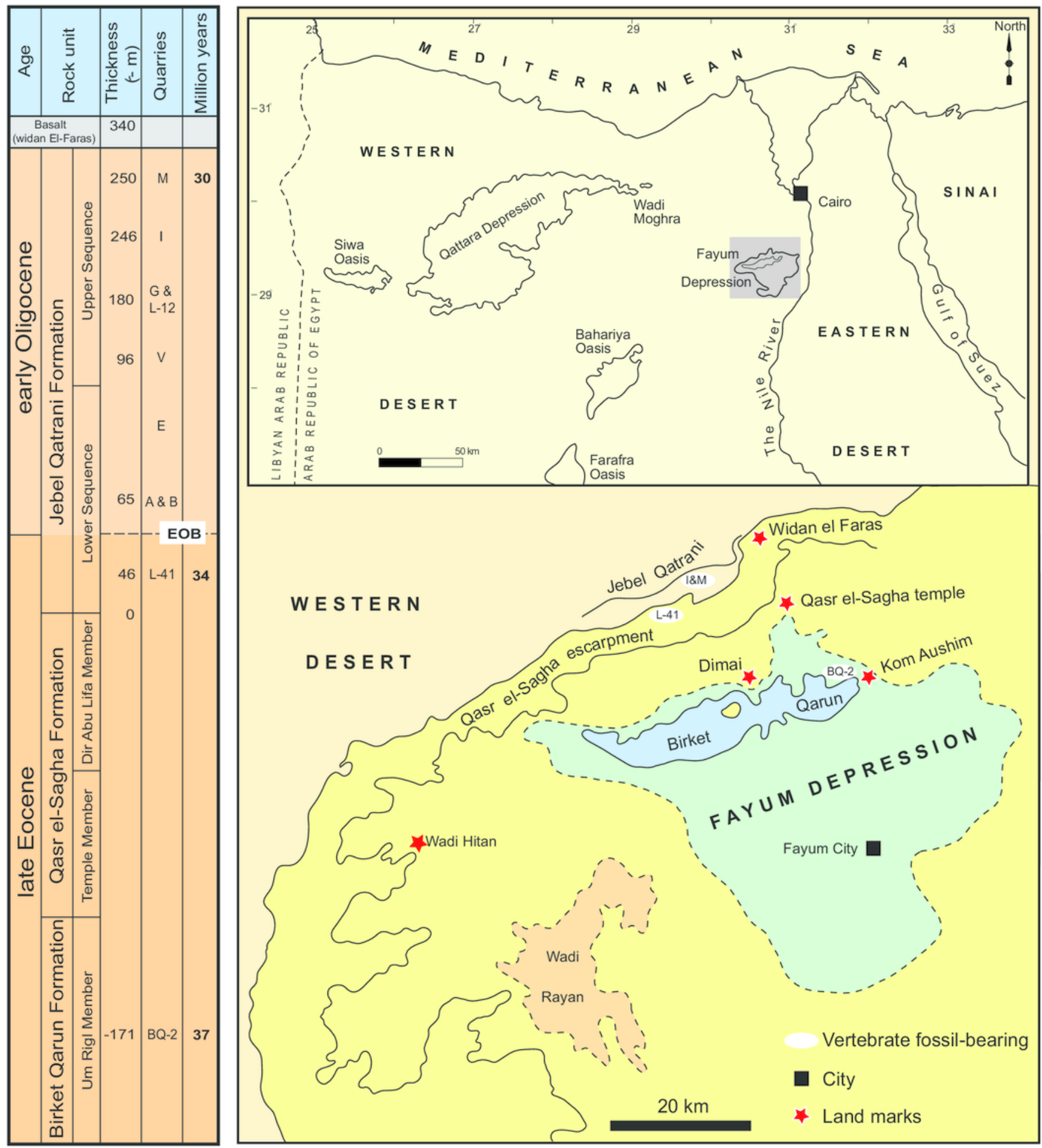
2

Dental terminology, based on Wood and Wilson (1936) and Marivaux et al. (2004). 


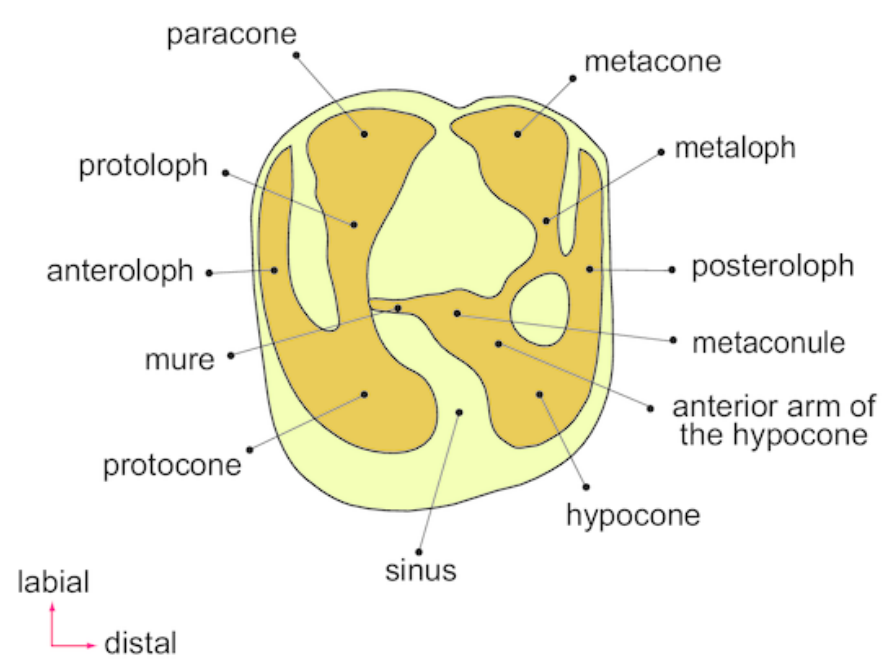

UPPER MOLAR

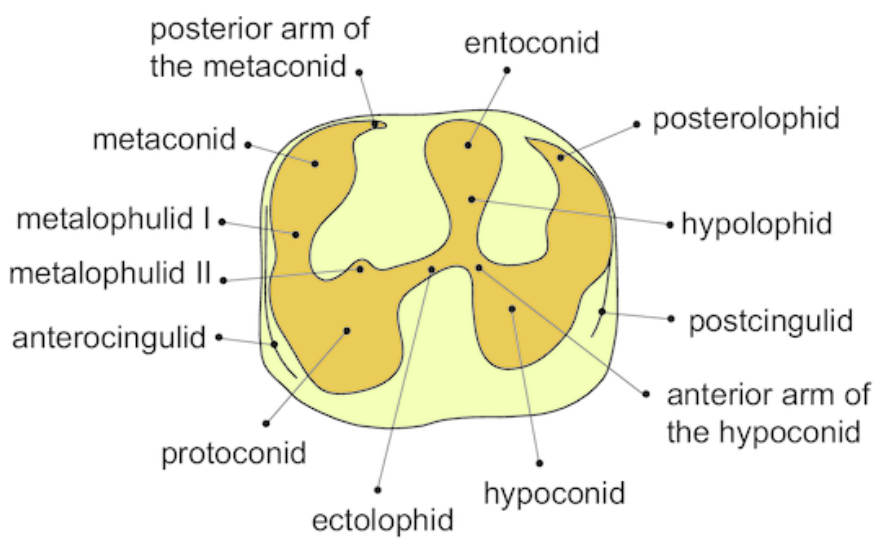

lingual

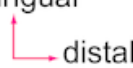

\section{LOWER MOLAR}


3

CGM 66000, holotype cranium of Birkamys korai, new genus and species, from the latest Eocene Locality L-41, Jebel Qatrani Formation, Fayum Depression, northern Egypt.

Volume renderings of high-resolution micro-CT scans of CGM 66000, in (A) dorsal view, (B) ventral, $(C)$ anterior, $(D \& E)$ lateral views. Occlusal surface of the upper teeth is shown in (F). 


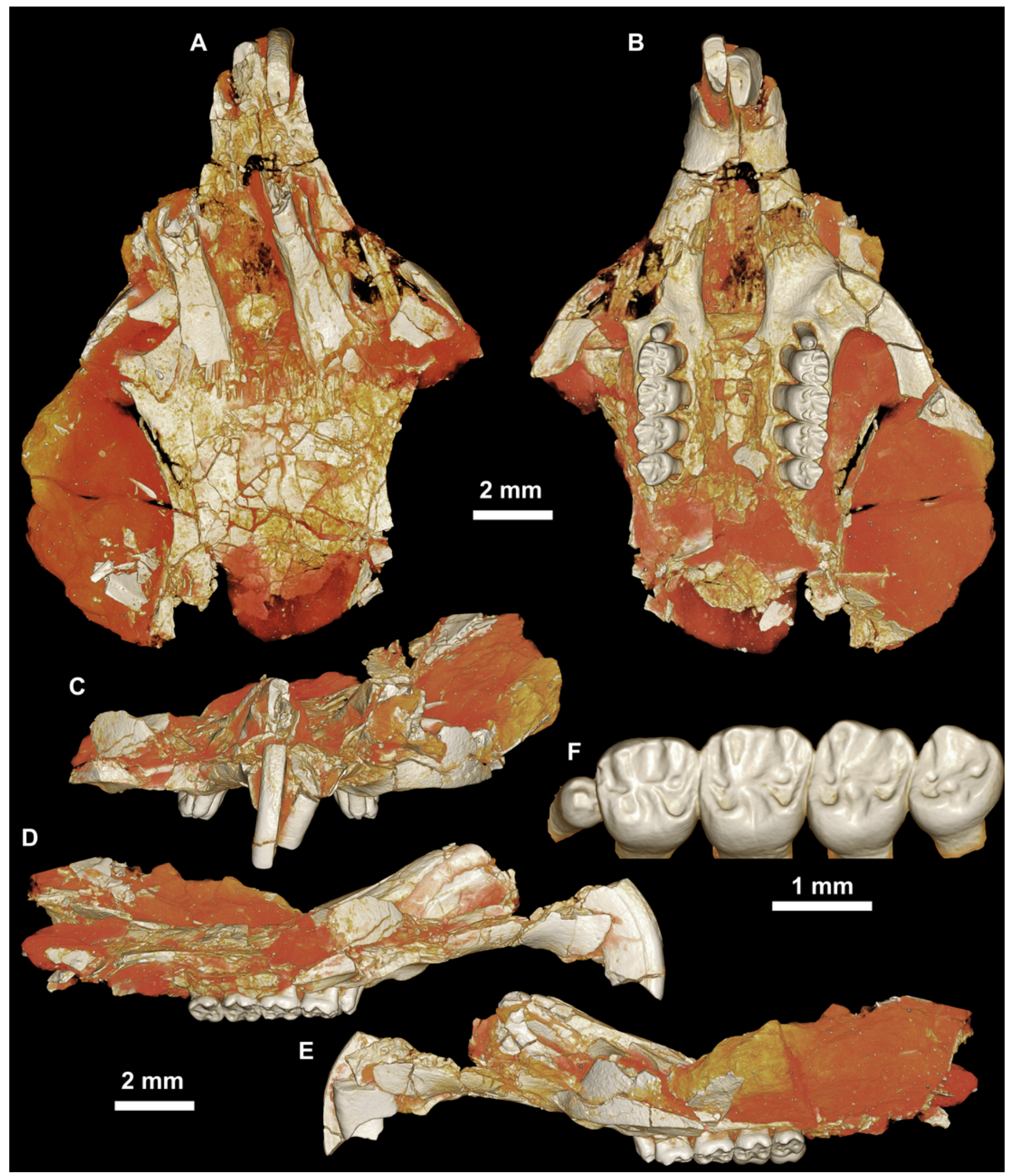


4

Maxillae and upper dentition of Birkamys korai, new genus and species, from Quarry L41.

A-D) right partial maxilla of DPC 17457 with $\mathrm{dP}^{3}-\mathrm{M}^{3}$, in (A) dorsal, (B) ventral, (C) anterior views and (D) occlusal surface; E-H) DPC 9276, left partial maxilla with $\mathrm{M}^{2-3}$ and alveoli for $\mathrm{dP}^{3-4}$ and $\mathrm{M}^{1}$, in (E) ventral, $(\mathrm{F})$ anterior, $(\mathrm{G})$ dorsal views and $(\mathrm{H})$ occlusal surface; DPC 15625, left partial maxilla with $\mathrm{M}^{1}$ and alveoli for $\mathrm{dP}^{3-4}$, in (I) dorsal, (J) anterior, (K) ventral views and (L) occlusal surface.

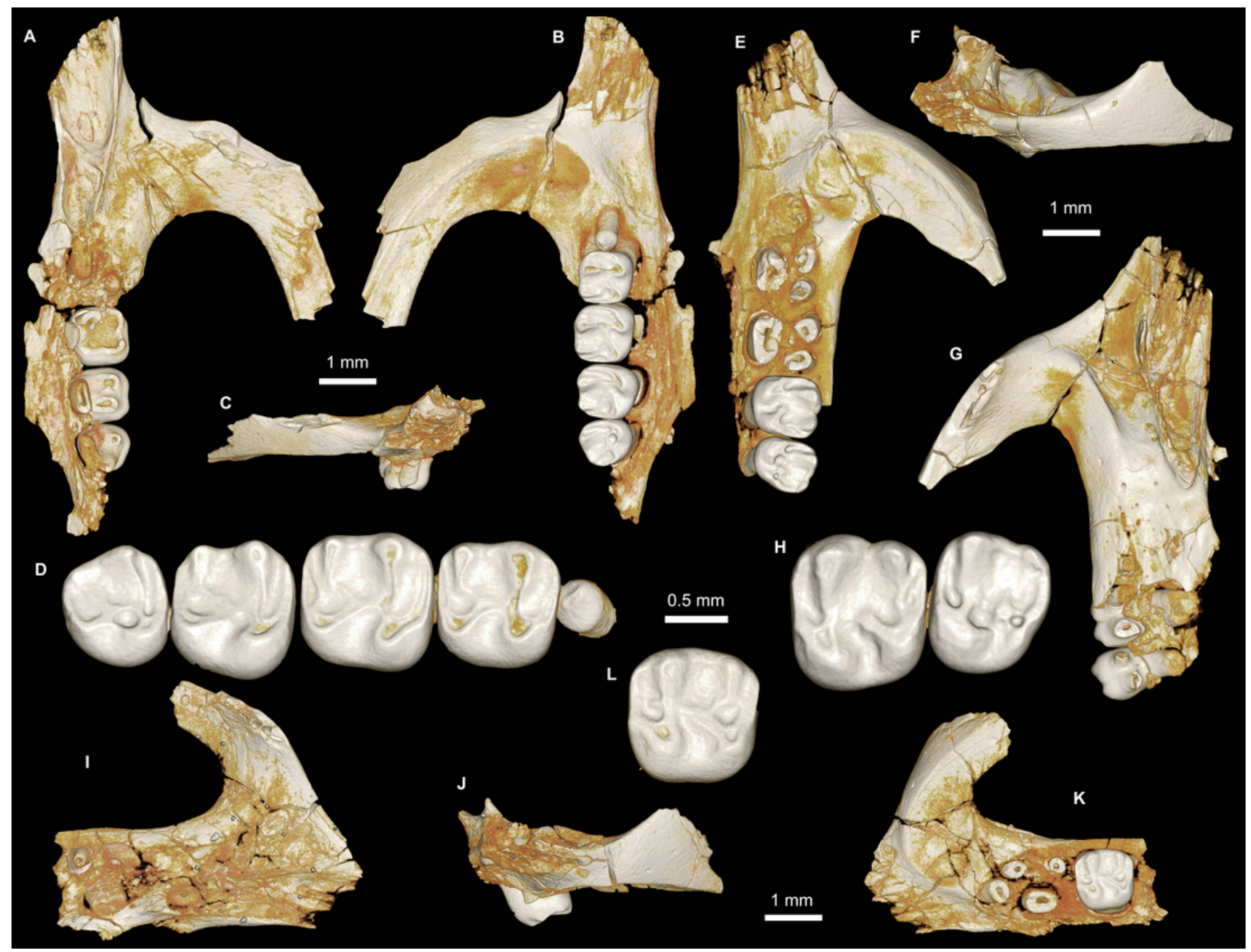




\section{5}

Mandible and lower dentition of Birkamys korai, new genus and species, from Quarry L41.

A-F) DPC 22737, left mandible with $\mathrm{dP}_{4}-\mathrm{M}_{3}$, in (A) medial, (B) lateral, (C) ventral and (D) dorsal views; (E) scanning electron stereopair illustrating the occlusal surfaces of $\mathrm{dP}_{4}-\mathrm{M}_{3}$; (F) microCT scans, illustrating the deep roots of the $\mathrm{dP}_{4}$ in cross-section.

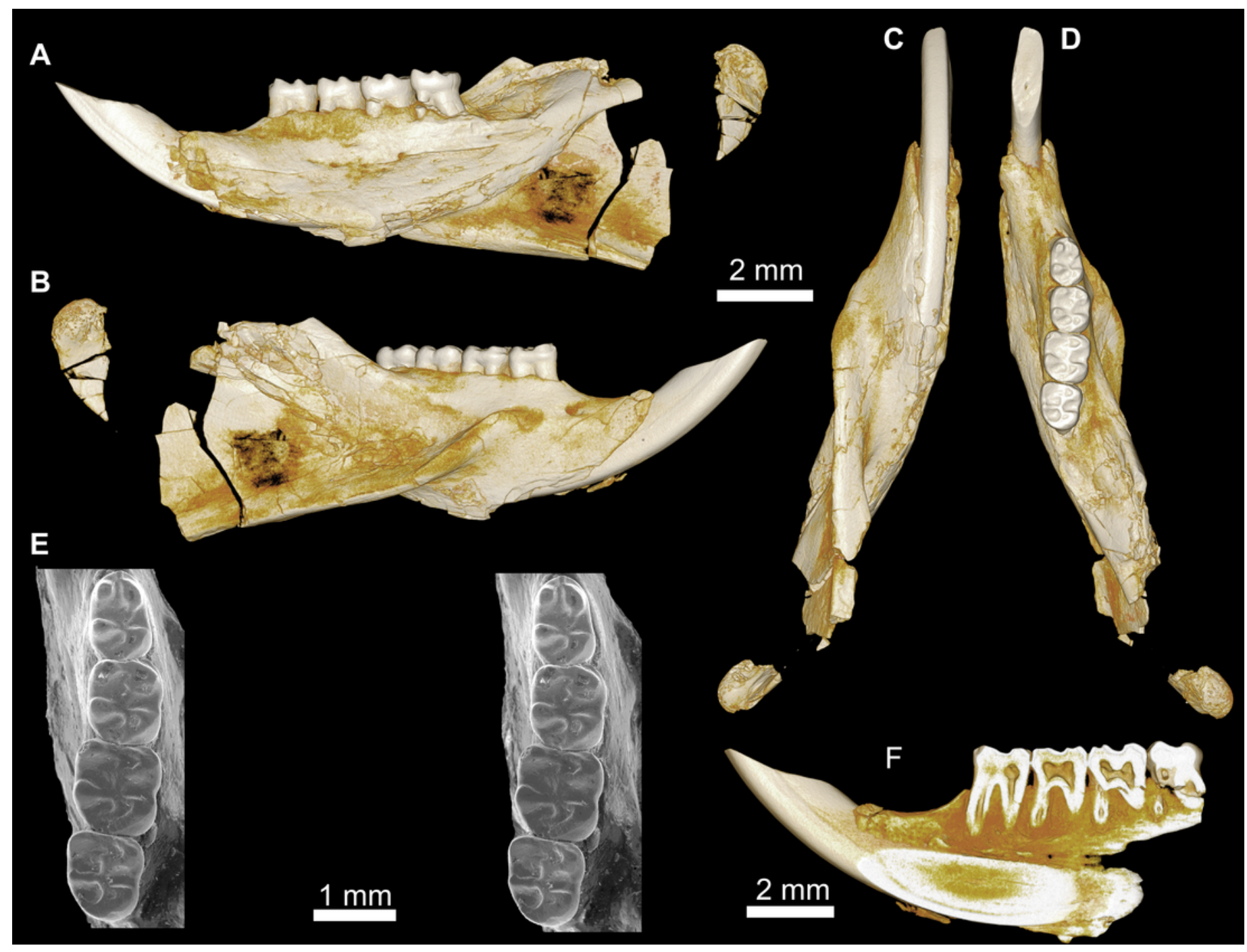


6

Mandible of cf. Birkamys from Quarry L-41.

A-E) DPC 17995, almost complete right mandible with I and $M_{1}$, in (A) lateral, (B) medial, (C) ventral and (D) dorsal views; (E) occlusal surface.

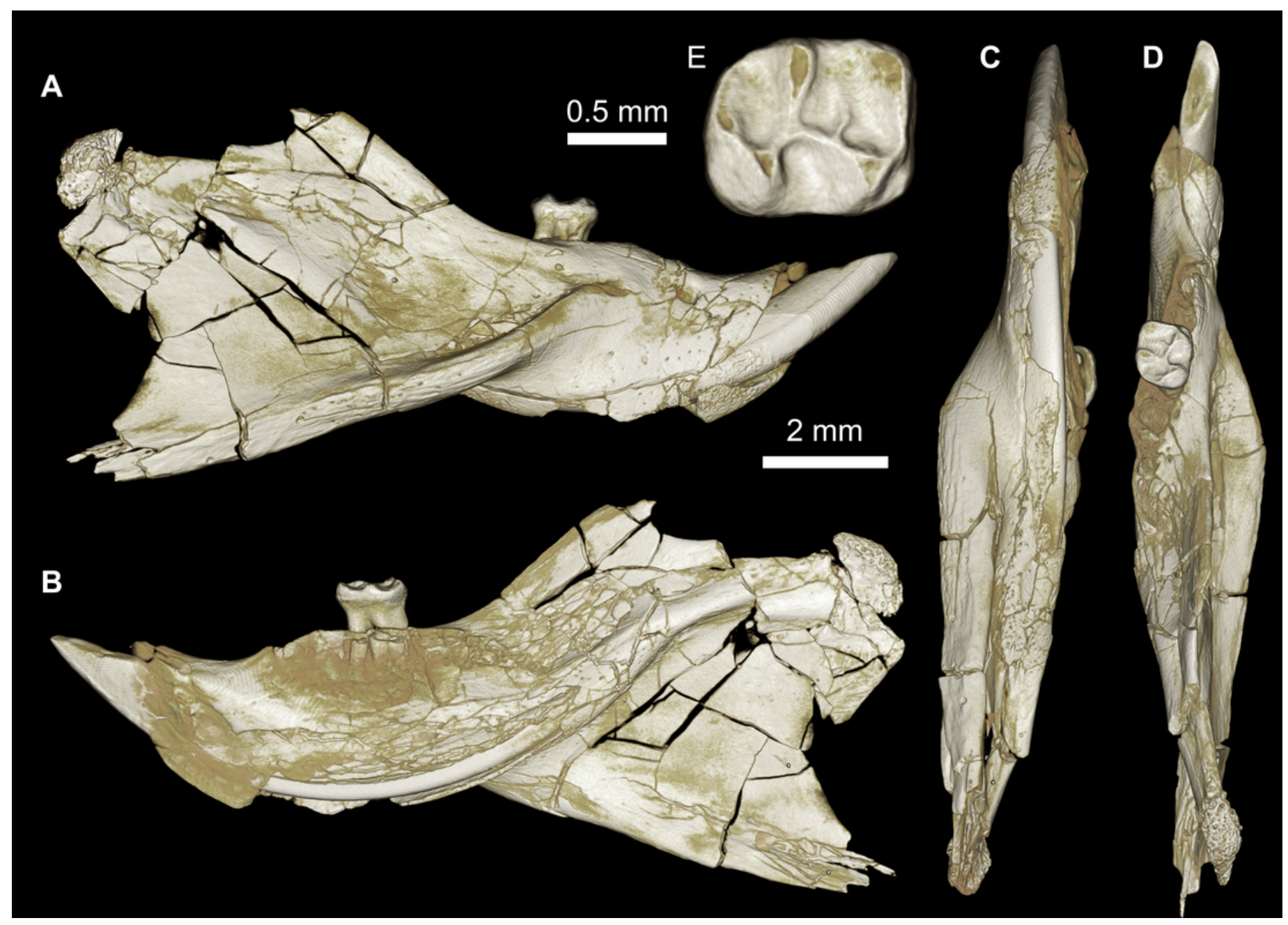




\section{7}

Maxillae and upper dentition of Mubhammys vadumensis, new genus and species, from the latest Eocene Quarry L-41, Jebel Qatrani Formation, Fayum Depression, northern Egypt.

A-B) CGM 66001, holotype left partial maxilla (upper left incisor, $\mathrm{dP}^{3-4}$ and $\mathrm{M}^{1-3}$ ) in (A) medial and (B) occlusal views; C-H) DPC 14324, left partial maxilla and upper dentition (I, $\mathrm{dP}^{3.4}$ and $M^{1}$ ) in (C) ventral, (D) anterior and (E) dorsal views; ( $F$ and G) medial and ventral surface of upper left incisor; $(\mathrm{H})$ occlusal surface. 


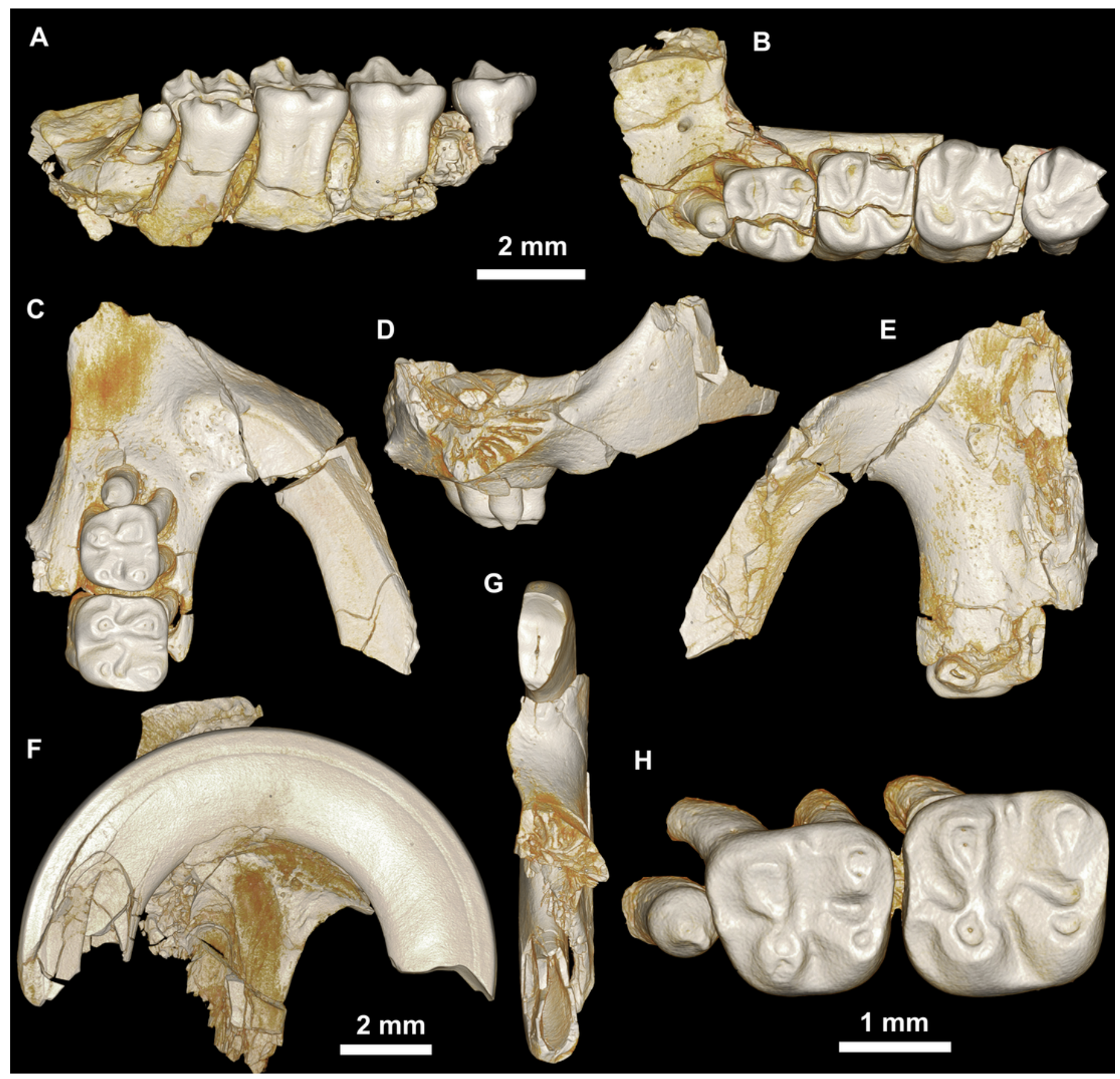


8

Lower dentition of Mubhammys vadumensis, new genus and species.

A-D) left mandibular fragment and lower dentition DPC $14141\left(\mathrm{dP}_{4}-\mathrm{M}_{1}\right)$, (A) occlusal surface,

(B) lateral, (C) dorsal and (D) medial views; E-H) left mandibular fragment and lower dentition

DPC $13220\left(\mathrm{dP}_{4}-\mathrm{M}_{3}\right),(\mathrm{E})$ occlusal surface, (F) lateral, and $(\mathrm{H})$ medial views and $(\mathrm{G})$ micro-CT scans, illustrating the deep roots of the $\mathrm{dP}^{4}$ in cross-section.

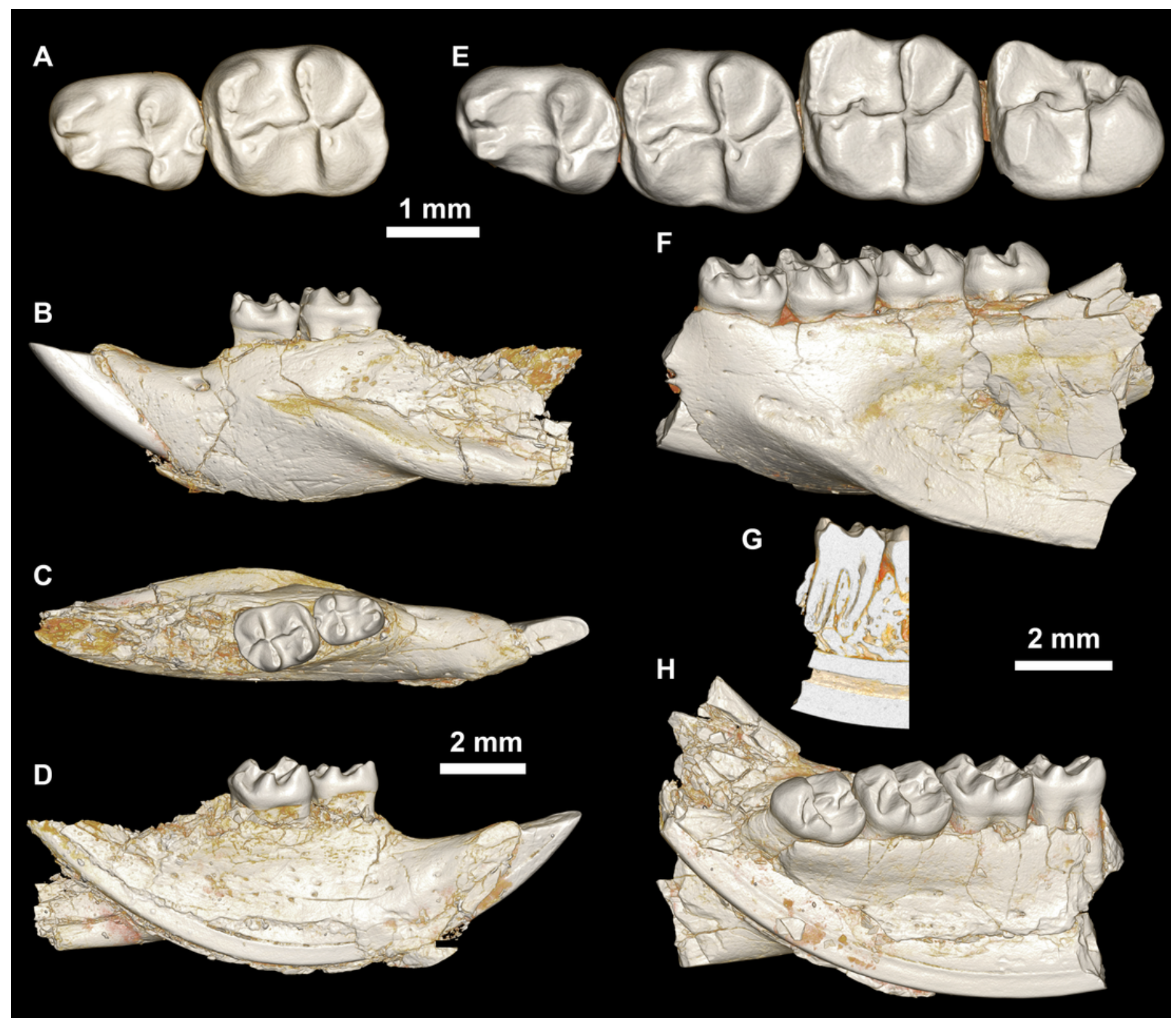


9

Plot of length versus width of $\mathrm{M}_{1}$ comparing Mubhammys vadumensis and Birkamys korai with other hystricognaths from the Fayum Depression.

Measurements for "Paraphiomys", Metaphiomys, Phiomys, and "Phiomys" lavocati are from Wood (1968) and Holroyd (1994); Gaudeamus spp. from Wood (1968) and Sallam et al. (2011); Acritophiomys from Sallam et al. (2012); Waslamys and Protophiomys are from Sallam et al. (2009).

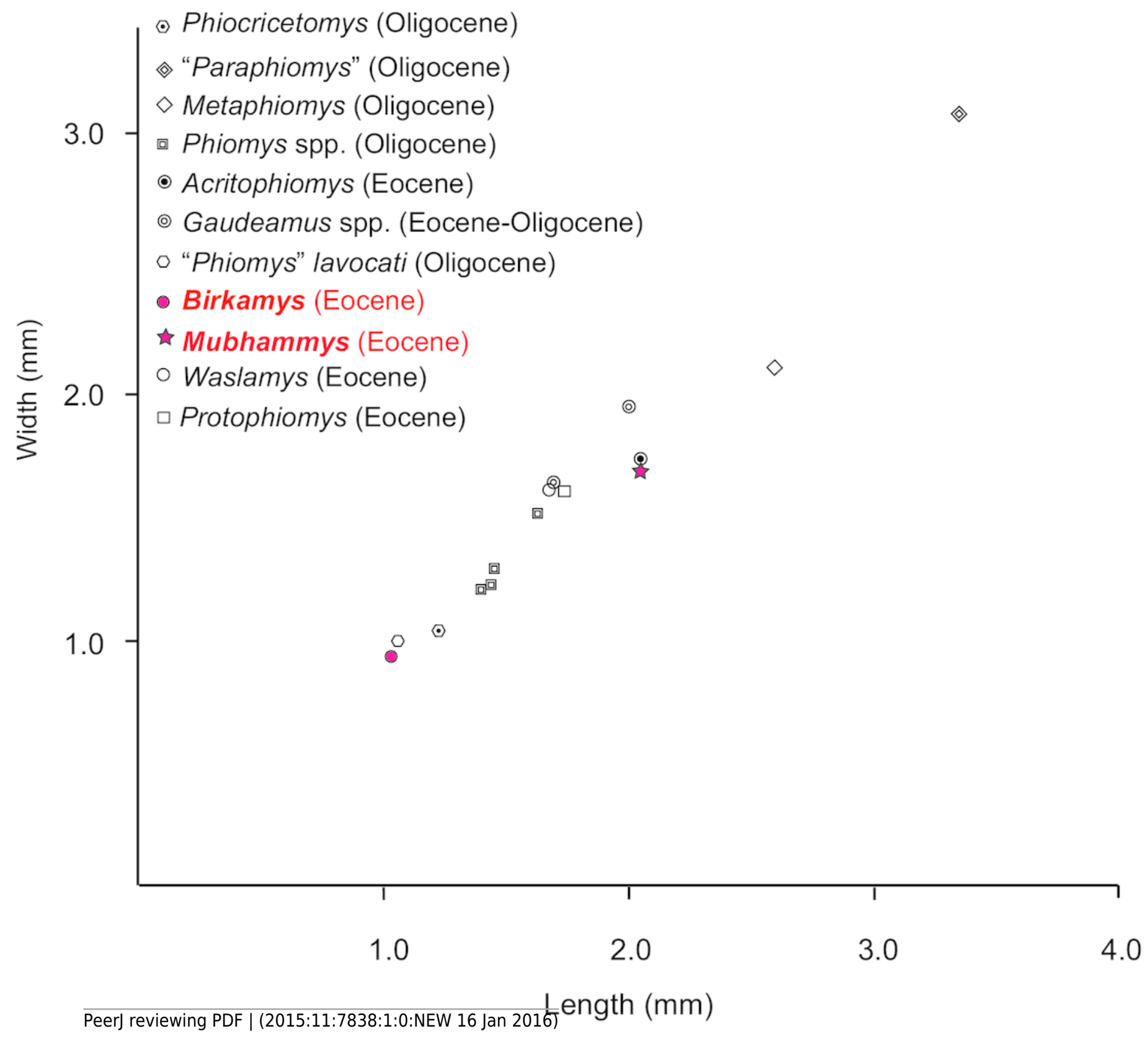


10

Parsimony analysis of living and extinct hystricognathous rodents, based on 118 morphological characters, largely from the dentition, 77 of which were treated as ordered and unweighted.

A) Strict consensus of 10 MPTs recovered by parsimony analysis with all characters equally weighted. Tree length $(T L)=907$, consistency index excluding uninformative characters $(\mathrm{Cl})$ $=0.2892$, retention index $(\mathrm{RI})=0.5821$, rescaled consistency index $(\mathrm{RCI})=0.1720 . \mathrm{B})$ Adams consensus of 119 MPTs recovered by parsimony analysis with transitions between "fixed" and polymorphic states weighted as a half-step; dashed branches break down in the strict consensus. $\mathrm{TL}=595, \mathrm{Cl}=0.3109, \mathrm{RI}=0.5769, \mathrm{RCl}=0.1847 . \mathrm{C})$ Maximum agreement subtree of all 119 trees summarized in (B). Taxon names are colored according to their geographical location. Bootstrap support values, based on 1000 pseudoreplicates, are found above or below branches that are supported at a level $>50 \%$.

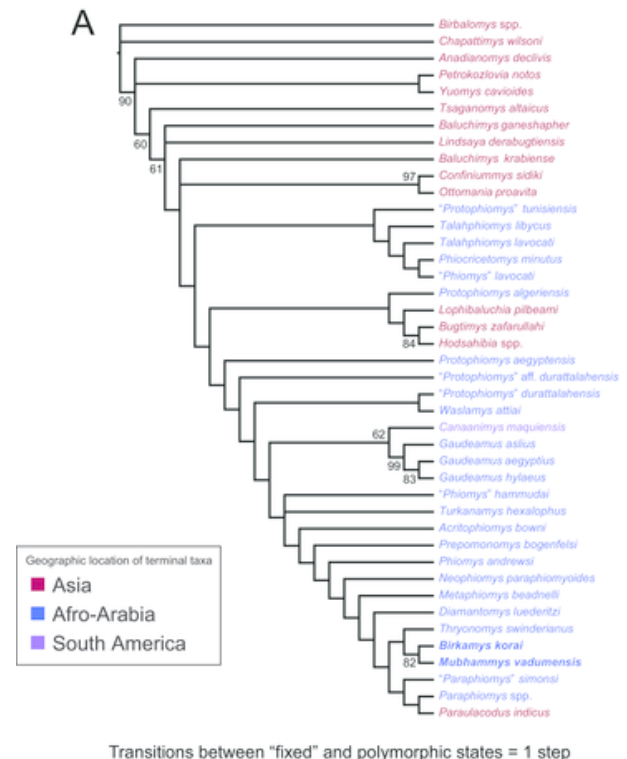

Strict consensus, $10 \mathrm{MPTs}, \mathrm{TL}=907$
Stween "fixed" and polymorphic states
$\mathrm{B}$

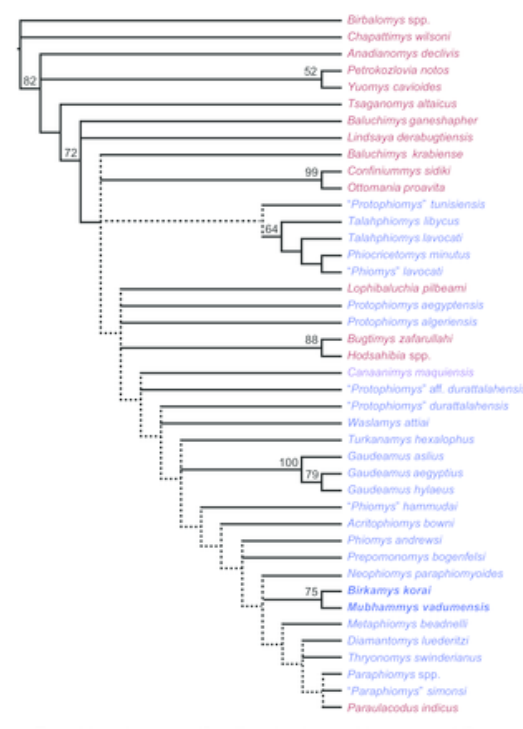

Transitions between "fixed" and polymorphic states $=1 / 2$ step Adams consensus of $119 \mathrm{MPTs}, \mathrm{TL}=595$
Dashed branches break down in the strict consensus
C

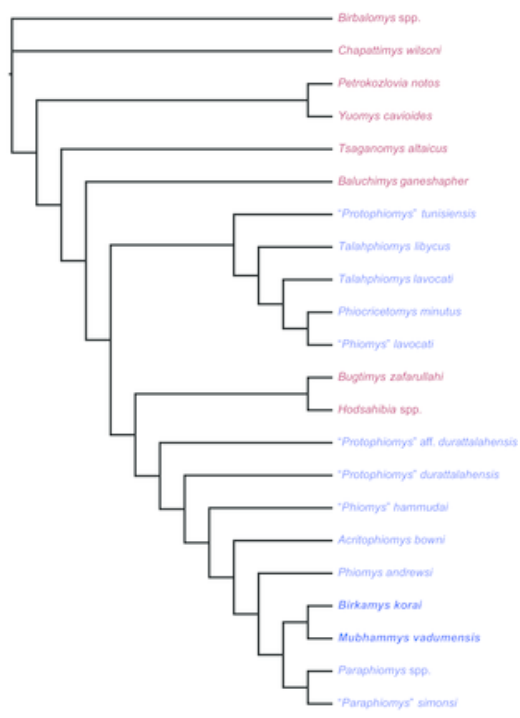

Transitions between "fixed" and polymorphic states $=1 / 2$ step Maximum agreement subtree of $119 \mathrm{MPTs}, \mathrm{TL}=595$ 
"Allcompat" consensus (majority-rule plus compatible groups) of 50,000 post-burn-in trees retained by Bayesian analysis of the 118-character matrix in MrBayes 3.2.5.

Taxon names are colored according to their continental geographic location. Numbers above or below branches represent posterior probabilities (x 100).

Birbalomys spp.

Chapattimys wilsoni
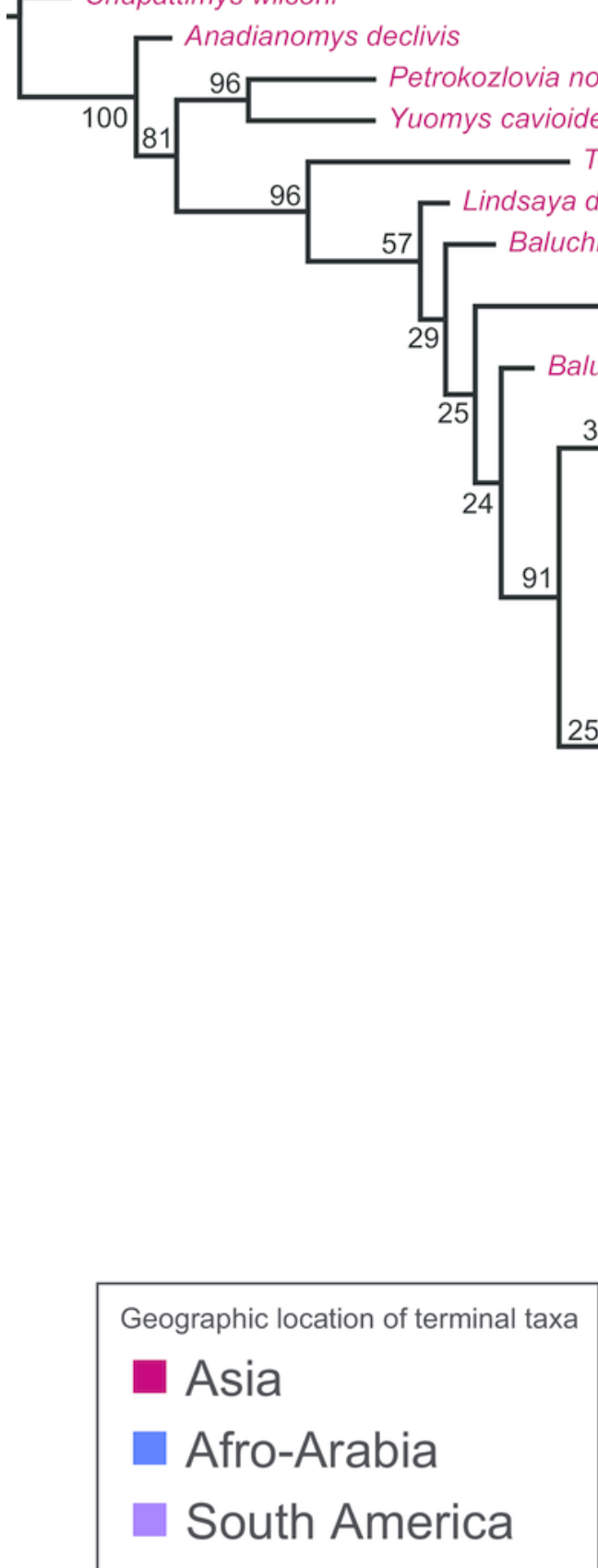

PeerJ reviewing PDF | (2015:11:7838:1:0:NEW 16 Jan 2016)

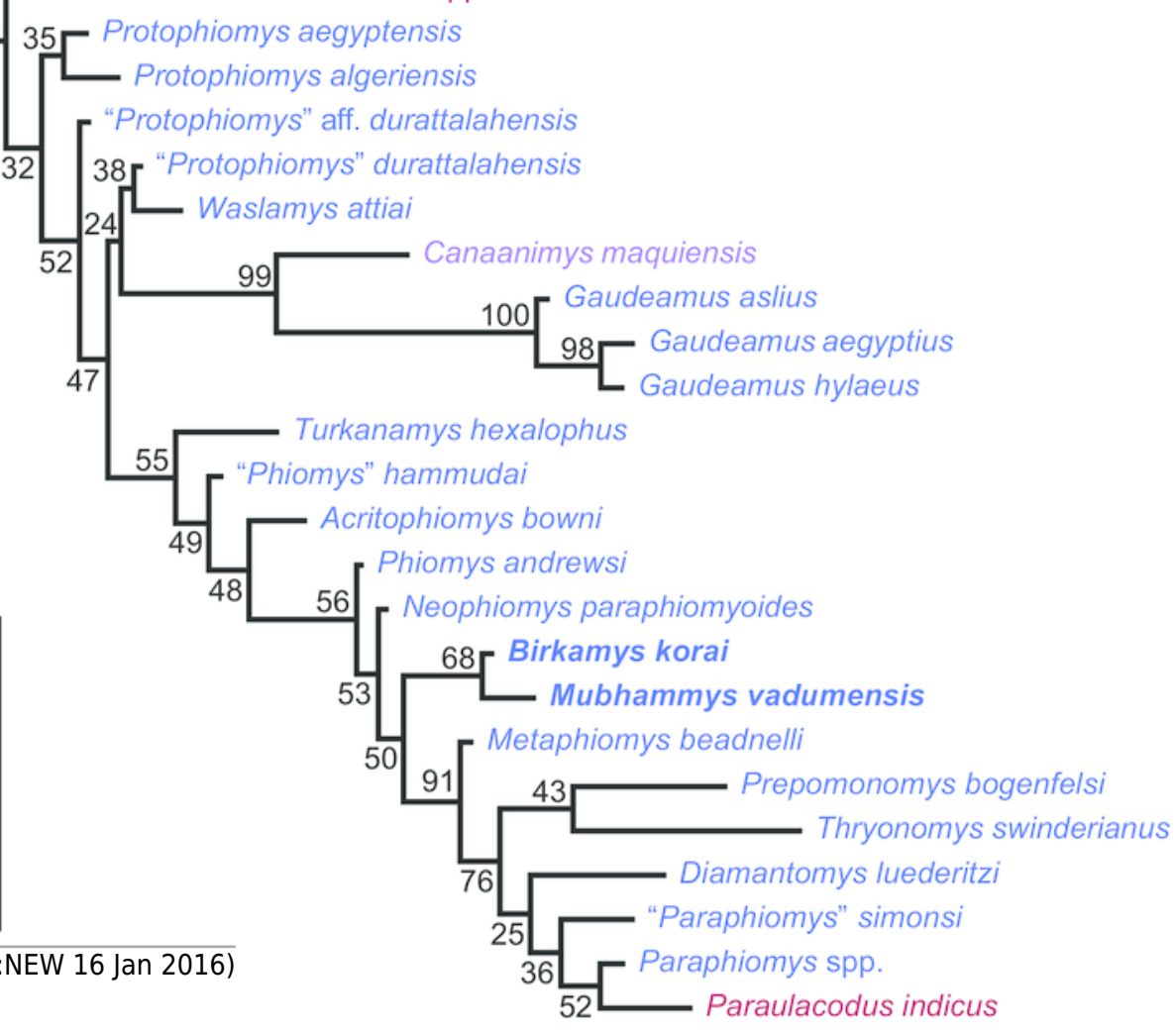


12

Uniform age priors for localities from which species in this analysis were sampled, with the sole or mean estimates provided by the tip-dating analysis (as output in the MrBayes "*.vstat" file.

Geological timescale was created using the program TSCreator 6.4

(http://www.tscreator.org). 


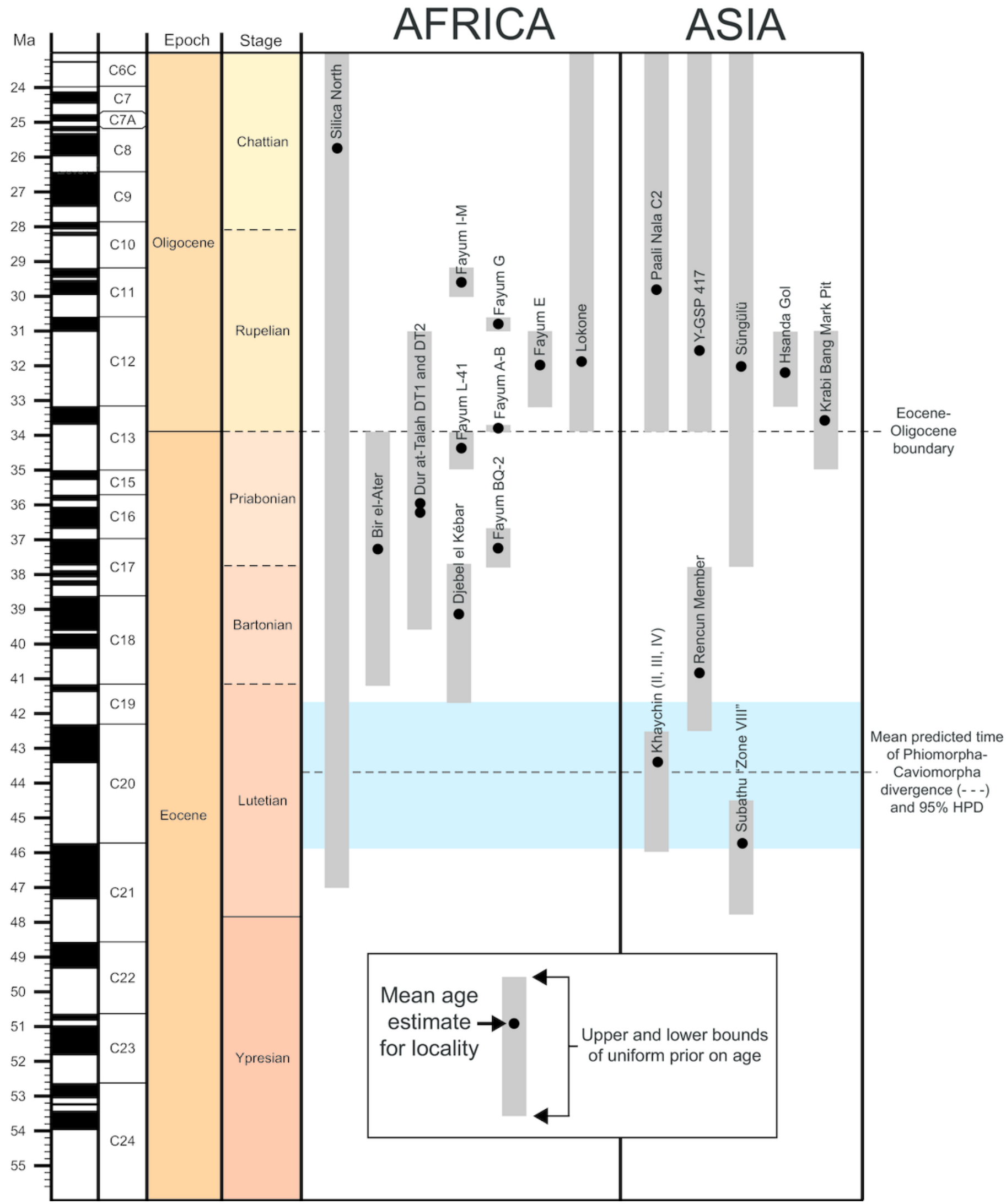




\section{3}

"Allcompat" consensus (majority-rule plus compatible groups) of 50,000 post-burn-in trees retained by tip-dating analysis ("TD2") of the 118-character matrix in MrBayes 3.2.5 with locality ages fixed based on sole or mean estimates calculated by analysis

Branch lengths are colored according to rates of morphological evolution (calculated by multiplying the median rate for each branch, by the median clock rate for the entire tree), with the adjacent heat map showing the range of variation in the dataset. Taxon names are colored according to their continental geographic location. Numbers above or below branches represent posterior probabilities (x 100). 


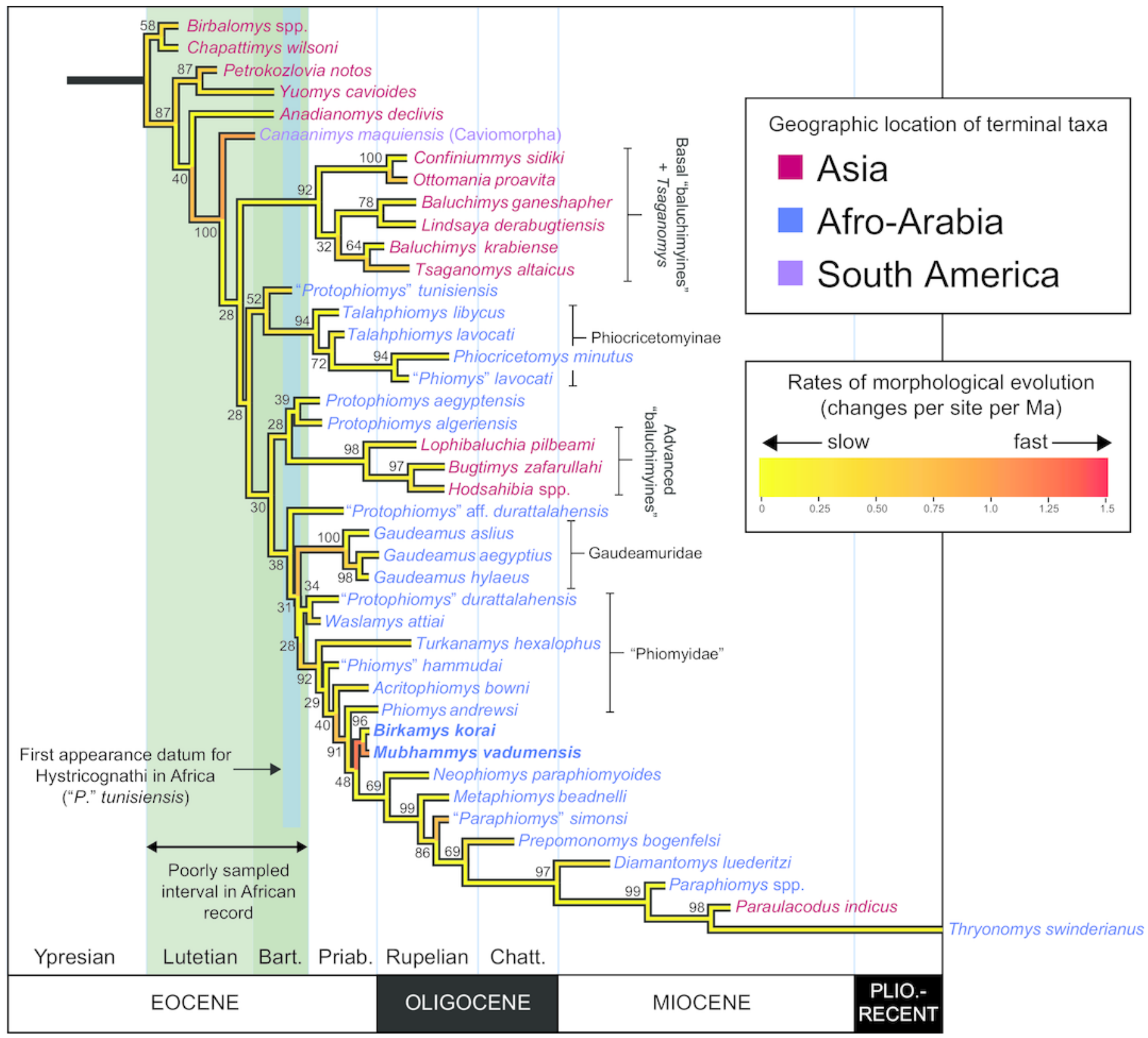




\section{4}

Evolution of lower first molar area (on a natural log scale) ( $x$ - axis) through time ( $y$ axis), based on ancestral values calculated in BayesTraits, using both directional and random walk models, each with a lambda scaling parameter.

Ancestral values from each model are represented by points, and the intervening space at each node is infilled to reflect uncertainty between the mean estimates. 


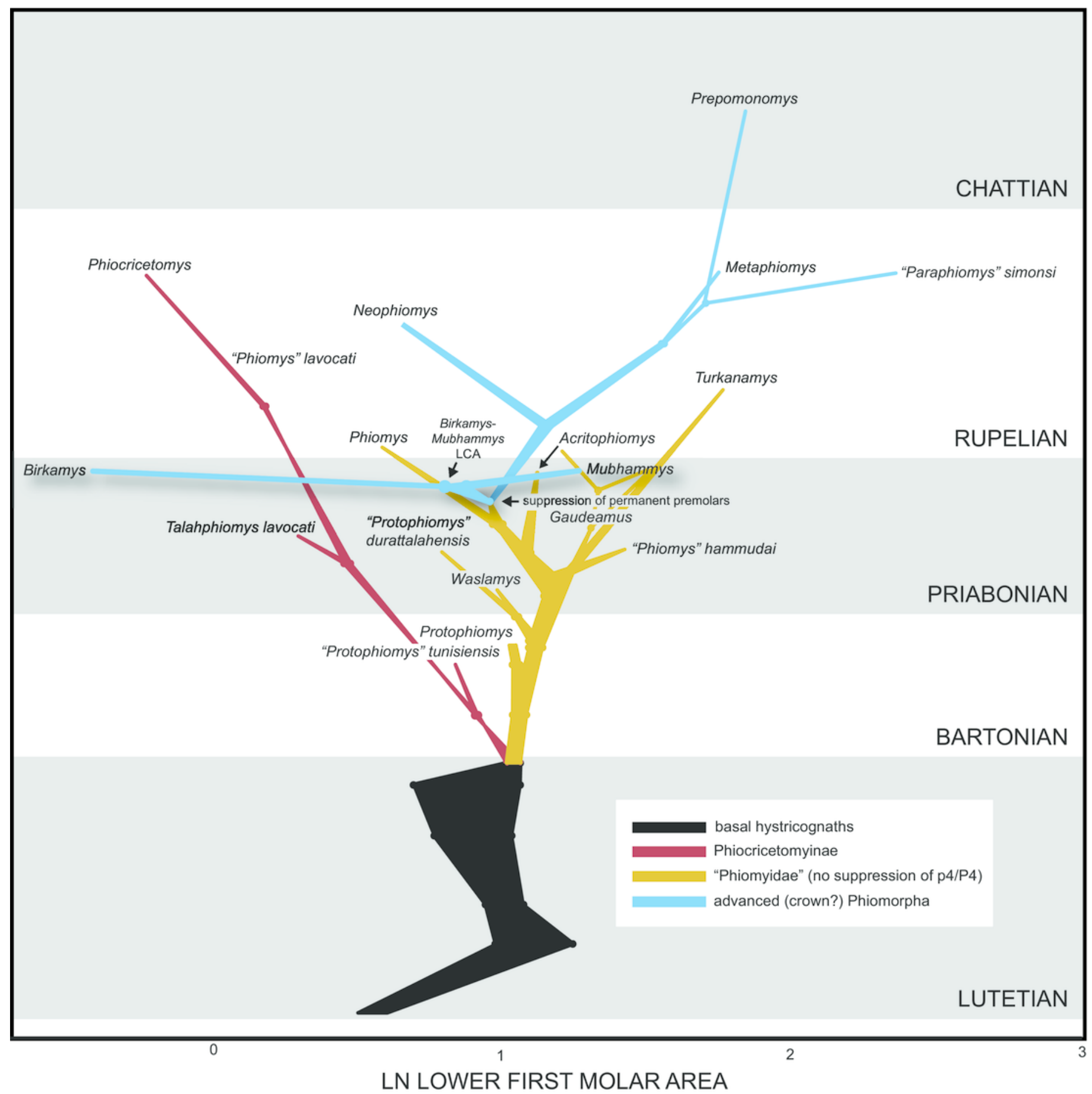


15

"Sum of branch lengths" calculation across time-scaled topologies.

Tip-dating topology (D) compared to time-scaled strict consensus derived from parsimony analysis with all characters equally weighted (A) and Bayesian allcompat (B) topologies (species durations and internodes are arbitrarily scaled to $1 \mathrm{Ma}$ ) and (C) minimum (0) length parsimony topology. 
A

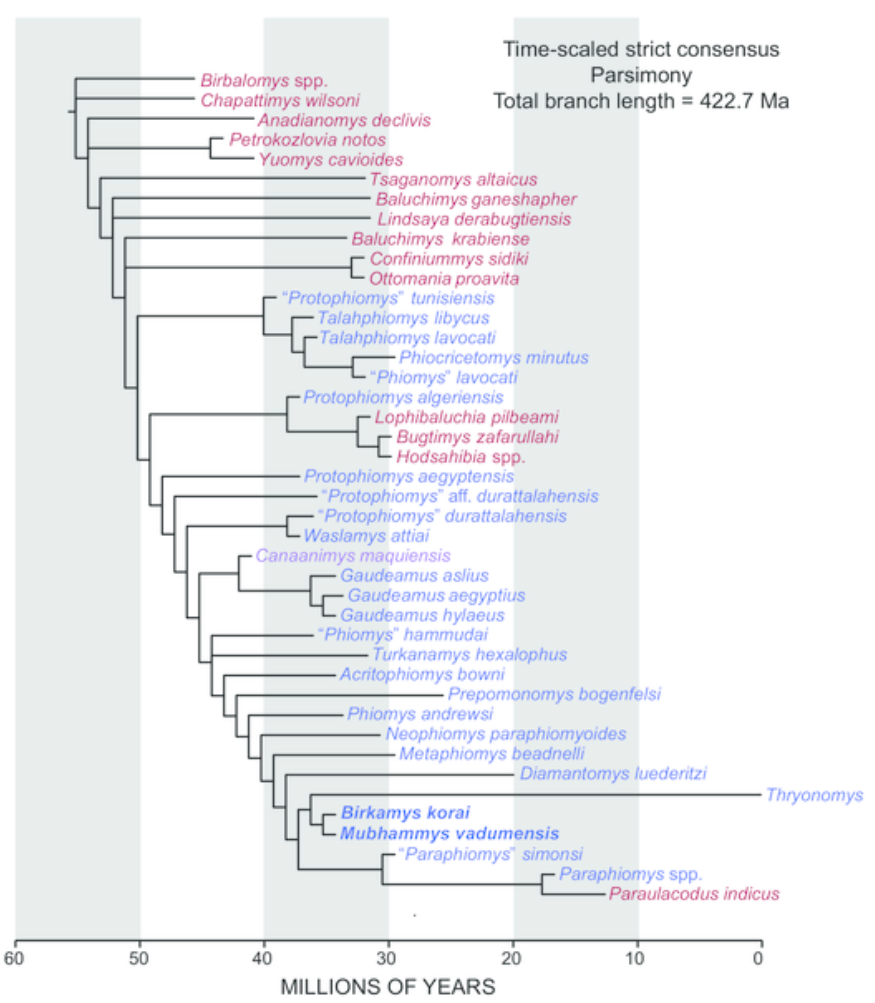

C

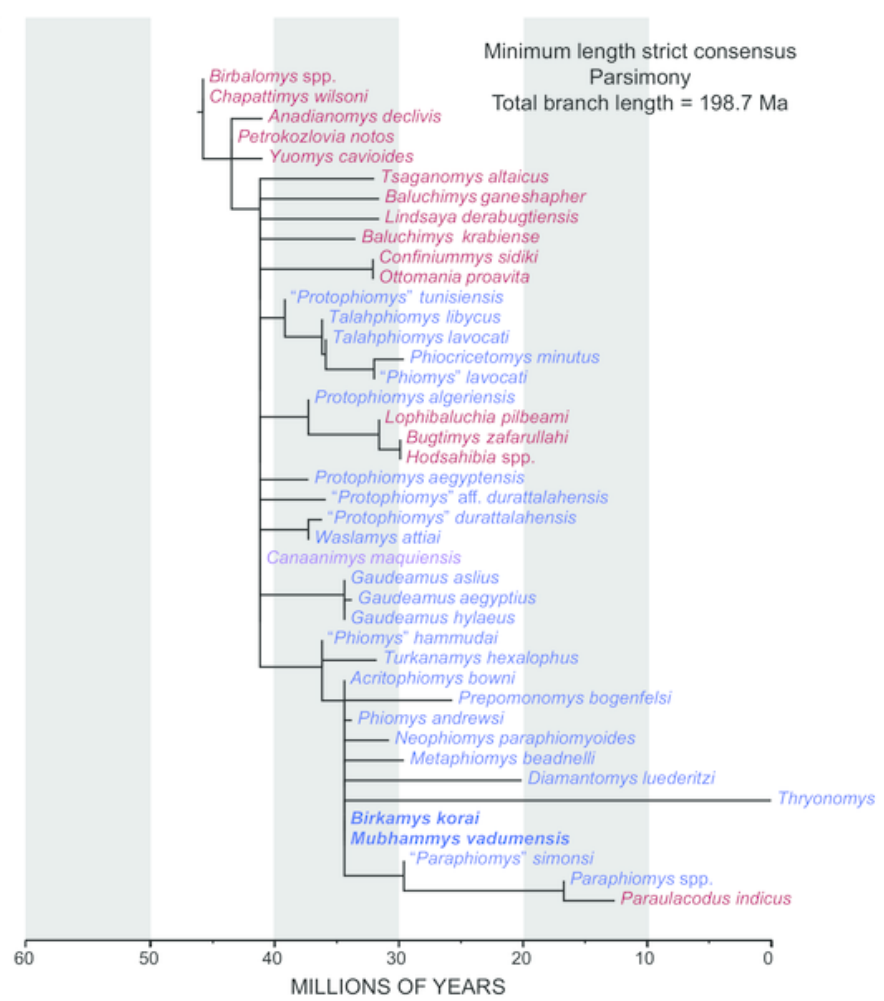

B

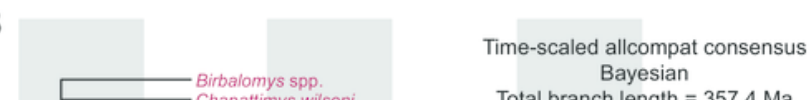

Total branch length $=357.4 \mathrm{Ma}$

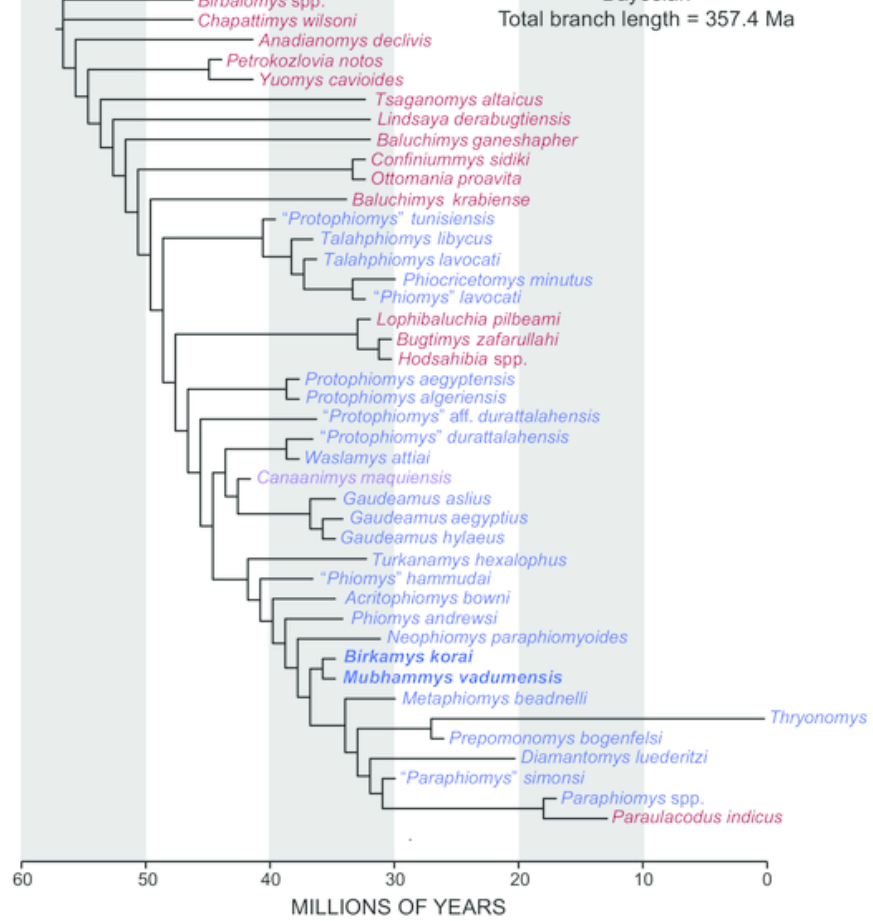

D

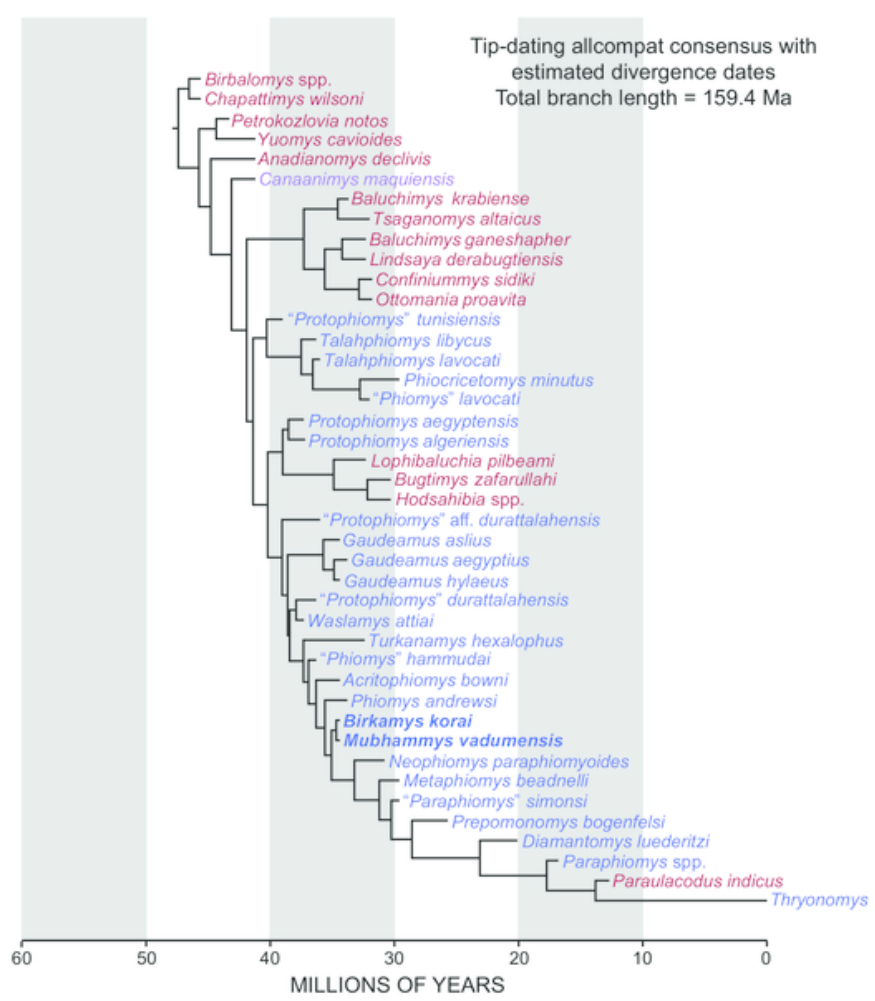




\section{6}

Comparison of the incisive foramina in late Eocene and early Miocene phiomorphs.

A) CGM 66000, late Eocene Birkamys korai from Quarry L-41; B) DPC 21311, late Eocene Acritophiomys bowni from Quarry L-41; C) KNM-SO 710, early Miocene Renefossor songhorensis from Songhor, Kenya; D) CGM 66006, late Eocene Gaudeamus aslius from Quarry L-41; E) mirror-imaged maxilla of CGM 83690, late Eocene Waslamys attiai from Locality BQ-2; F) KNM-SO 884, early Miocene Lavocatomys aequatorialis from Songhor, Kenya; G) KNM-RU 2318, early Miocene Proheliophobius leakeyi from Rusinga Island, Kenya; H) KNM-LG 834, early Miocene Simonimys genovefae from Legetet, Kenya. 


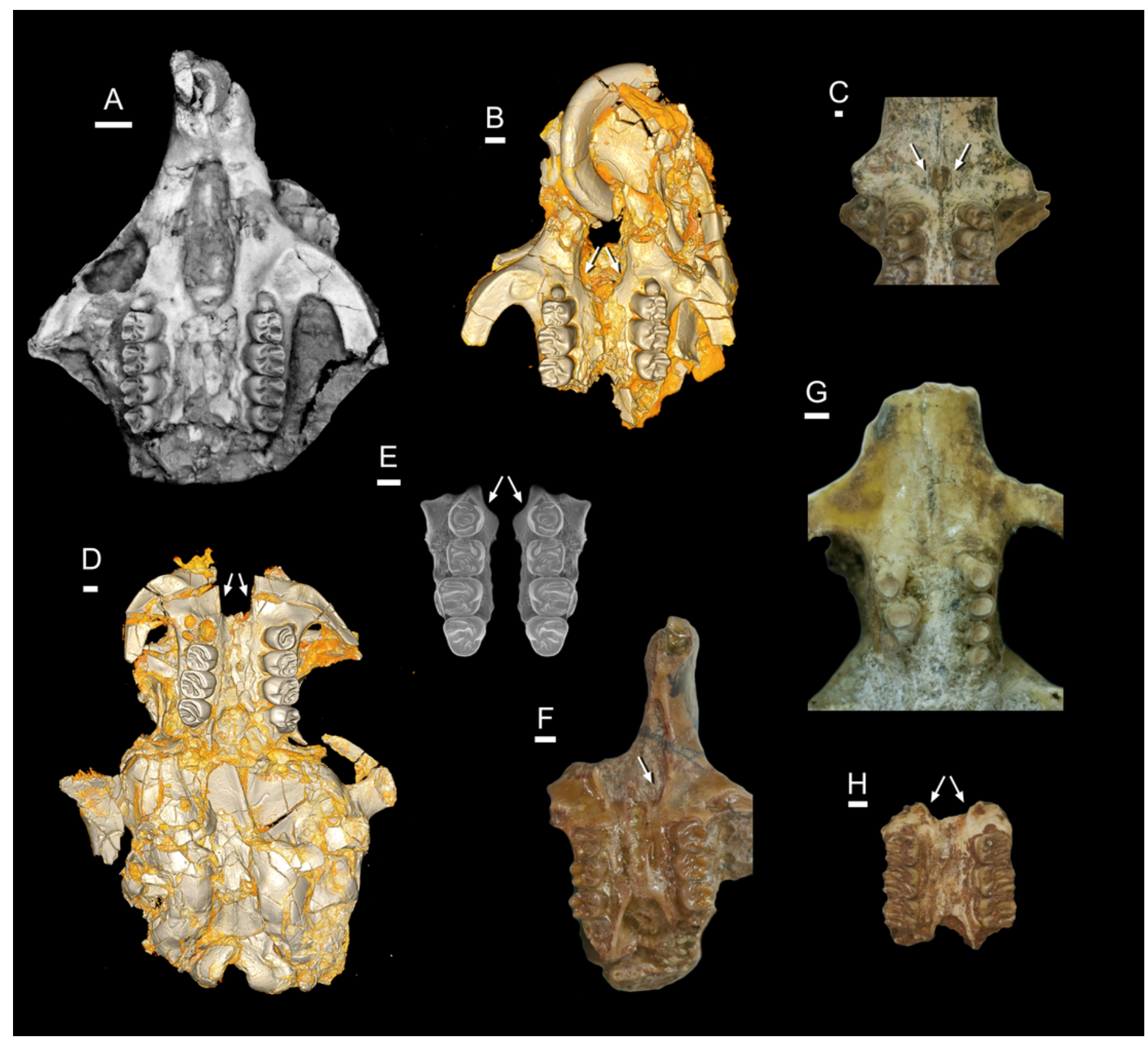




\section{Table $\mathbf{1}$ (on next page)}

Table 1. Length and width of teeth (in millimeters) in the hypodigm of Birkamys korai, cf. Birkamys, and Mubhammys vadumensis. 
1 Table 1. Length and width of teeth (in millimeters) in the hypodigm of Birkamys korai, cf.

2 Birkamys, and Mubhammys vadumensis gen. et sp. nov.

\section{Birkamys korai}

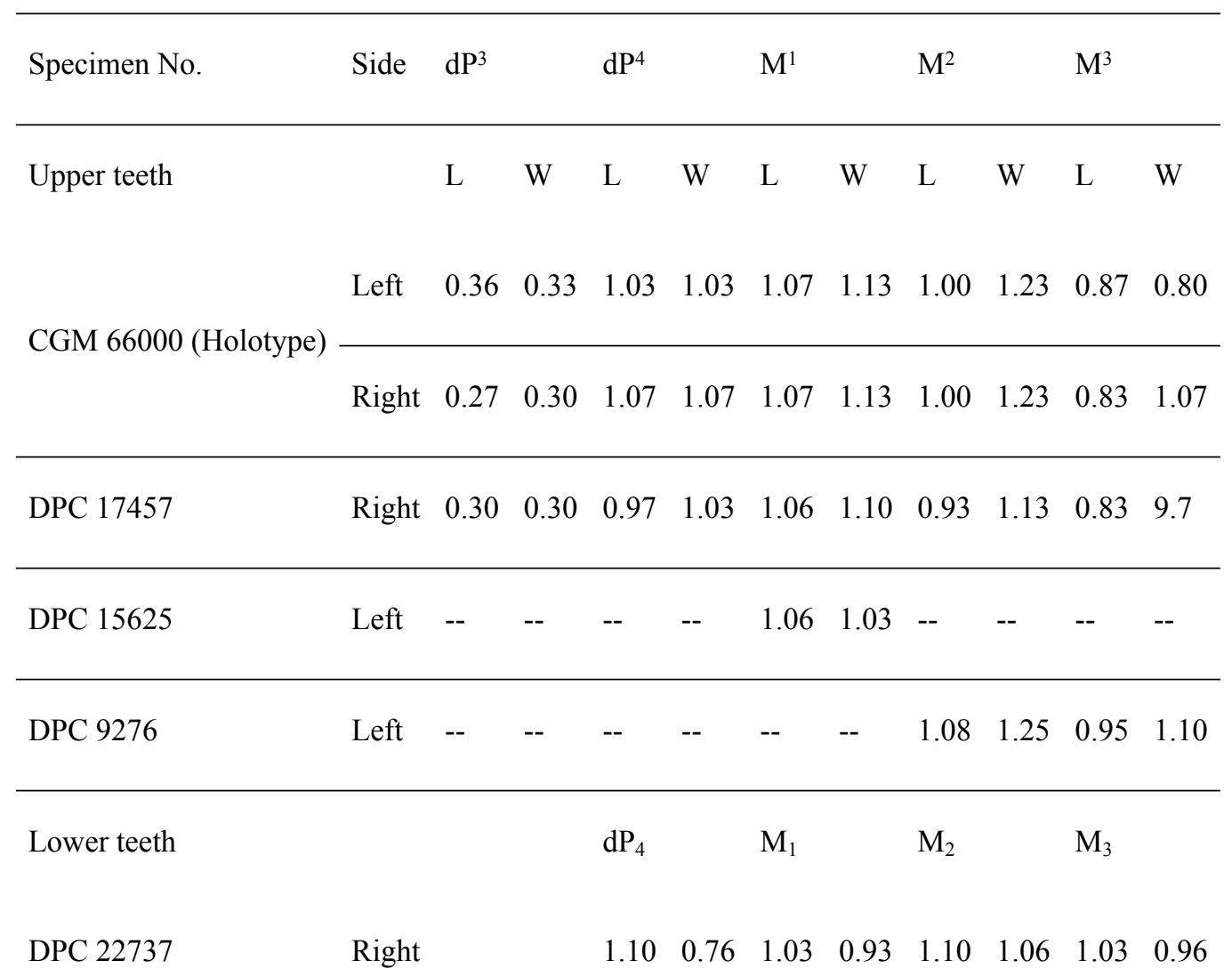

\section{Cf. Birkamys korai}

\begin{tabular}{llll}
\hline Specimen No. & Side & $\mathrm{M}_{1}$ & \\
& & & \\
\hline DPC 17995 & Right & 1.10 & 0.87
\end{tabular}

Mubhammys vadumensis

\begin{tabular}{llllllllllllll}
\hline Upper teeth & & $\mathrm{dP}^{3}$ & & \multicolumn{2}{c}{$\mathrm{dP}^{4}$} & & $\mathrm{M}^{1}$ & & \multicolumn{2}{c}{$\mathrm{M}^{2}$} & \multicolumn{3}{c}{$\mathrm{M}^{3}$} \\
& & & & & & & & & & & \\
CGM 66001 (Holotype) & Left & 0.68 & 0.76 & 1.8 & 1.9 & 1.90 & -- & 1.95 & 2.10 & -- & 1.80
\end{tabular}




\begin{tabular}{|c|c|c|c|c|c|c|c|c|c|c|}
\hline DPC 14324 & Left & $0.58 \quad 0.68$ & 1.70 & 1.60 & 1.85 & 1.80 & -- & -- & -- & -- \\
\hline Lower teeth & & & $\mathrm{dP}_{4}$ & & $\mathrm{M}_{1}$ & & $\mathrm{M}_{2}$ & & $\mathrm{M}_{3}$ & \\
\hline DPC 13220 & Left & & 1.83 & 1.43 & 2.00 & 1.75 & 1.95 & 1.80 & 1.83 & 1.70 \\
\hline DPC 14141 & Left & & 1.66 & 1.29 & 1.90 & 1.67 & -- & -- & -- & -- \\
\hline
\end{tabular}


Table 2 (on next page)

Estimated mean ages and upper and lower HPD intervals for species with relatively broad uniform age priors, derived from the tip-dating analysis 1 (TD1) with a fossilized birth-death prior. 
1 Table 2. Estimated mean ages and upper and lower HPD intervals for species with relatively

2 broad uniform age priors, derived from the tip-dating analysis with a fossilized birth-death prior.

3

$\begin{array}{lcccc}\text { Taxon } & \text { Locality } & \text { Mean } & \text { L 95\% } & \text { U 95\% } \\ & & & \text { HPD } & \text { HPD } \\ \text { Baluchimys ganeshaper } & \text { Y-GSP 417 } & 31.66 & 28.11 & 33.90 \\ \text { Baluchimys krabiense } & \text { Krabi, Bang Mark Pit } & 33.54 & 31.59 & 35.00 \\ \text { Bugtimys zafarullahi } & \text { Paali Nala C2/Y-GSP } & 30.21 & 25.64 & 33.90 \\ \text { Confiniummys sidiki } & 417(?) & 32.76 & 28.68 & 37.20 \\ \text { Hodsahibia gracilis } & \text { Süngülü } & 29.64 & 24.93 & 33.90 \\ \text { Lindsaya derabugtiensis } & \text { Paali Nala C2 } & 31.72 & 28.16 & 33.90 \\ \text { Lophibaluchia pilbeami } & \text { Y-GSP 417 } & 31.34 & 27.09 & 33.90 \\ \text { Ottomania proavita } & \text { Y-GSP 417 } & 31.40 & 28.10 & 35.58 \\ \text { "Phiomys" hammudai } & \text { Süngülü } & 35.56 & 32.31 & 38.56 \\ \text { Prepomonomys bogenfelsi } & \text { Dur at-Talah DT1 } & 25.71 & 20.00 & 30.41 \\ \text { Protophiomys algeriensis } & \text { Silica North } & 37.27 & 33.90 & 40.45 \\ \text { Protophiomys durattalahensis } & \text { Bir el-Ater } & 37.60 & 35.49 & 39.60 \\ \text { Protophiomys aff. } & \text { Dur at-Talah DT1 } & 38.22 & 35.84 & 39.60 \\ \text { durattalahensis } & \text { Dur at-Talah DT2 } & 39.17 & 37.70 & 41.18 \\ \text { Protophiomys tunisiensis } & \text { Djebel el Kébar } & 39.60 \\ \text { Talahphiomys lavocati } & \text { Dur at-Talah DT2 } & 33.65 & 31.00 & 36.60 \\ \text { Talahphiomys libycus } & \text { Dur at-Talah DT1 } & 35.31 & 31.20 & 38.87 \\ \text { Turkanamys hexalophus } & \text { Lokone } & 31.88 & 28.30 & 33.90\end{array}$

